\title{
DIVERSIDAD DE ENTOMONEMÁTODOS ASOCIADOS A INSECTOS ORTÓPTEROS PLAGA DEL SUELO (GRYLLIDAE Y GRYLLOTALPIDAE) EN EL GRAN LA PLATA.
}

Trabajo de investigación para optar por el título de Doctor en Ciencias Naturales

\section{LIC. RUSCONI, JOSÉ MATÍAS}

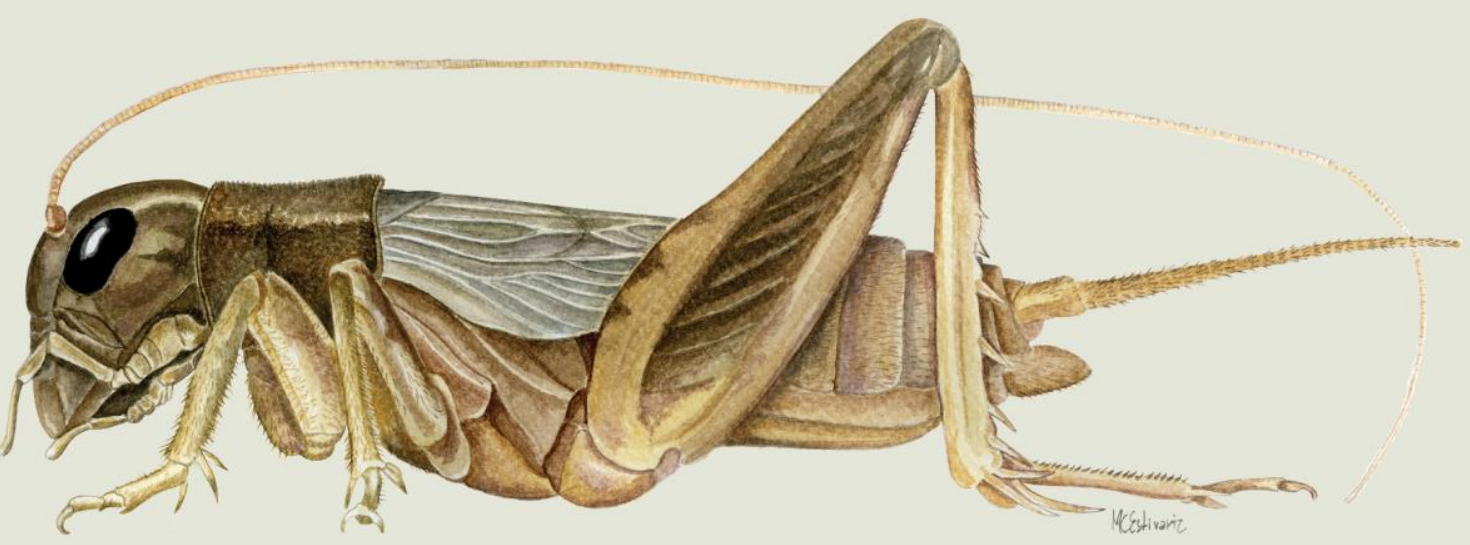




\section{AGRADECIMIENTOS}

En primer lugar agradezco a mi familia por todo lo que me ha apoyado, a mis padres por darme la posibilidad de estudiar y por hacer un esfuerzo para que pueda terminar la carrera. Por bancarme siempre, a pesar de los contratiempos que se presentaron. A mis hermanos Juan y Guido por su buena predisposición siempre que los necesité.

A mi directora Nora Camino por su conducción y dirección en este trabajo, por sus correcciones apropiadas y buena voluntad.

A mi co-directora Fernanda Achinelly por su dedicación y compromiso con la labor cientifica; por su profesionalismo y gentileza.

Al Doctor Eliseo Chaves por abrirme las puertas de su casa, por su amabilidad y colaboración.

A mis amigos del CEPAVE, especialmente a Daiana Eliceche, Augusto Salas y Matías Rosales por su buena onda y sentido del humor. Por ayudarme cada vez que tuve dudas en lo concerniente a los nematodos, por su tiempo, amabilidad y por apoyarme en los momentos dificiles.

A las autoridades e integrantes del CEPAVE, por estar siempre dispuestos a colaborar en lo que necesité.

A Patricia Sarmiento por las fotos de M.E.B del Museo de La Plata y a Luis Giambelluca, Profesional de Apoyo CONICET, CEPAVE por las fotos de microscopía óptica.

A María Cristina Estivariz y a María Laura Morote, Profesionales de Apoyo CONICET, CEPAVE por la confección de la portada de esta tésis.

A Graciela Minardi, Profesional de Apoyo CONICET, CEPAVE por el análisis estadístico.

A Diego, Federico, Pablo y Nicolás, por su amistad. A la Comisión de Investigaciones Cientificas de la provincia de Buenos Aires (CIC) y al Consejo Nacional de 
Investigaciones Científicas y Técnicas (CONICET) por proporcionarme, mediante becas, el sustento necesario para llevar a cabo esta tesis.

A la Facultad de Ciencias Naturales y Museo de la Universidad Nacional de La Plata por darme la posibilidad de realizar este estudio doctoral. 


\section{ÍNDICE}

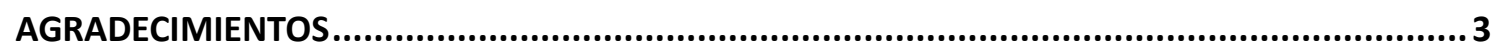

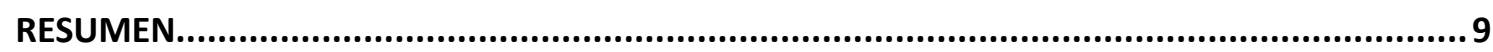

ABSTRACT

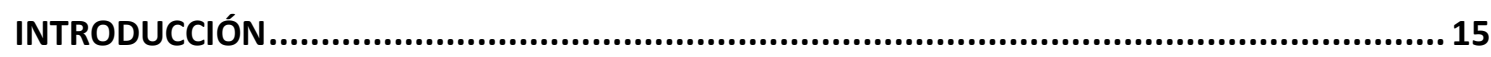

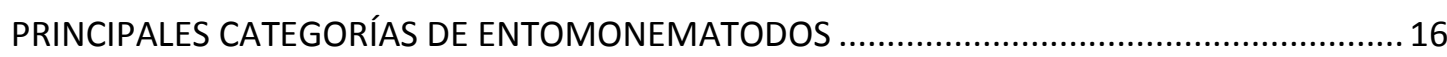

RELACIONES DE LOS ENTOMONEMATODOS CON SUS HOSPEDADORES ................................ 16

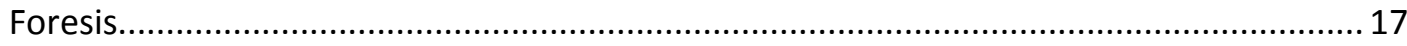

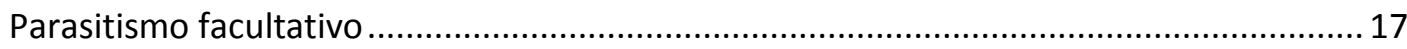

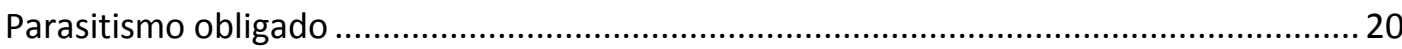

En tracto digestivo y sistema reproductor ................................................................. 20

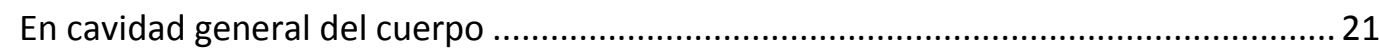

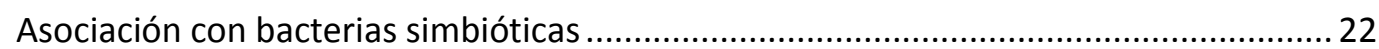

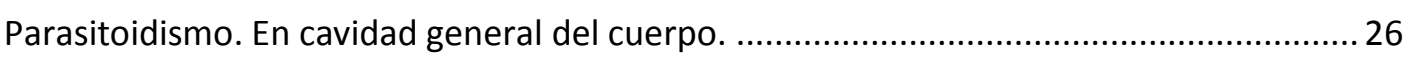

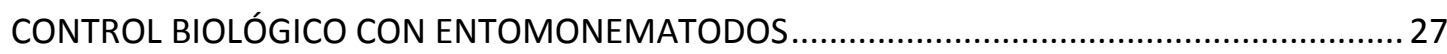

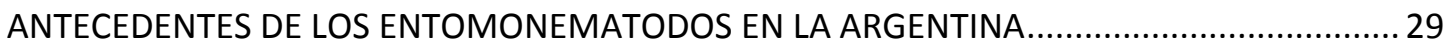

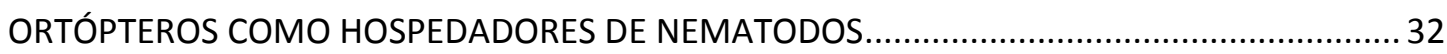

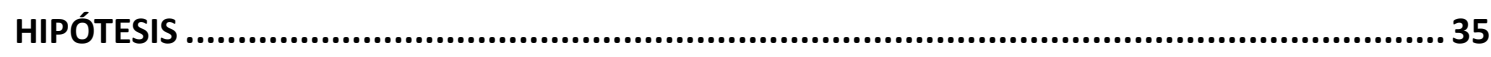

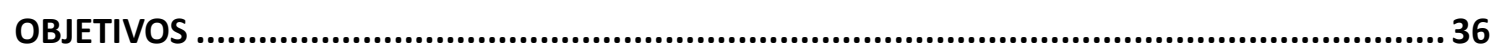

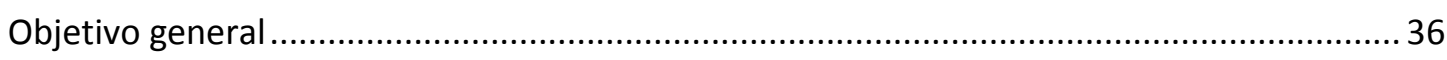

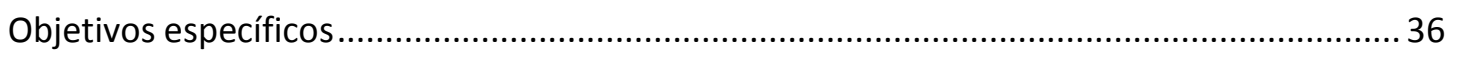

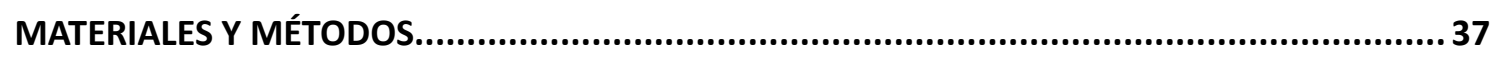

ORTHOPTERA (GRYLLIDAE Y GRYLLOTALPIDAE) COMO INSECTOS PLAGA DEL SUELO.

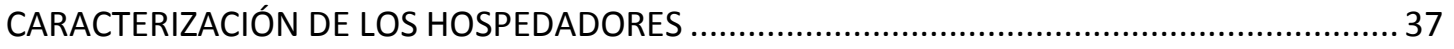

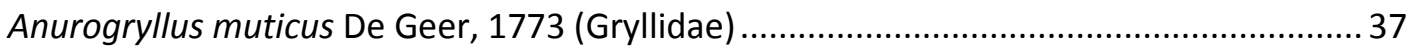

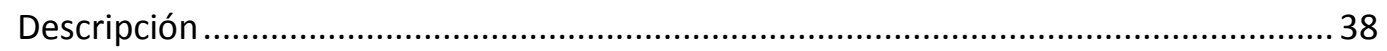

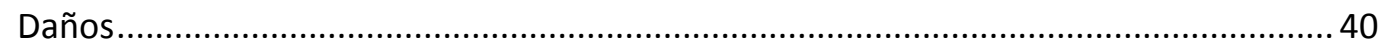

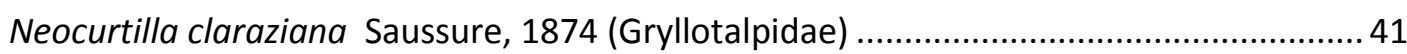

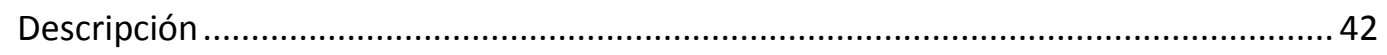

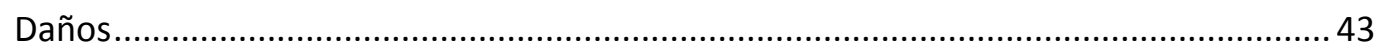

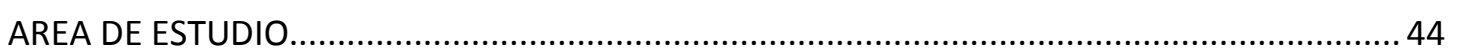

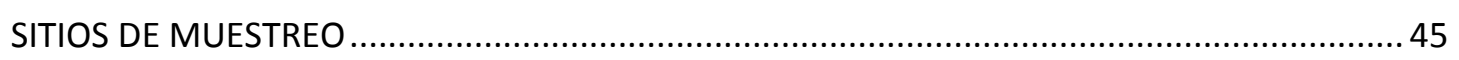

RECOLECCIÓN Y PROCESAMIENTO DE LOS ENTOMONEMATODOS ….................................. 52 
A PARTIR DE MUESTRAS DE SUELO (ENTOMOPATÓGENOS) …........................................ 52

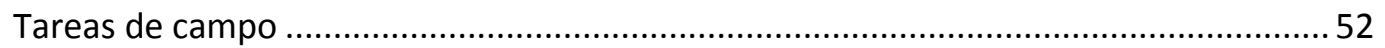

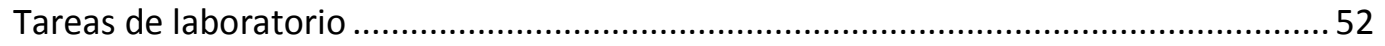

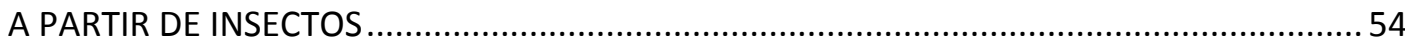

RECOLECCIÓN, PROCESAMIENTO E IDENTIFICACIÓN DE LOS HOSPEDADORES .......................54

RECOLECCIÓN Y PROCESAMIENTO DE LOS ENTOMONEMATODOS ........................................55

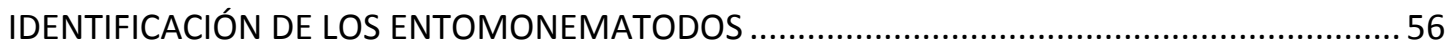

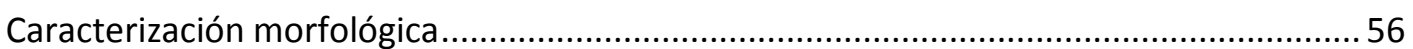

Preparación de muestras de nematodos para microscopía electrónica de barrido (MEB) 57

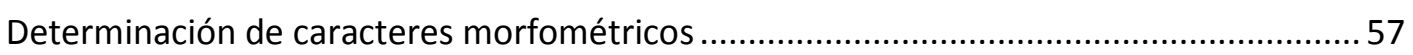

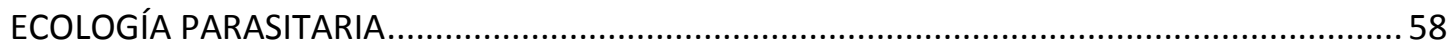

MORTALIDAD POR NEMATODOS ENTOMOPATÓGENOS (NEPS) EN ORTÓPTEROS DEL SUELO

60

Susceptibilidad de A. muticus al nematodo Heterorhabditis bacteriophora Poinar, 1976 en

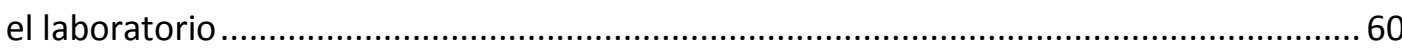

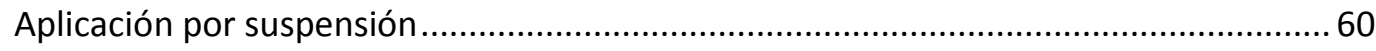

Aplicación utilizando cadáveres de Tenebrio molitor infestados.....................................60

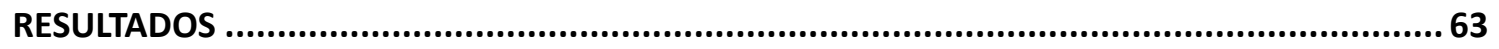

RELEVAMIENTO E IDENTIFICACIÓN DE INSECTOS ORTÓPTEROS (GRYLLIDAE Y

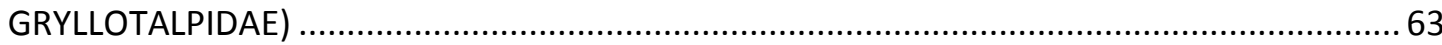

NEMATODOS ASOCIADOS A ORTÓPTEROS PLAGA DEL SUELO (GRYLLIDAE Y

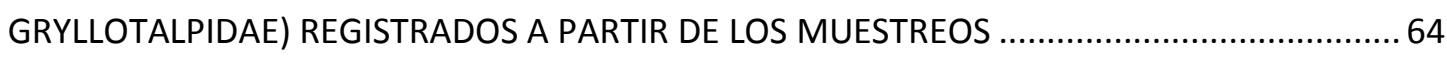

DESCRIPCIÓN DE LOS NEMATODOS ASOCIADOS A ORTÓPTEROS PLAGA DEL SUELO

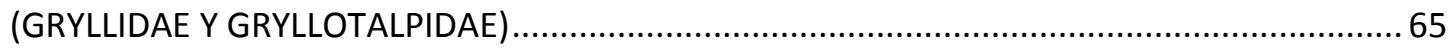

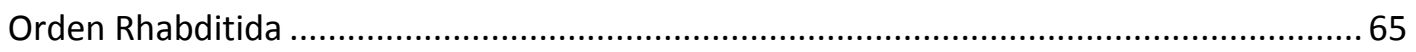

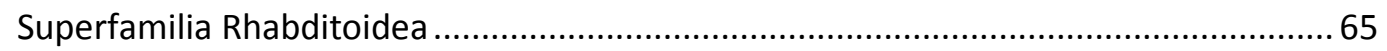

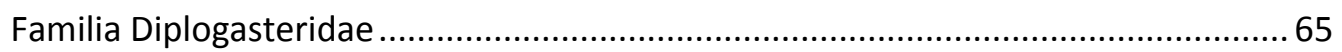

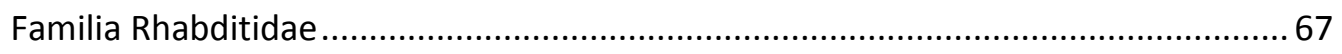

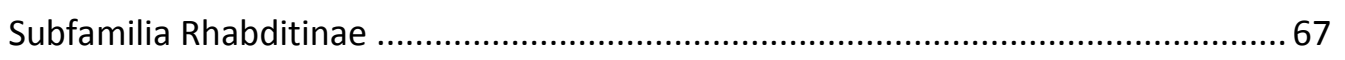

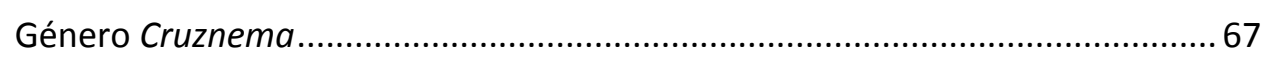

Cruznema tripartitum (Linstow, 1906), Zullini, 1982...................................... 67

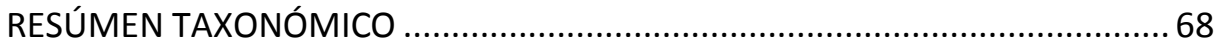

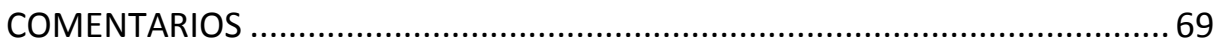

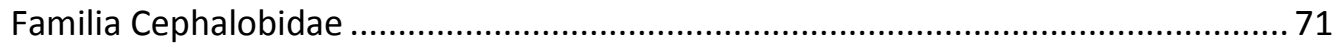

Subfamilia Cephalobinae …………………………........................................ 71

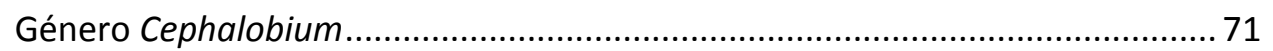




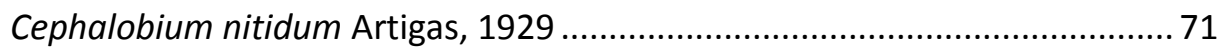

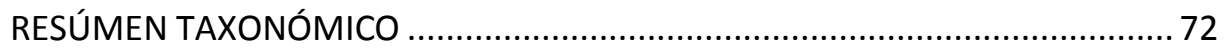

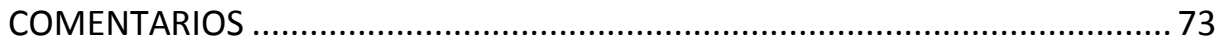

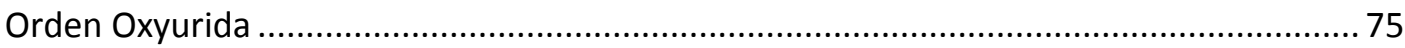

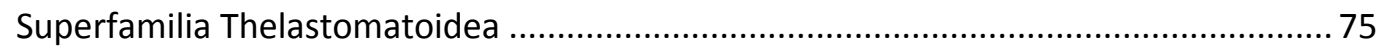

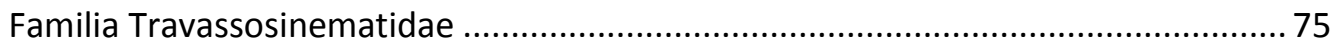

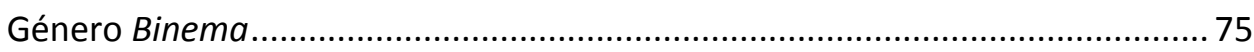

Binema bonaerensis Camino y Reboredo, 1999............................................ 75

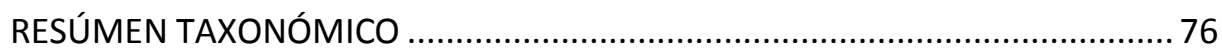

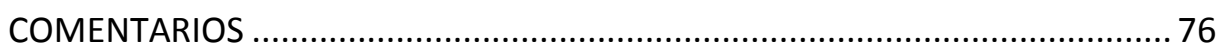

Binema klossae (Marchissio y Miralles, 1993).............................................. 79

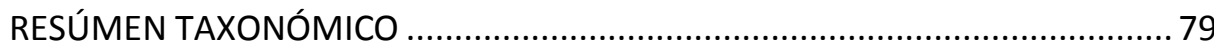

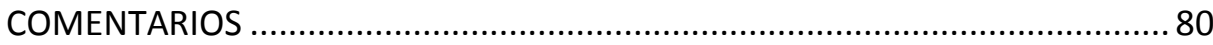

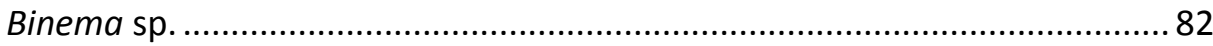

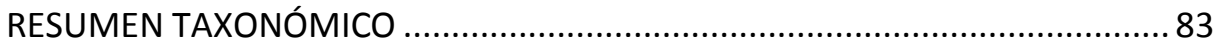

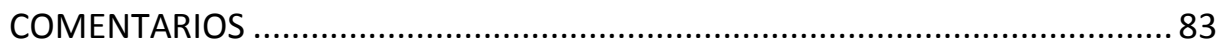

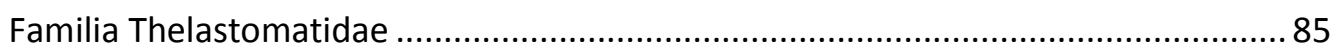

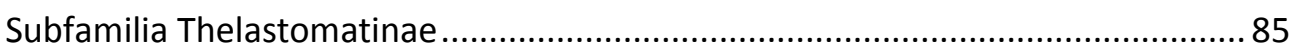

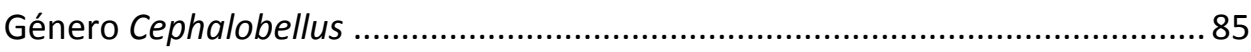

Cephalobellus magalhaesi (Schwenk, 1926) .............................................. 85

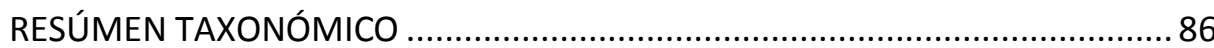

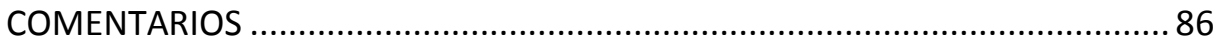

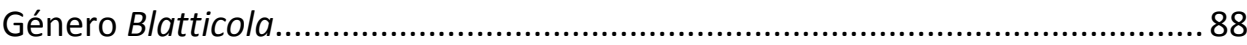

Blatticola cristovata Achinelly y Camino, 2007 ................................................... 88

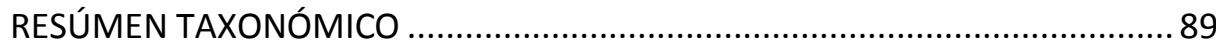

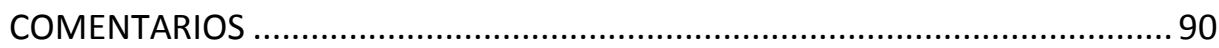

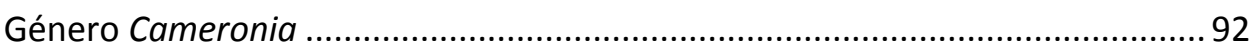

Cameronia n. sp

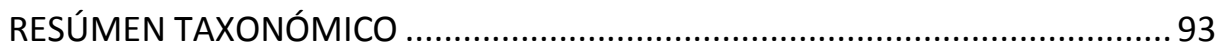

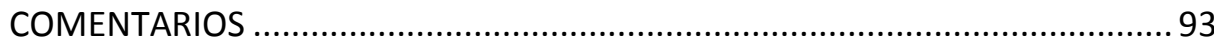

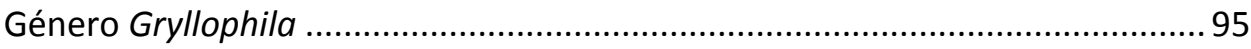

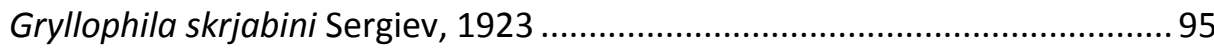

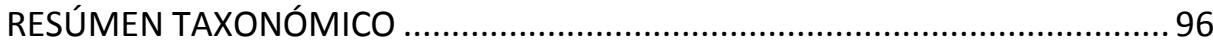

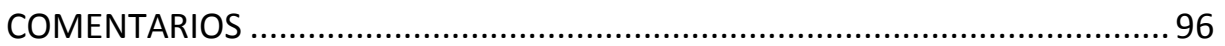




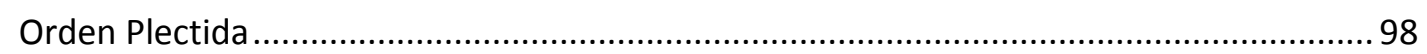

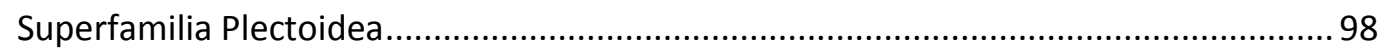

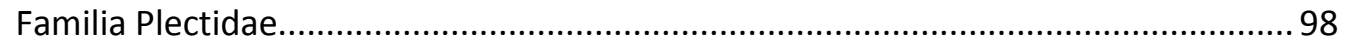

Subfamilia Plectinae ........................................................................ 98

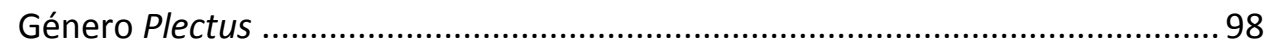

Plectus parietinus Bastian, 1865...................................................... 98

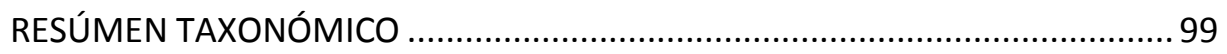

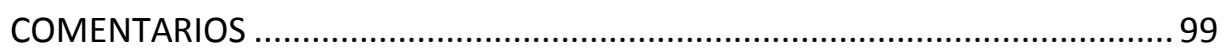

RESUMEN DEL MATERIAL HALLADO ................................................................. 100

MORTALIDAD POR NEMATODOS ENTOMOPATÓGENOS (NEPS) EN ORTÓPTEROS DEL SUELO

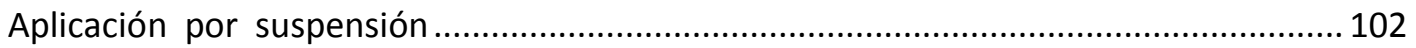

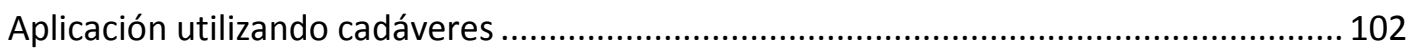

CARACTERIZACIÓN ECOLÓGICA DE LOS EJEMPLARES ENCONTRADOS ............................... 106

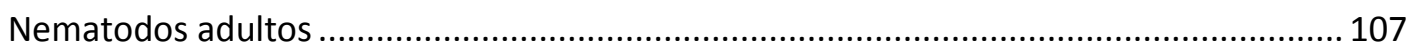

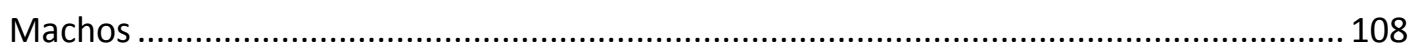

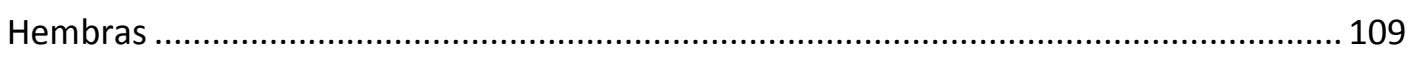

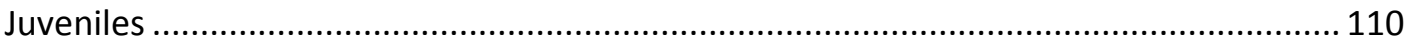

Índices parasitarios.................................................................................. 111

Análisis de comunidad componente .......................................................... 112

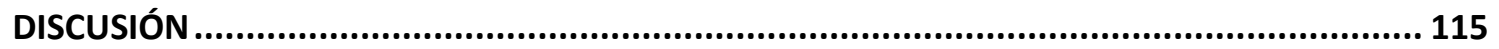

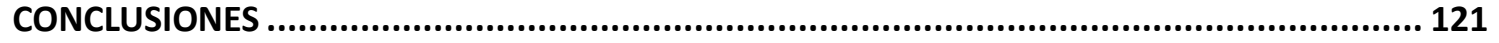

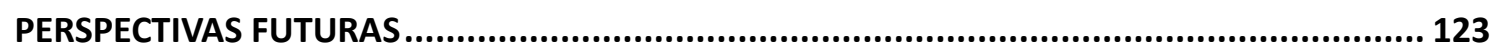

REFERENCIAS BIBLIOGRÁFICAS ..................................................................... 124

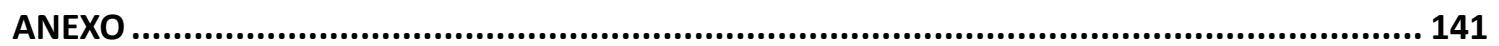




\section{RESUMEN}

El objetivo de este trabajo consistió en brindar información acerca de la diversidad, taxonomía y ecología de los nematodos parásitos y patógenos hallados en una especie de grillo perteneciente a la familia Gryllidae, Anurogryllus muticus y en una especie de grillotopo correspondiente a la familia Gryllotalpidae, Neocurtilla claraziana. Estos ejemplares se recolectaron en estaciones experimentales, plazas, parques y espacios de recreación de la ciudad de La Plata y el Gran La Plata. Estas especies habitan madrigueras subterráneas y fueron recolectadas utilizando una solución tensioactiva y pala de jardinería. Este tipo de solución consiste de agua y detergente, obstruyendo los espiráculos y dificultando el intercambio gaseoso, lo cual provoca que los insectos emerjan de la madriguera en busca de oxígeno. Los nematodos se caracterizaron a nivel morfológico y morfométrico. Se llevaron a cabo descripciones a nivel de genéro y especie de los individuos recuperados. Se tomaron medidas como longitud total del cuerpo, ancho máximo, distancia del anillo nervioso en relación al extremo anterior, entre otras.

Las observaciones en ninfas y adultos de grillos y grillotopos revelaron 11 especies de nematodos: Cruznema tripartitum, Cephalobium nitidum, Cephalobellus magalhaesi, Binema bonaerensis, Binema klossae, Binema sp., Blatticola cristovata, Cameronia n. sp., Gryllophila skrjabini y Plectus parietinus. Además, se encontraron dos individuos de la familia Diplogasteridae. Debido a que se trató de estadios juveniles, no fue posible su identificación a nivel específico.

De las 11 especies recuperadas en el presente trabajo, una podría llegar a ser una especie nueva (Binema sp.), mientras que a otra (Cameronia n. sp.) se le da este status. Se hace mención, además, de tres registros nuevos para Argentina: Cephalobium nitidum, Cephalobellus magalhaesi y Gryllophila skrjabini. La primera de estas especies fue citada para Brasil en el grillotopo Gryllotalpa sp. y la segunda, también para Brasil en la cucaracha salvaje "Barata selvagem". Gryllophila skrjabini fue citada para la ex U.S.S.R. (actual Kazajstán), Brasil, España, Francia, Alemania, Madagascar e India en Gryllotalpa vulgaris, Gryllotalpa hexadactyla, Gryllotalpa europaeus, Gryllotalpa gryllotalpa, Gryllotalpa septemdecimchromosomica y Gryllotalpa africana. 
Se determinaron los indicadores de infección parasitaria para las especies de nematodos: prevalencia, intensidad media, abundancia media y dominancia. En $A$. muticus la especie Cephalobium nitidum fue la que presentó los valores más altos de abundancia, dominancia e intensidad, mientras que Blatticola cristovata mostró los valores más elevados de prevalencia. Por otra parte, en $N$. claraziana la especie $B$. cristovata evidenció los valores más elevados de prevalencia, dominancia y abundancia. Binema bonaerensis mostró la intensidad más elevada. Estos valores podrían relacionarse al ciclo de vida de los nemtodos. Los valores mínimos de frecuencia en $N$. claraziana se dieron en los juveniles de la familia Diplogasteridae, los de intensidad en Binema sp., los de prevalencia en Cameronia n. sp., G. skrjabini, B. klossae y en los juveniles de los diplogastéridos, los cuales presentaron similares valores y finalmente los de abundancia en los juveniles de la familia Diplogasteridae.

Los valores de diversidad específica fueron determinados mediante los índices de riqueza específica e índice de Shannon-Weaver, y el grado de semejanza entre comunidades mediante el coeficiente de similaridad de Sørensen. En N. claraziana se halló una mayor diversidad de nematodos parásitos que en $A$. muticus. El coeficiente de similaridad de Sørensen reflejó un bajo grado de semejanza entre las comunidades parásitas de ambos hospedadores.

Finalmente, se llevaron a cabo experiencias de laboratorio utilizando diferentes concentraciones de juveniles infectivos (JIs) del nematodo entomopatógeno Heterorhabditis bacteriophora para evaluar la susceptibilidad del grillo A. muticus. Las experiencias con $H$. bacteriophora dieron positivas a la infección de A. muticus, llegando a completar el nematodo su ciclo biológico en el hospedador, lo que permitiría su establecimiento y posibilidad de reciclarse en el ambiente. No se observaron diferencias significativas entre las concentraciones utilizando el test de Fisher.

Los nematodos encontrados naturalmente en las especies de grillos y grillotopos analizados poseen un ciclo biológico monoxeno, no requiriendo de hospedadores intermediarios para completar su ciclo, al igual que en las infecciones experimentales con individuos de la familia Heterorhabditidae. 
Podemos concluir que la región del Gran La Plata es una zona con gran diversidad de entomonematodos oxyúridos parásitos de la familia Gryllidae y Gryllotalpidae y que Heterorhabditis bacteriophora constituiría un potencial agente de biocontrol nativo. 


\section{ABSTRACT}

The objective of the investigation to be reported here was to garner information on the diversity, taxonomy, and ecology of the parasitic and pathogenic nematodes found in both Anurogryllus muticus, a species of cricket from the family Gryllidae and in Neocurtilla claraziana, a species of mole cricket from the family Gryllotalpidae. The specimens studied were collected in experimental stations, plazas, parks, and recreation areas of La Plata and Gran La Plata. These species live in underground burrows and were collected through the use of a gardening spade along with a surfactant solution. Since the detergent obstructs the insect's spiracles causing an inhibition of gaseous exchange, the crickets emerge from the hole seeking oxygen.

The nematodes parasitizing the crickets were characterized morphologically and morphometrically and by that means identified down to the level of genus and species. The measurements made included the total body length and maximum width along with the distance from the nerve ring to the anterior end of the body among others.

The following 11 species of nematodes were observed and identified in nymph and adult crickets and mole crickets: Cruznema tripartitum, Cephalobium nitidum, Cephalobellus magalhaesi, Binema bonaerensis, Binema klossae, Binema sp., Blatticola cristovata, Cameronia n. sp., Gryllophila skrjabini, and Plectus parietinus. In addition, two individuals were found that belonged to the Diplogasteridae family; but since the two were developmentally still in the juvenile stage, they couldn't be characterized at the level of species.

Of the 11 species recovered in the present study, one could be a novel finding (Binema sp.), while another (Cameronia n. sp.) is given the status of new species. There are also three new records for Argentina: Cephalobium nitidum, Cephalobellus magalhaesi, and Gryllophila skrjabini. The first of the latter 3 had been cited earlier in a mole cricket in Brazil, and the second in the wild cockroach Barata selvagem also in Brazil. Finally, G. skrjabini had been recorded in Kazakhstan (former U. S. S. R), Brazil, Spain, France, Germany, Madagascar, and India in the mole-cricket species Gryllotalpa vulgaris, Gryllotalpa hexadactyla, Gryllotalpa europaeus, Gryllotalpa gryllotalpa, Gryllotalpa septemdecimchromosomica, and Gryllotalpa africana. 
The following parameters of parasitic infection by the different species of nematodes were determined: prevalence, mean intensity, mean abundance, and dominance. In A. muticus, C. nitidum, was the nematode exhibiting the highest values of abundance, dominance, and intensity; while B. cristovata was associated with the highest values of prevalence. In contrast, in $N$. claraziana, the species of highest prevalence, dominance, and abundance was B. cristovata. Binema bonaerensis evidenced the highest level of intensity in $N$. claraziana. These values could be related to the life cycle of the nematodes. The minimum values for frequency in $N$. claraziana were recorded for the juveniles of the family Diplogasteridae; those of intensity for Binema sp.; those of prevalence for Cameronia sp., G. skrjabini, B. klossae, and the juveniles of Diplogasteridae, the latter exhibiting similar values; and finally, those of the abundance for Diplogasteridae juveniles.

The values of species diversity were determined through the indices of species richness and Shannon-Weaver and the degree of similarity among communities by the coefficient of similarity of Sørensen. Neocurtilla claraziana contained a greater diversity of nematode parasites than A. muticus. Sørensen's coefficient of similarity indicated a low degree of diversity among the parasitic communities in both cricket hosts.

Finally, laboratory experiments were conducted involving different concentrations of infective juveniles of the entomopathogenic nematode Heterorhabditis bacteriophora in order to evaluate the susceptibility to infection of $A$. muticus. The experiments indicated that $H$. bacteriophora could successfully infect $A$. muticus and complete its life cycle within that host, thus enabling the nematode's parasitic establishment and the possibility of a reproductive recycling within the immediate environment. Fisher's test indicated no significant differences among the various concentrations used.

The nematodes that were found under natural conditions in the species of cricket and mole cricket analyzed are monoxenous and thus do not require intermediate hosts for the completion of their life cycle, as was also true of the individuals of the family Heterorhabditidae in the experimental infections. 
We conclude that Gran La Plata is a region with a wide diversity of oxyurid parasites that act on members of the families Gryllidae and Gryllotalpidae and that $H$. bacteriophora, in particular, constitutes a potential agent of natural control. 


\section{INTRODUCCIÓN}

El Phylum Nematoda es posiblemente el de mayor cantidad de especies en el planeta. Hasta el presente se han descrito 20.000, pero se especula que hay miles más por ser descubiertas. Los nematodos se encuentran entre los metazoos más abundantes y distribuidos en el mundo. Han sido hallados desde los polos a los trópicos en todo tipo de ambientes, incluyendo desiertos, montañas altas y el fondo del mar. Son abundantes en hábitats bentónicos de agua dulce y salada, en el suelo y como parásitos de una gran variedad de hospedadores vertebrados, invertebrados y plantas (Rupert et al., 2004).

Los parásitos de invertebrados abarcan un amplio espectro de hospedadores. Se los puede encontrar en moluscos, quelicerados, crustáceos y hexápodos, entre otros (Brusca y Brusca, 2005).

Poseen un tracto digestivo bien desarrollado, compuesto por 4 regiones: el estoma (incluye estructuras asociadas a la boca), la faringe o esófago, el intestino y el recto. Dependiendo del hábito alimenticio estas secciones pueden sufrir modificaciones (Chitwood y Chitwood, 1977).

El sistema reproductor de la hembra consta de dos ovarios que abren al exterior en el lado ventral del cuerpo por la vulva, que a su vez se conecta por la vagina a los úteros. Los machos poseen estructuras accesorias: una o dos espículas esclerotizadas relacionadas con músculos que le brindan movimiento para la cópula (Bird y Bird, 1991).

Aquellos que se encuentran parasitando a insectos tanto acuáticos como terrestres, son llamados "nematodos entomógenos" o "entomonematodos". Muchos de ellos son notables no sólo desde el punto de vista científico, sino también del práctico, ya que pueden servir como posibles agentes para el control biológico de insectos de interés agrícola y sanitario, sin contaminar el ambiente (Vega y Kaya, 2012). 


\section{PRINCIPALES CATEGORÍAS DE ENTOMONEMATODOS}

Los entomonematodos pueden agruparse en 4 grandes órdenes: Mermithida, Rhabditida, Tylenchida y Oxyurida (Poinar, 1979). El orden Mermithida, está formado por dos familias: Mermithidae, parasitoides de mántidos y blátidos, y Tetradonematidae, parásitos de dípteros entre otros artrópodos. Los Rhabditida incluyen un gran número de nematodos que abarcan un amplio rango de hábitats y que divergen morfológica y ecológicamente, existiendo especies terrestres de vida libre y parásitas. Las familias Diplogasteridae y Rhabditidae han sido halladas parasitando grillos y coleópteros (Fedorko y Stanuszek, 1971; Reboredo y Camino, 1998). Al menos dos géneros de las familias Heterorhabditidae y Steinernematidae desarrollaron un método llevando e introduciendo una bacteria en los insectos, por lo cual son utilizados como controladores biológicos (Vega y Kaya, 2012).

El orden Tylenchida presenta dos familias que establecen relaciones con insectos: la familia Allantonematidae, parásita de coleópteros y hemípteros, y la familia Sphaerulariidae, con representantes hallados en abejorros (Camino y Achinelly, 2008).

Thelastomatoidea es una de las dos superfamilias del orden Oxyurida. Según Adamson y van Waerebeke (1992 a, b, c) se reconocen cinco familias dentro de esta superfamilia: Protrelloididae, encontrados solamente en cucarachas; Hystrignathidae, exclusivos de escarabajos pasálidos; Travassosinematidae, citados principalmente en grillotopos; Pseudonymidae, parásitos de escarabajos hidrofílidos y Thelastomatidae, con 31 géneros que parasitan a una gran diversidad de insectos.

\section{RELACIONES DE LOS ENTOMONEMATODOS CON SUS HOSPEDADORES}

Los diferentes tipos de simbiosis pueden estar separados funcionalmente en términos de relaciones tróficas entre organismos. Asi, si no hay interacción trófica, la relación se denomina foresis. Por otro lado, de haber interacción trófica directa entre organismos se habla de parasitismo o parasitoidismo (Bush et al., 2001). 


\section{Foresis}

Existen dos clases de foresis: la externa (el nematodo está adherido a diferentes partes del cuerpo del insecto en su hábitat) y la interna (se encuentra en órganos del hospedador sin alimentarse, sólo para su transporte). Existe una estrecha separación entre la foresis y el parasitismo. Tan pronto como los nematodos exhiben un desarrollo a expensas del hospedador, la relación deja de ser una foresis (Poinar, 1975).

La foresis es la relación más común entre los rhabdítidos y los insectos, en la cual estos últimos son utilizados sólo como medio de transporte, no obteniendo el nematodo alimento del hospedador. Esto ocurre cuando los miembros de ambos grupos ocupan el mismo nicho ecológico, como por ejemplo el túnel de un escarabajo (Poinar, 1975).

La relación forética es muy común en algunos aphelenchoididos (Tylenchida) asociados a escarabajos de la madera. Especies de los géneros Bursaphelenchus Fuchs, 1937, Aphelencoides Fischer, 1894 y Laimaphelenchus Fuchs, 1937, se alimentan de hongos de las galerías de estos coleópteros y son transportados de árbol en árbol por estos insectos. Cuando el alimento escasea, las larvas de tercer estadio se pegan al exoesqueleto del insecto para ser trasladadas a otro lugar donde se establecen. Un paso siguiente hacia el parasitismo lo muestran los miembros del género Cryptaphelenchus Fuchs, 1937, que también son acarreados por coleópteros de la corteza. Estos nematodos tienden a penetrar por las aberturas naturales del insecto, sugiriendo un tipo de foresis interna (Poinar, 1975).

\section{Parasitismo facultativo}

Los nematodos representantes del parasitismo facultativo en insectos, conservan la capacidad de reproducirse y desarrollarse en condiciones de vida libre (Camino y Achinelly, 2008). 
El juvenil de tercer estadio es de vida libre y actúa como un estadio infectivo. En algunos casos, esta larva puede penetrar dentro de la cavidad corporal del hospedador e iniciar su desarrollo, o ingresar al hospedador por la boca y desarrollarse y reproducirse en el tracto digestivo del hospedador o en glándulas con aberturas al exterior. Entre los más estudiados se encuentra el diplogasterido Eudiplogaster aphodi (Bovien, 1937) Meyl, 1961, parásito del coleóptero Aphodius fimetarius L., 1758. El juvenil infectivo es ingerido por la larva del coleóptero, atravesando la pared del intestino para alcanzar el hemocele. Este juvenil crece gradualmente en longitud y espesor, pero no muda, persistiendo en la pupa y el estado adulto del insecto; en este momento los nematodos almacenan alimento que obtienen a través de su cutícula y salen al exterior conjuntamente con la oviposición de los coleópteros. Fuera del insecto, se desarrollan, se alimentan de bacterias y se reproducen en el hábitat del hospedador. Este ciclo continúa hasta que el ambiente se torna desfavorable; es ahí cuando aparecen nuevamente los juveniles infectivos para comenzar con su vida parasitaria (Camino y Achinelly, 2008).

En el género Parasitaphelenchus Fuchs, 1937 los estadios juveniles y los adultos se alimentan de hongos, pero el tercer estadio larval penetra en la larva del escarabajo y alcanza el cuarto estadio. Este nematodo está obligado a retornar al ambiente y alimentarse del hongo para poder completar su ciclo biológico, ya que solo utiliza parcialmente los nutrientes del hospedador (Poinar, 1983). Otro tipo de parasitismo facultativo ocurre en algunos representantes de la familia Neotylenchidae que se alimentan de hongos o de partes aéreas de las plantas. Es de particular interés el género Deladenus Thorne, 1941, que vive en el moho de la madera en galerías del roble, alimentándose de un hongo perteneciente a la división Basidiomycota y ocasionalmente parasitando el hemocele de una avispa de la madera (Poinar, 1975).

En las formas parásitas de la familia Rhabditidae, el juvenil J3 penetra por la cutícula del hospedador dirigiéndose a su intestino y madurando al estado adulto. Los machos y las hembras copulan y los huevos llevan a cabo el desarrollo embrionario en el proctodeo del hospedador. Los juveniles infectantes o J3 salen con las heces en búsqueda de un nuevo hospedador (Stock y Camino, 1996) (Fig. 4). 


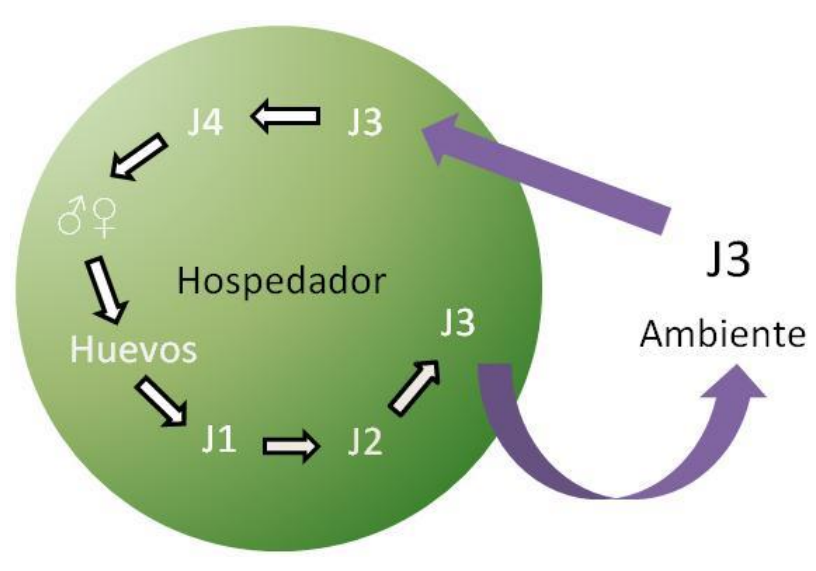

Figura 1. Esquema del ciclo de vida para la familia Rhabditidae

Un paso próximo hacia el completo parasitismo se da en Rhabditis insectivora Körner, 1954, parásito facultativo del lucánido (Coleoptera) Dorcus parallelopipedus L., 1758. Los juveniles penetran al tracto digestivo y a la cavidad general del cuerpo de la larva del insecto, persistiendo aún dentro del hospedador adulto. Durante este tiempo, los nematodos maduran a adultos y copulan, abandonando al hospedador para oviponer. Cuando son muy abundantes, el insecto muere y los nematodos se reproducen dentro del cadáver (Poinar, 1983).

Otro tipo de parasitismo facultativo es ejemplificado por Diplogasteritus labiatus Cobb, Pristionchus iheritieri Maupas, 1919 y Pristionchus uniformis Fedorko y Stanuszek, 1971 que eventualmente pueden llegar a matar al hospedador, siendo considerados como candidatos para el control biológico. El ciclo biológico de estas tres especies es muy similar. Los juveniles infectivos entran al intestino del insecto por ingestión o a través del ano. Una vez dentro del tracto digestivo, comienzan el desarrollo y se establece la colonia de nematodos, alimentándose de bacterias. El hospedador muere y estos se alimentan del cadáver (Poinar, 1983). 


\section{Parasitismo obligado}

Los nematodos parásitos obligados requieren de un hospedador para completar su desarrollo. Pueden parasitar al insecto en el tracto digestivo, en el sistema reproductor o en la cavidad general del cuerpo (Poinar, 1983).

\section{En tracto digestivo y sistema reproductor}

Miembros del género Oryctonema Poinar, 1970, están extremadamente adaptados a sus hospedadores y viven permanentemente en la bolsa copulatriz de escarabajos dinástidos, alimentándose de secreciones del sistema reproductor. Estos nematodos penetran por el aedeagus del macho durante la cópula y llegan así a las hembras durante los subsecuentes apareamientos. En este caso los parásitos carecen de estado de resistencia, por lo que deben permanecer indefinidamente en el sistema reproductor de los escarabajos, alimentándose de secreciones glandulares y microorganismos (Camino y Achinelly, 2008).

Unos pocos rhabdítidos especializados son parásitos obligados del tubo digestivo de insectos. Syrphonema intestinalis Laumond y Lyon, 1971, se reproduce en el intestino de adultos sírfidos y Eudronema intestinalis Remillet y van Waerebeke, 1973 en el intestino de escarabajos. Relación similar de un parasitismo obligado se ve en representantes de la familia Cephalobidae, como por ejemplo Cephalobium microviborum Ackeret y Wadley, 1921 que se desarrolla en el intestino de grillos, y Gynopoecilia pseudovipara Chabaud Golvan, Bain y Brygoo, 1965 que parasita el intestino de mántidos (Poinar, 1983).

Los oxyuridos comprenden un grupo de parásitos obligados del tubo digestivo de los insectos. La diferencia que existe con el resto de los nematodos radica en que la forma infectante es el huevo o el segundo estadio larval eclosionado, ingerido por el hospedador. Posteriormente se establecen en el intestino del mismo. Un ejemplo son las especies del género Thelastoma Leidy, 1849 (Poinar, 1975). 
En el ciclo de vida de los thelastomátidos los huevos ingeridos por el insecto hospedador llegan al estomodeo donde eclosionan a J2. Estos juveniles experimentan sucesivas mudas alcanzando el estado adulto. Luego de la cópula los machos mueren y ocurre la oviposición. Los huevos son eliminados con las heces al exterior, esperando ser ingeridos por un nuevo hospedador (Camino y Reboredo, 1998) (Fig. 2).

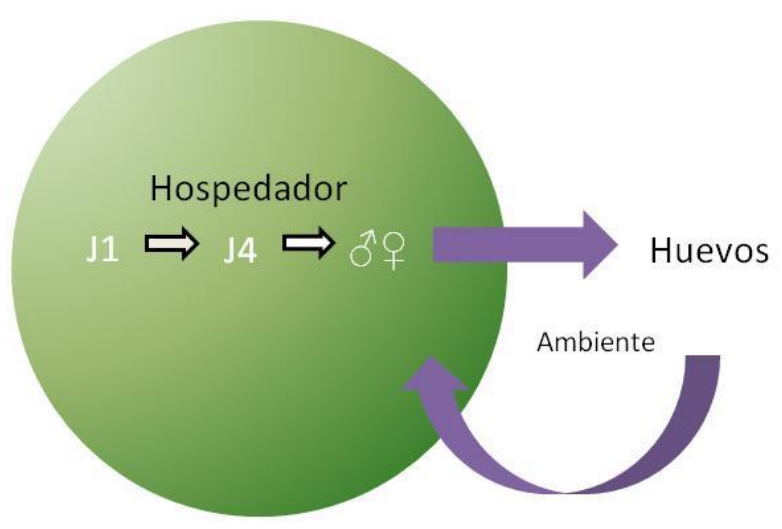

Figura 2. Esquema del ciclo de vida para la familia Thelastomatidae

\section{En cavidad general del cuerpo}

Algunos rhabdítidos obtienen su alimento de la hemolinfa de los insectos. El diplogastérido Parasitodiplogaster sycophilon Poinar, 1979 es un ejemplo de parásito de la cavidad corporal. Juveniles y adultos se encuentran en la avispa del higo Elisabethiella stuckenbergi Grandi, 1955. Este caso representa un significativo desarrollo en la evolución del parasitismo en la familia Diplogasteridae. Otro ejemplo es el nematodo parásito de escarabajos carábidos, Carabonema hasei Stammer y Wacher, 1952. El estado infectivo juvenil entra en el intestino y penetra en la cavidad corporal del coleóptero. Después de madurar al estado adulto, los parásitos copulan y se reproducen, matando al hospedador. Cuando los juveniles alcanzan el estado infectivo dejan el cadáver y buscan a otro hospedador (Poinar, 1975). 
La capacidad de obtener los nutrientes del hemocele del insecto se ha dado de dos maneras diferentes en los Rhabditida que desarrollan un parasitismo obligado. El primer método consiste en el uso de enzimas que actúan sobre los fluídos corporales del insecto como en los casos recientemente mencionados. El segundo no involucra tal grado de evolución bioquímica y se encuentra en los grupos menos especializados, ya que necesitan la presencia de una bacteria para obtener el alimento (Poinar, 1983).

\section{Asociación con bacterias simbióticas}

La asociación que existe entre las bacterias y los nematodos rhabdítidos corresponde a un mutualismo. La bacteria puede ser propia del intestino del insecto o del medio externo, en ambos casos pueden causar septicemia y destruir al hospedador cuando alcanzan la cavidad general del cuerpo. Al menos dos géneros de Rhabditida han desarrollado este método llevando e introduciendo una bacteria en los insectos. Estos nematodos pertenecen a dos familias, Steinernematidae y Heterorhabditidae, con los géneros Steinernema Glaser, 1932 y Heterorhabditis Poinar, 1976, respectivamente. Las especies de estos géneros son portadoras de una bacteria correspondiente a dos géneros, Xenorhabdus Thomas y Poinar, 1979 y Photorhabdus Boemare et al., 2003, respectivamente. Estas bacterias son de suelo y no tienen acción patogénica si no alcanzan la cavidad del insecto. Las bacterias se encuentran en la primera porción del intestino del nematodo. Uno de los roles primordiales de las bacterias es convertir los tejidos y órganos del insecto en una "sopa de nutrientes" que aporta al crecimiento y desarrollo del nematodo. Heterorhabditis tiene un requerimiento obligatorio por Photorhabdus para su crecimiento y desarrollo y esta asociación ha evolucionado a tal grado que el nematodo solo puede crecer con esta bacteria o con una cercana filogenéticamente. La relación nutricional entre Steinernema y Xenorhabdus aparenta ser de algún modo más distendida, y hay informes en donde Steinernema experimenta un crecimiento y desarrollo limitado con otras bacterias como Escherichia coli Escherich, 1885 (Vega y Kaya, 2012).

El mutualismo es evidente ya que el nematodo en su fase parasitaria depende de la bacteria para optimizar su reproducción, posibilitando que haya varias generaciones dentro del hospedador. Las bacterias, por su parte, no pueden penetrar al 
insecto sin ayuda del nematodo. Además, la tasa reproductiva de las bacterias se ve incrementada dentro del insecto (Vega y Kaya, 2012).

En el ciclo de vida de un heterorhabdítido, el juvenil infectivo de tercer estadio, recubierto por la cutícula del segundo estadio, conocido como larva dauer, invade al insecto hospedador a través de aberturas naturales: boca, ano o espiráculos o con ayuda de un diente atravesando los intersegmentos. Este penetra en el hemocel del insecto introduciendo células bacterianas en la hemolinfa que portan en su intestino, lo cual produce la muerte del hospedador entre las 24-48 hs postinfección. Poco después de liberar la bacteria en el hospedador, el juvenil infectivo de tercer estadio cambia a cuarto estadio y luego a adulto. Los adultos en general aparecen cinco días posteriores a la infección del hospedador. Cada juvenil infectivo de la primera generación invasiva se desarrolla en una hembra hermafrodita. Generaciones subsiguientes en el mismo hospedador constan de machos y hembras (Poinar, 1990). Los adultos se aparean y producen huevos; algunos son liberados por la hembra, pero la mayoría son retenidos en su interior. Los juveniles retenidos dentro de la hembra consumen su contenido corporal, causando su ruptura. Una o más generaciones adicionales pueden ocurrir dentro del hospedador antes de que los juveniles (J3) emerjan del hospedador y se dispersen en el suelo, constituyendo los juveniles infectivos (Vega y Kaya, 2012) (Fig. $5)$. 


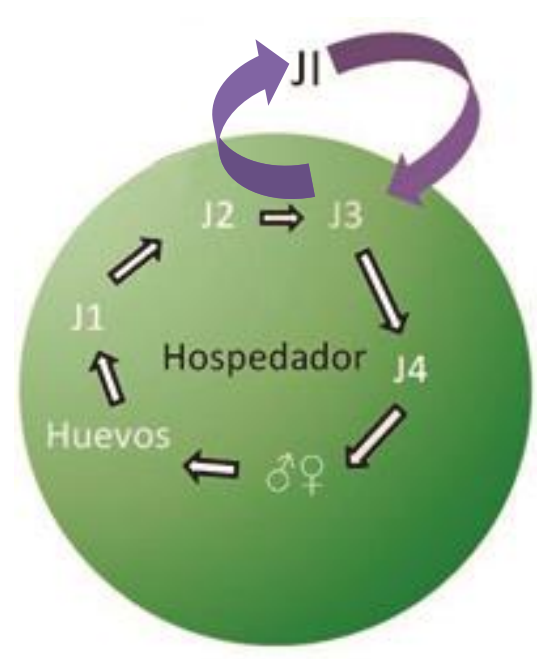

Ambiente

Figura 3. Esquema del ciclo de vida para la familia Heterorhabditidae

Dentro del orden Mermithida, los representantes de la familia Tetradonematidae, se desarrollan dentro de la hemolinfa del insecto. Los cinco géneros, con sus respectivas especies, matan al hospedador. La especie más conocida es Tetradonema plicans Cobb, 1919, un parásito de moscas sciáridas. Después de penetrar al hospedador, los juveniles infectivos maduran a adultos que copulan. Inmediatamente ocurre la muerte del insecto, las hembras escapan y oviponen en el exterior y de esos huevos eclosionan las formas infectivas (Camino y Achinelly, 2008).

Los Thylenchida raramente matan al hospedador, pero causan esterilidad, reduciendo la fecundidad, retardando el desarrollo y alterando su comportamiento. Las formas parásitas son las hembras grávidas. Las hembras fertilizadas, envainadas en la cutícula del cuarto estadio larval, penetran por los intersegmentos del insecto utilizando el estilete y la secreción de las glándulas faringeales. Evierten parcialmente los úteros a través de la abertura vulvar y las células uterinas comienzan a absorber los nutrientes de la hemolinfa del hospedador. Los huevos son depositados en el hemocele y se desarrollan hasta $\mathrm{J} 4$, los cuales salen del hospedador por el tracto digestivo y maduran a adultos. Después de la cópula, los machos mueren y las hembras grávidas buscan un nuevo hospedador (Poinar, 1979) (Fig. 6). 


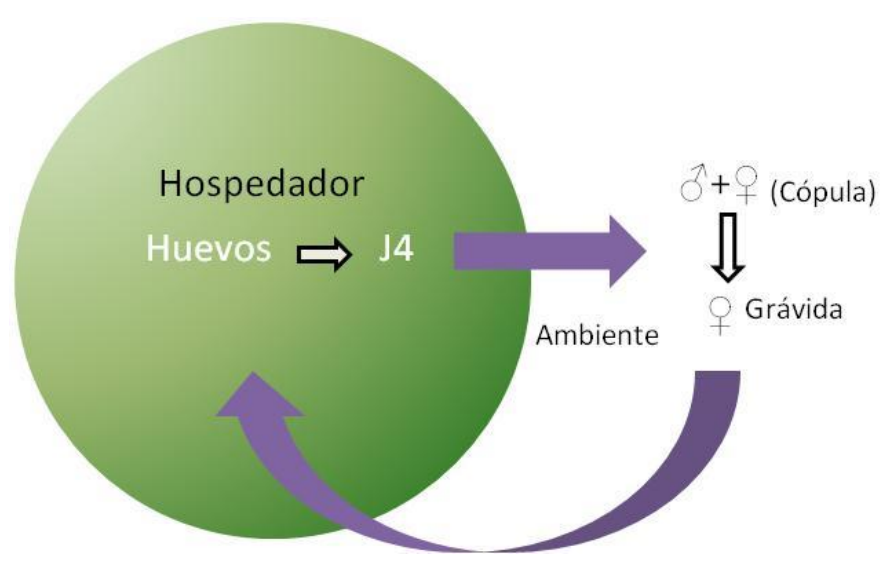

Figura 4. Esquema del ciclo de vida para la familia Tylenchidae

Este tipo de asociación es común para los miembros de las familias Allantonematidae y Sphaerulariidae. Entre los primeros encontramos una larga lista de especies comprendida por 17 géneros que principalmente atacan a una amplia variedad de escarabajos, moscas, pulgas, ácaros y trips. Cada especie está restringida a uno o a unos pocos géneros de hospedadores y raramente atacan a insectos de diferentes familias; esto se debe al alto grado de especialización nutricional que alcanzaron los nematodos con sus hospedadores. Un ejemplo de allantonemátidos parásitos obligados es Heterotylenchus autumnalis Nickle, 1967 que parasita a la mosca Musca autumnalis De Geer, 1776 la cual se alimenta de secreciones lagrimales de las vacas (Poinar, 1983). Tripius Chitwood, 1935 y Sphaerularia Dufour, 1837, dos de los 3 géneros de la familia Sphaerulariidae, presentan este tipo de asociación (parásitos de moscas y abejorros respectivamente), que absorben nutrientes a través de su singular y modificado sistema reproductor. El estadio infectivo es la hembra grávida, que en el hemocele del insecto expulsa el sistema reproductor por la abertura vulvar; las células del útero evertido se agrandan y al contactar con la hemolinfa del insecto captan los nutrientes (Poinar, 1975) 


\section{Parasitoidismo. En cavidad general del cuerpo.}

Los mermítidos son parásitos obligados que se ubican generalmente en el hemocele de los insectos. Solamente el tercer estadio juvenil (J3) es la forma parásita (larva parásita). Las formas infectivas, J2 o larvas preparásitas, entran al insecto hospedador por penetración activa a través de la cutícula utilizando el estilete y se dirigen al hemocele, donde maduran a J3. En mermítidos parásitos de algunos ortópteros la penetración puede ser pasiva por ingesta de huevos. Durante la fase parasitaria el nematodo absorbe los nutrientes del hospedador directamente a través de la cutícula y los almacena en el trofosoma. Una vez finalizada esta fase, el juvenil J4 (4to. estadio juvenil o postparásito) emerge del insecto y comienza la etapa de vida libre. La muerte del hospedador ocurre por el daño causado ante la emersión del nematodo a través de la cutícula del insecto. En el ambiente los postparásitos maduran a adultos, copulan, y aproximadamente a los 10 días las hembras oviponen. El desarrollo embrionario se completa permaneciendo el J1 y J2 dentro del huevo eclosionando del mismo y buscando un nuevo hospedador, reiniciándose el ciclo (Fig.1) (Poinar, 1979).

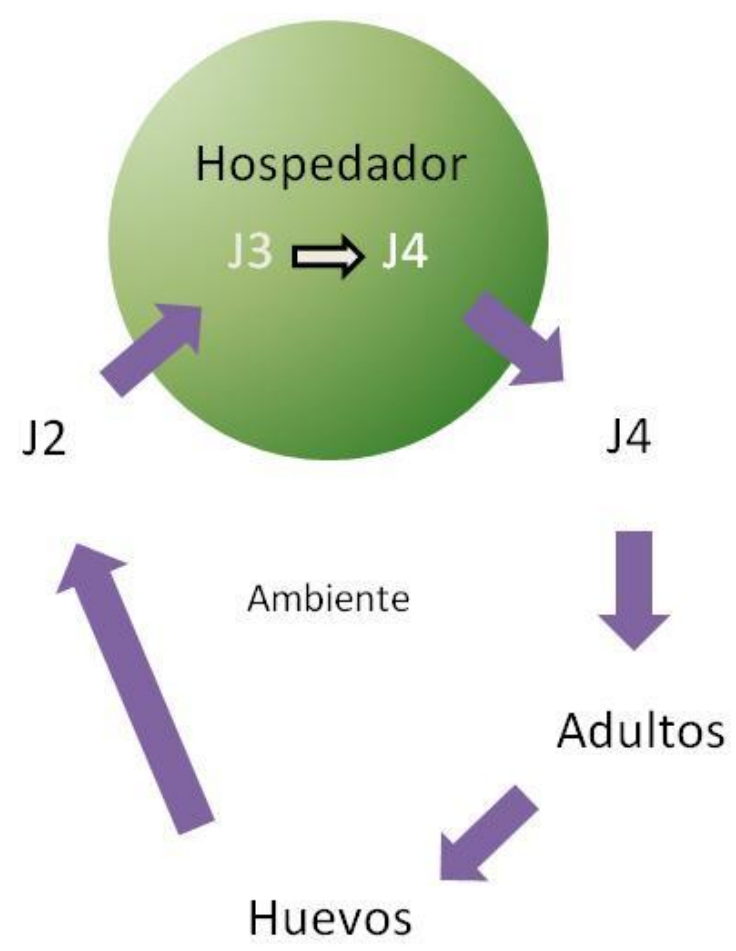

Figura 5. Esquema del ciclo de vida para la familia Mermithidae 
Estos parasitoides, que descienden de los nematodos predadores, son altamente especializados en obtener los nutrientes de la hemolinfa del insecto (Wise de Valdez, 2006). Los mermítidos parasitoidizan a la mayoría de los insectos, tanto a estadios preimaginales como adultos, entre los que se incluyen varios de importancia sanitaria y agrícola. Existen más de 30 géneros con numerosas especies, todos con un ciclo de vida semejante. Como consecuencia de este parasitoidismo provocan la muerte y/o esterilización del hospedador, siendo considerados como potenciales agentes para el control biológico (Poinar, 1983).

\section{CONTROL BIOLÓGICO CON ENTOMONEMATODOS}

El uso de entomonematodos patógenos de insectos dañinos se ha desarrollado como una disciplina de la Patología de Insectos y es comparable al uso de virus, bacterias, hongos y protozoos (Gaugler y Kaya, 1990).

Los entomonematodos definidos como enemigos son muy pocos, ya que es menester realizar primeramente estudios de la biología y la etología del insecto dañino,

para luego analizar el comportamiento del nematodo, su acción sobre el insecto a controlar y la factibilidad a bajo costo económico de su cría masiva. Cuando un nuevo entomonematodo es hallado, se debe determinar la especificidad y el grado de patogenia sobre los hospedadores (Gaugler y Kaya, 1990).

Para considerar al entomonematodo como eficiente agente de biocontrol, es necesario que el mismo responda a los postulados (modificados) de Koch (según Poinar, 1975):

- $\quad$ La especie del nematodo debe estar asociada con la enfermedad del insecto.

- $\quad$ Debe ser fácilmente aislado y obtenerse el estado infectivo.

- $\quad$ El estado infectivo al estar en contacto con el hospedador debe provocar la enfermedad o infección. 
- $\quad$ El mismo nematodo debe poder ser recuperado de las infecciones experimentales del hospedador para poder repetirlas.

Para que el control sea eficiente, se deben plantear varios objetivos como crear una conciencia general sobre el impacto en el ecosistema, énfatizansdo los factores de mortalidad natural del insecto a controlar; emplear productos orgánicos, no tóxicos, como estrategia de biocontrol. En este contexto el objetivo principal es proteger el ambiente y a los animales benéficos para el hombre, ampliando el conocimiento de los enemigos naturales.

El control biológico con entomonematodos presenta ventajas y desventajas. Al specto y desde el punto de vista de las ventajas, la especificidad al atacar solamente a algunos de ellos considerados insectos dañinos y su capacidad de multiplicación y dispersión. A su vez, los efectos subletales no ocasionan la muerte directa del insecto a controlar, pero provocan alteraciones en su ciclo biológico, como por ejemplo la disminución de posturas de huevos, esterilización de machos y reducción de la viabilidad de los mismos.

El establecimiento o control permanente del entomonemátodo puede mantener a la población del insecto a controlar por debajo de los niveles de daño económico. Pueden ser aplicados en asociación a subdosis de mezclas de varios patógenos, en algunos casos incrementando su patogenia. No presentan contaminación ni toxicidad y económicamente su uso permitiría un ahorro de divisas considerable, debido al mejoramiento de la salud humana en todos sus aspectos.

Las desventajas del uso de entomonematodos son importantes y deben considerarse. Son muy sensibles a ciertos parámetros climáticos como temperatura, humedad relativa, luminosidad, entre otros, que pueden perjudicar su acción. Algunos de estos inconvenientes pueden ser superados con el tipo de formulación (incorporación de protectores) y el momento de aplicación (horas de menor insolación). Otro elemento que debe considerarse es el impacto ambiental que provoca la aplicación de un entomonemátodo natural o introducido al ecosistema, que es a veces evidenciado con posibles efectos indirectos sobre los insectos no perjudiciales. De esta manera, cuando la población del insecto plaga disminuye en número, la población de predadores de la 
misma se ve afectada disminuyendo también su número. Esta reducción es temporaria, ya que los predadores suelen no ser estrictamente específicos.

\section{ANTECEDENTES DE LOS ENTOMONEMATODOS EN LAARGENTINA}

Una gran diversidad de especies de nematodos asociados a insectos (parásitos, parasitoides y patógenos) ha sido descripta en Argentina a través de investigaciones llevadas a cabo en los últimos 36 años. Los estudios se centraron principalmente en las descripciones de numerosas especies, determinación de ciclos biológicos, ecología de especies patogénas y la dinámica en condiciones naturales para las familias Mermithidae, Thelastomatidae, Cephalobidae, Rhabditidae, Heterorhabditidae y Steinernematidae (Doucet, 1986; Doucet y Bertolotti, 1995; Achinelly y Micieli, 2013; Del Valle et al., 2013; Camino et al., 2014; Di Battista et al., 2015).

Una amplia gama de insectos, cubriendo nueve ordenes y 41 familias, la mayoría de importancia agrícola y sanitaria, han sido registradas como hospedadores de entomonematodos, presentando una vasta distribución en una variedad de ambientes. Se han registrado ocho familias y 52 géneros de nematodos, de las cuales tres presentaron potencial para el control biológico (Mermithidae, Steinernematidae y Heterorhabditidae) (Poinar, 1975; Poinar, 1979; Doucet, 1986).

Entre estas investigaciones se encuentra el estudio de Strelkovimermis spiculatus Poinar y Camino, 1986, como controlador biológico de mosquitos de importancia sanitaria, con investigaciones acerca de la optimización de la producción, los efectos de los factores bióticos y abióticos en la actividad infectiva y parasitaria y la dinámica poblacional en el campo (Poinar y Camino, 1986; Camino, 1988; 1989; Camino y Stock, 1989; Achinelly, 2004; Micieli et al., 2012; Belaich et al., 2015).

Cerca de 30 aislamientos de heterorhabdítidos y 40 de steinernemátidos han sido citados por investigadores de Argentina por más de 35 años de estudio.

Nueve especies de nematodos entomopatógenos: Steinernema carpocapsae (Weiser, 1955) Wouts, Mracek, Gerdin y Bedding, 1982, S. feltiae (Filipjev, 1934) 
Wouts, Mracek, Gerdin y Bedding, 1982, S. scapterici Nguyen y Smart, 1985, S. rarum (Doucet, 1986) Mamiya, 1988 , S. ritteri Doucet y Doucet, 1990, S. glaseri Steiner, 1929, S. diaprepesi, Heterorhabditis bacteriophora Poinar, 1976 y H. argentinensis Stock, 1993 fueron registradas en las provincias de Córdoba, Neuquén, Río Negro, Santa Fe, La Pampa y Buenos Aires. Las especies de Heterorhabditis fueron sinonimizadas por Adams et al., 1998. Steinernema rarum y S. ritteri fueron descriptas como nuevas especies por primera vez en Argentina (Doucet, 1986; Doucet y Bertolotti, 1995; Del Valle et al., 2013; Salas et al., 2013; Camino et al., 2014).

Heterorhabditis bacteriophora (cepa VELI) fue aislada de jardines orgánicos constituyendo en la localidad de Villa Elisa, siendo el segundo registro de esta especie en la Provincia de Buenos (Achinelly et al., 2011). Esta provincia es un area principal donde se desarrolla la agricultura, y los productos obtenidos se utilizan para consumo domestico y exportación. Por esta razón, se han realizado investigaciones sobre el potencial de este aislamiento como agente de biocontrol. La patogenia y virulencia de $H$. bacteriophora se puso a prueba en ensayos a campo de manera conservativa, incrementando la población ya existente en el ambiente, donde se logró disminuir la densidad de insectos plaga en cultivos de berenjena y frutilla. Estudios sobre la biología en condiciones naturales y en laboratorio permitieron diseñar una tecnología de producción masiva, control de calidad y aplicación de este nematodo (Achinelly et al., en prensa).

En la Provincia de Buenos Aires las familias Gryllidae y Gryllotalpidae representan dos grupos de plagas del suelo que resultan un grave problema para las pasturas y la zona hortícola del Gran La Plata. Cuando sus ataques son intensos es común observar la presencia de zonas amarillas y secas que a menudo se confunden con la falta de riego (Figs. 9 y 12).

En esta región se encuentran descriptas cuatro especies de grillos (Anurogryllus muticus De Geer, 1773, Gryllus argentinus Saussure, 1874, Gryllus assimilis Fabricius, 1775, Gryllodes laplatae Saussure, 1874) y dos de grillotopos (Neocurtilla claraziana Saussure, 1874 y Scapteriscus borelli Giglio-Tos, 1894). De las 6, Gryllus argentinus y Gryllus assimilis no son consideradas plaga del suelo (Orthoptera Species File, 2016).

Para el control de estos insectos plaga se han citado principalmente pesticidas químicos, prácticas culturales y agentes biológicos. 
El control químico de grillos en áreas extensivas se considera dificultoso por el hábito que tienen los insectos de protegerse en las galerías evitando el consumo de plantas tratadas con estos productos. Las aplicaciones con insecticidas foliares realizan un control insatisfactorio, eliminando un 30\% de los individuos. Los cebos tóxicos son el método de control más eficiente siempre que sean aplicados cuando hay carencia de alimento (Betancourt y Scatoni, 2010).

El control de estos insectos plaga mediante el uso exclusivo y excesivo de insecticidas, posee no sólo limitaciones, sino efectos desfavorables tales como el desarrollo de resistencia en las plagas, destrucción de especies benéficas, resurgimiento de las poblaciones tratadas, concentración de los residuos tóxicos perjudiciales para la salud humana y contaminación del ambiente (Stenersen, 2004).

Por lo tanto es necesaria la búsqueda de alternativas para el control y/o regulación de estos insectos plaga, que permitan desarrollar estrategias efectivas y no contaminantes para el ambiente.

Un tipo de control alternativo es el cultural, donde una sustancia tensioactiva (agua y detergente) es vertida sobre las madrigueras. Dicho procedimiento se realizó en este trabajo, pero aplicado al muestreo.

El estudio de los nematodos asociados a ortópteros de interés agroeconómico, radica principalmente en la búsqueda de algún organismo, que por sus características, pueda ser considerado como agente de control biológico. La utilización de los entomonematodos como agentes de control implica el conocimiento de la diversidad y la biología, de parásitos y hospedadores, los niveles de infección a campo a lo largo del tiempo, y la susceptibilidad de estos últimos, tal que permita determinar posibles candidatos a utilizar y una correcta estrategia de aplicación.

Respecto de estos parásitos como agentes de control biológico, las principales carencias se encuentran en la falta de experiencias a campo, y oportunidad de los tratamientos, para lo cual es importante diseñar estrategias de control. 


\section{ORTÓPTEROS COMO HOSPEDADORES DE NEMATODOS}

Uno de los primeros registros de nematodos parásitos de estos insectos puede ser encontrado en los extensos escritos de Aldrovandi (1623). En su "De Animalibus Insectis" el autor encontró saltamontes cubiertos con gusanos largos y consideró a estos últimos responsables de la muerte de los insectos. Linster (1671) citó a Aldrovandi al haber encontrado un gusano similar en una hoja de un jardín. Este gusano fue descripto teniendo el grosor de un pelo de caballo, siendo negro con la superficie ventral y los extremos de color blanco. En el momento del escrito, ambos autores consideraron a estos gusanos como miembros del orden Nematomorpha, sin embargo, es probable que estas observaciones se refirieran al nematodo parásito de insectos Mermis nigrescens Dujardin, 1842. Posteriormente, Christie (1937) describió la coloración de las hembras maduras e ilustró como las hembras grávidas migran en la vegetación para depositar sus huevos (Poinar, 1975).

En lo que respecta a nematodos asociados a la familia Gryllidae el primer registro se remonta a 1922. En su trabajo "Eine Mermithidae aus der Leibeshole von Lyogrillus campestris", Regen describe al mermíthido Mermis liogrylli Regen, 1922 hallado en el grillo de campo Gryllus campestris L., 1758 (Poinar, 1975).

Por su parte, Sergiev fue el primer investigador en encontrar un nematodo en un representante de la familia Grillotalpidae. En 1923 logró recuperar y describir al thelastomatido Gryllophila skrjabini Sergiev, 1923 del intestino de Gryllotalpa africana Palisot de Beauvois, 1805 (Poinar, 1975).

Basir (1956) llevó a cabo una recopilación de los oxyúridos de artrópodos, en donde menciona a diversas especies de thelastomátidos parasitando a grillotopos.

En 1992, Adamson y van Waerebeke realizaron una revisión de la superfamilia Thelastomatoidea; donde muchos de estos nematodos son parásitos de grillotopos.

A principios de siglo, Rizvi y Jairajpuri (2002) describieron al thelastomátido Cameronia basiri, y Shah et al. (2012) C. triovata y C. manipurensis, las tres especies parasitando a G. africana. 
En Argentina, Camino ha dedicado parte de su investigación a los nematodos parásitos de grillos y grillotopos. Ha publicado numerosos trabajos y descripto especies pertenecientes a distintos géneros, teniendo a estos ortópteros como hospedadores. Entre ellos se pueden destacar el primer registro del género Binema en un grillotopo, la primera mención del género Blatticola en un grillo y la descripción de nuevas especies (Reboredo y Camino, 1998; Camino y Reboredo, 1999; Achinelly y Camino, 2007).

En la provincia de Buenos Aires han sido citados nematodos parásitos de ortópteros plaga. Asociados a especies de la familia Acrididae, siete mermítidos: Agamermis decaudata Cobb, Steiner y Christie, 1923, Amphimermis bonaerensis Miralles y Camino, 1923, Amphimermis dichroplusi Camino y Lange, 1997, Amphimermis ronderosi Camino y Lange, 1997, Hexamermis cochlearius Stock y Camino, 1992, Hexamermis ovistriata Stock y Camino, 1992 y Longimermis acridophila Camino y Stock, 1989. Parasitando especies de la familia Gryllidae, en la especie Gryllodes laplatae, dos mermítidos (Amphimermis sp., Hexamermis macrostomata Camino y Stock, 1994), tres thelastomátidos (Blatticola cristovata Achinelly y Camino, 2007, Cameronia laplatae Reboredo y Camino, 2001, Neyraiella distinctus Camino y de Villalobos, 2001), siete cephalóbidos (Cephalobium bidentata Camino, Brividoro y Leigh, 2006, Cephalobium dispar Camino y Reboredo, 2004 , Cephalobium laplata Camino y Reboredo,2004, Cephalobium polidentatum Camino y Reboredo, 2004, Cephalobium magdalensis Reboredo y Camino, 1998, Cephalobium tridentata Camino, Brividoro y Leigh, 2006, Cephalobium odontolateralis Camino y Maiztegui, 2002), un diplogastérido (Micoletzkya sp.) y tres rhabdítidos (Alloionema sp., Pelodera sp., Cruznema lincolnensis Reboredo y Camino, 1998). En lo que respecta a la familia Gryllotalpidae, se conocen parasitosis por cinco thelastomátidos (Cephalobellus cyclocephalae Singh et al., 2014, Euryconema brevicauda Camino y Reboredo, 1999, Fontanema gracilis Camino, 2011, Gryllophila cephalolobulata Camino y Maiztegui, 2002, Schwenkiella tetradentatum Camino, 2011) un mermítido (Agamermis decaudata Cobb, Steiner y Christie, 1923) y un travassosinemátido (Binema bonaerensis) en $N$. claraziana. También fueron relevados entomonematodos en las provincias de Córdoba, Entre Ríos y Chaco (Camino y Stock, 1989, 1994; Reboredo y Camino, 1998, 2001; Camino y Reboredo, 1999, 2000b; 2004; Camino y Maiztegui, 2002; Achinelly y Camino, 2007). 
Stock halló por primera vez a la especie Steinernema scapterisci en el grillotopo Scapteriscus borelli Nickle, 1992 en la ciudad de Colón (Buenos Aires), durante un relevamiento de nematodos entomofílicos (Stock, 1992). Este constituye el primer y único nematodo entomopatógeno aislado en el campo en un grillotopo para Argentina.

En el mismo sentido, Doucet et al. (2008) realizaron pruebas en el laboratorio utilizando una cepa del nematodo entomopatógeno H. bacteriophora cepa RIV, para evaluar la susceptibilidad del acrídido Xylelus modestus. 


\section{HIPÓTESIS}

Un gran número de entomonematodos tienen la capacidad de reducir las densidades de insectos plaga ya sea por castración, reducción de la fecundidad, alteraciones en el comportamiento, o directamente provocándoles la muerte.

Las especies nativas de nematodos entomopatógenos (NEPs) se hallan adaptadas a las condiciones ambientales y climáticas locales por lo cual podrían ser mejores candidatos para su uso como agentes de control biológico asegurando una eficiencia y control más seguro, y evitando el desplazamiento de especies por la introducción de biocontroladores exóticos.

Nuestra hipótesis sostiene que ortópteros plaga de las familias Gryllidae y Gryllotalpidae de la zona del Gran La Plata albergan una gran diversidad de entomonematodos que debido a su patogenia y especificidad actúan como agentes de biocontrol de estos insectos. 


\section{OBJETIVOS}

\section{Objetivo general}

- Evaluar la diversidad de nematodos parásitos de ortópteros plaga del suelo, pertenecientes a las familias Gryllidae y Gryllotalpidae y determinar los niveles de parasitismo y patogenia sobre sus hospedadores.

\section{Objetivos específicos}

- Determinar la diversidad de ortópteros pertenecientes a las familias Grillidae y Gryllotalpidae en pasturas naturales de La Plata y Gran La Plata.

- Identificar y caracterizar las poblaciones de nematodos asociados a estos hospedadores.

- Determinar el grado de asociación entre los nematodos y sus hospedadores.

- Evaluar la tasa de mortalidad de un NEP nativo de la Provincia de Buenos Aires sobre ortópteros de la familia Gryllidae.

- Comparar, a través del cálculo de índices ecológicos, las comunidades parasitarias de entomonematodos de los diferentes hospedadores. 


\section{MATERIALES Y MÉTODOS}

\section{ORTHOPTERA (GRYLLIDAE Y GRYLLOTALPIDAE) COMO INSECTOS PLAGA DEL SUELO. CARACTERIZACIÓN DE LOS HOSPEDADORES}

Los ortópteros (Orden Orthoptera, del griego opӨóc orthós, "recto, derecho", y $\pi \tau \varepsilon \rho o v$ pteron, "alas") son insectos hemimetábolos, hipognatos, con aparato bucal masticador, alas posteriores membranosas y abdomen constituído típicamente de 11 segmentos. Se conocen aproximadamente 19.000 especies distribuídas por todo el planeta (De la Fuente, 1994). A este orden pertenecen, entre otras, las familias Gryllidae y Gryllotalpidae, ambas con representantes considerados plaga del suelo. En Argentina, específicamente en la región del Gran La Plata, las especies Anurogryllus muticus De Geer, 1773 y Neocurtilla claraziana Saussure, 1874 ocasionan daños en cultivos, césped y en pasturas (Camino y Reboredo, 2001; Cigliano, et al., 2011).

Anurogryllus muticus De Geer, 1773 (Gryllidae)

Esta especie mide entre 16 y $19 \mathrm{~mm}$ de longitud y posee una coloración castaño clara (Fig. 7). Ambos sexos tienen el mismo tamaño. Los machos poseen alas un poco más largas que las hembras. El ovipositor es de menor tamaño que el de otros grillos. Se puede diferenciar del grillo común porque éste es de color oscuro y presenta alas más largas (West y Alexander, 1963). Habitan en las galerías que construyen en el suelo. Después de una lluvia se pueden observar los montículos de tierra que forman, producto de la excavación. La galería puede alcanzar entre 20-30 cm de profundidad (en algunos casos hasta 60) y se ensancha en el extremo distal para formar la cámara de cría, donde llevan los trozos de plantas cortadas. A medida que aumenta el fotoperíodo, es profundizada. Esta es una estrategia que les permite sobrevivir a condiciones de déficit hídrico. También la ingestión del sustrato durante la construcción de la galería puede ser una manera de adquirir humedad adicional. El orificio de entrada a la galería es pequeño 
y oval, y generalmente para una misma galería hay dos orificios de salida (Weaver y Sommers, 1969).

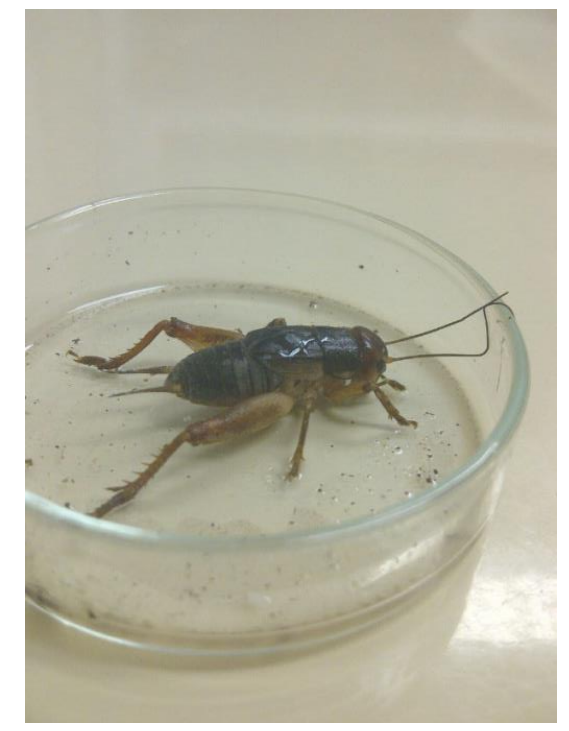

Figura 6. Adulto de Anurogryllus muticus

\section{Descripción}

Huevos: los huevos son oblongos, glabros y blanquecinos. Promedian 2,48 \pm $0,18 \mathrm{~mm}$ de largo y $0,97 \pm 0,13 \mathrm{~mm}$ de ancho; el intervalo de medida va de 1,76 a 2,79 $\mathrm{mm}$ de largo y 0,59 a 1,18 $\mathrm{mm}$ de ancho (Weaver y Sommers, 1969).

Ninfas: según Liebermann (1955) hay 6 estadios durante el ciclo de vida. Las mayores diferencias morfológicas entre estadios son el tamaño y el desarrollo de los esbozos alares. La coloración es marrón clara en todos los estadios. Los especímenes más grandes en el estadio final pueden llegar a una longitud corporal de $16 \mathrm{~mm}$ (Weaver y Sommers, 1969).

Adultos: la proporción de sexos es 1:1. El tamaño de los sexos es similar, pero las alas del macho miden cerca de $3 \mathrm{~mm}$ más que las de la hembra. Las alas totalmente desarrolladas son de una coloración cercana al negro. La genitalia externa del macho está escondida por un gran esternito (noveno). El ovipositor de la hembra es corto. El par de alas posteriores no se desarrolla completamente (Weaver y Sommers, 1969). 
Ciclo de vida: estos insectos completan su ciclo en un año, pasando por los 3 estadios: huevo, ninfa y adulto (Fig. 8). La diferencia entre ninfas y adultos se encuentra en el tamaño y en el desarrollo de las alas. Los adultos se observan desde fines de octubre hasta marzo. En cada galería se encuentra una hembra, que luego de ser fecundada, deposita sus huevos (100-130) en el fondo de la misma. Las ninfas emergen luego de dos o tres semanas y permanecen en la cámara de cría al menos durante un mes. Se alimentan de los trozos de plantas que introduce la hembra. En otoño, comienzan a vivir en forma solitaria, construyen su propia galería y almacenan alimento para pasar los meses de invierno. Durante esta estación la actividad disminuye considerablemente. En septiembre y octubre, las ninfas se reactivan y alcanzan el quinto estadio de desarrollo, para convertirse finalmente en adultos hacia principios de noviembre e iniciar la reproducción. De acuerdo al ciclo, la población comienza a incrementarse en primavera hasta alcanzar su pico máximo en el otoño, en donde predominan las ninfas (Hayslip, 1943).

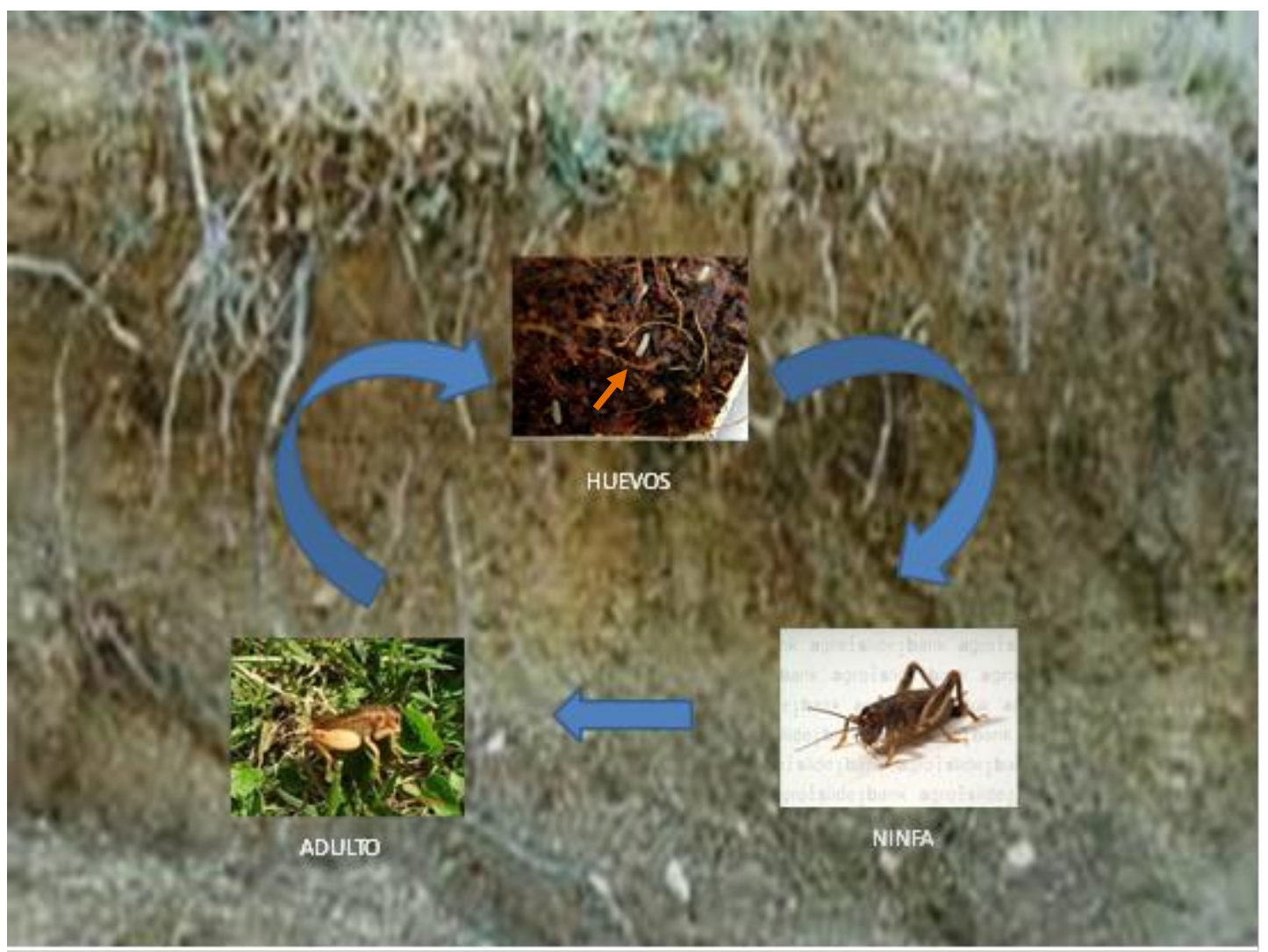

Figura 7. Ciclo de vida de Anurogryllus muticus 


\section{Daños}

Durante el día permanecen en la galería y a la noche salen a la superficie a cortar material vegetal. Los dos períodos de mayor consumo coinciden con las etapas de siembra y emergencia de pasturas y verdeos en otoño, y de cultivos en verano. Las hembras en el período entre la cópula y la oviposición, incrementan el consumo, por lo que el daño más intenso ocurre de octubre a diciembre. Por otra parte, los daños son más severos cuando se registran períodos con déficit hídricos y las temperaturas nocturnas son elevadas. Por el contrario, la presencia de lluvias y temperaturas bajas determinan una reducción de la actividad, permitiendo el crecimiento de las plantas y tolerando eventuales perjuicios (Hudson, 1984).

En sistemas de siembra directa, la población tiende a ser mayor que en el laboreo convencional y se convierten en plaga de cultivos con baja población de plantas. Causan daños en soja, girasol y maíz. En cultivos de verano los daños son causados durante la implantación. Un individuo es capaz de consumir de 6 a 8 plántulas de soja y de 4 a 6 plántulas de maíz.

Los daños en pasturas generalmente ocurren en otoño. En este caso son las ninfas las que pueden ocasionar severas pérdidas. En condiciones de escasa disponibilidad de agua una población de 8 a 20 grillos $/ \mathrm{m}^{2}$ afecta la producción de una pastura. Se estima que densidades de 20 grillos $/ \mathrm{m}^{2}$ consumen más de $16 \mathrm{~kg}$ de materia seca por día y por hectárea (Hudson, 1984) (Fig. 9). 


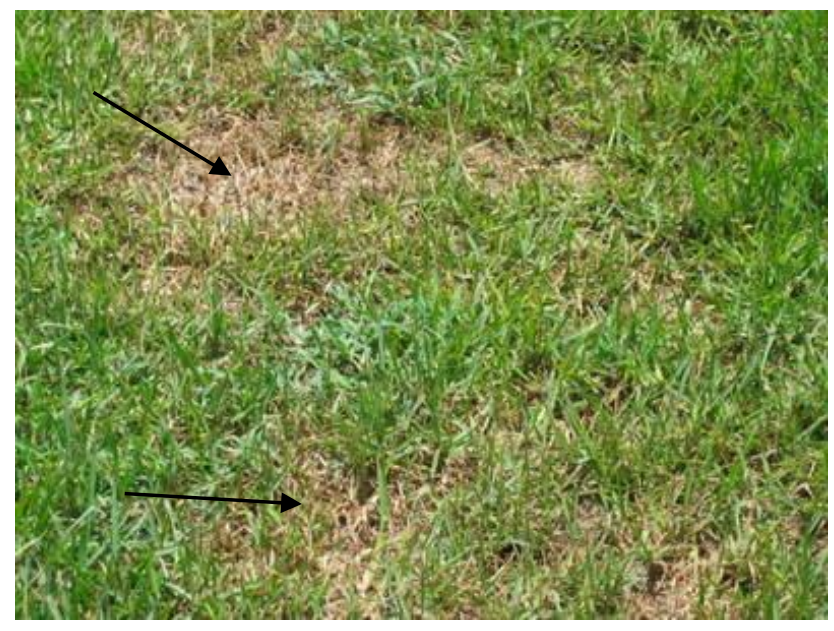

Figura 8. Daños ocasionados por A. muticus (extraído de http://www.breamslandscapinginc.com/common-florida-pests.html)

\section{Neocurtilla claraziana Saussure, 1874 (Gryllotalpidae)}

El cuerpo es de color marrón, cubierto por una fina capa de pelos sensitivos. Son de gran tamaño y están preparados para cavar. La longitud del cuerpo en los machos es de aproximadamente 35 a $41 \mathrm{~mm}$ y el de las hembras de 40 a $46 \mathrm{~mm}$ (Hayslip, 1943) (Fig.10).

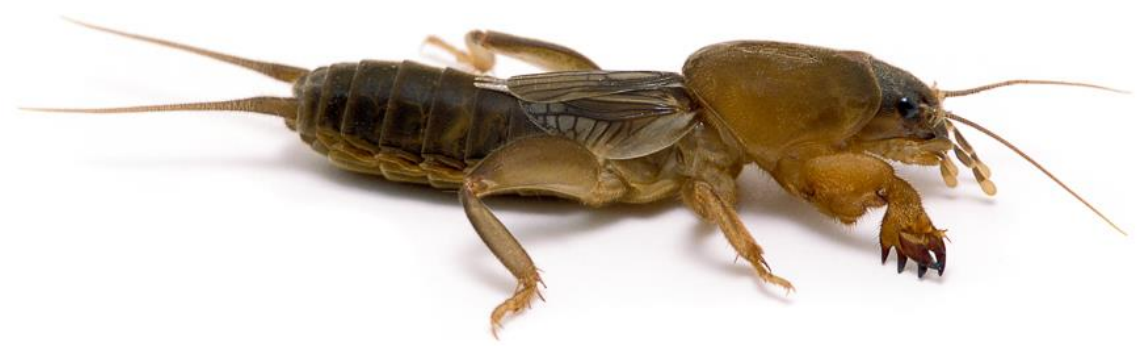

Figura 9. Adulto de Neocurtilla claraziana 


\section{Descripción}

Huevos: los huevos se depositan en una cámara en el suelo adyacente a uno de los túneles. La cámara está construida a una profundidad que puede llegar a los $30 \mathrm{~cm}$ por debajo de la superficie del suelo. Los huevos son de forma ovalada semejantes a un frijol, y miden aproximadamente $3 \mathrm{~mm}$ de longitud y 1,7 $\mathrm{mm}$ de ancho. Aumentan de tamaño a medida que absorben agua y con el tiempo logran una longitud de aproximadamente $3,9 \mathrm{~mm}$ y un ancho de $2,8 \mathrm{~mm}$. El color varía de gris a marrón. La duración de la etapa de huevo es de 10 a 40 días. La fecundidad total no es segura, pero se han obtenido más de 100 huevos a partir de una sola hembra (Hayslip, 1943).

Ninfas: las etapas juveniles se parecen a los adultos, pero tienen alas menos desarrolladas. El número de estadios es variable, probablemente de 8 a 10 (Hudson, 1984). Las ninfas y los adultos crean extensos sistemas de túneles bajo el suelo, por lo general dentro de los primeros 20 a $25 \mathrm{~cm}$. Cuando el suelo está húmedo y cálido cavan el túnel justo debajo de la superficie, pero lo hacen a mayor profundidad si el clima se vuelve más frío y el suelo se seca. Salen a la superficie para alimentarse durante la noche y por lo general aparecen poco después del anochecer si el clima es favorable (Hayslip, 1943).

Adultos: tienen peculiares patas delanteras desarrolladas que utilizan para cavar en el suelo. Sus tibias poseen grandes proyecciones similares a cuchillas, llamadas dáctilos, y tanto el número como la disposición se utilizan para la distinción entre especies (Fig. 10). Las antenas son más cortas que sus cuerpos. Las hembras carecen de un ovipositor distintivo. Ambos sexos poseen cercos alargados en la punta del abdomen (Hayslip, 1943).

Ciclo de vida: tienen un ciclo de vida incompleto (Fig. 11). Las crías son blanquecinas al principio, pero se oscurecen en 24 horas. Pueden consumir la cáscara del huevo o canibalizar a sus hermanos, y luego cavar en la superficie del suelo (Hudson, 1984). Tardan dos años aproximadamente en llegar a la madurez sexual y tienen un tipo de desarrollo bianual. Alcanzan su estado adulto a principios de otoño. El macho produce una canción de cortejo que es atractiva para las hembras, y normalmente se llaman durante la noche. El macho agranda la entrada a su madriguera, formando una 
abertura en forma de cuerno, en preparación para llamar. Esto aumenta el volumen de la llamada y permite a las hembras que vuelan, localizar a los machos. El apareamiento se produce dentro de la madriguera del macho, después de lo cual puede ser ocupada por la hembra. La hembra cuida de su descendencia, tanto de los huevos como de sus crías. (Hayslip, 1943).

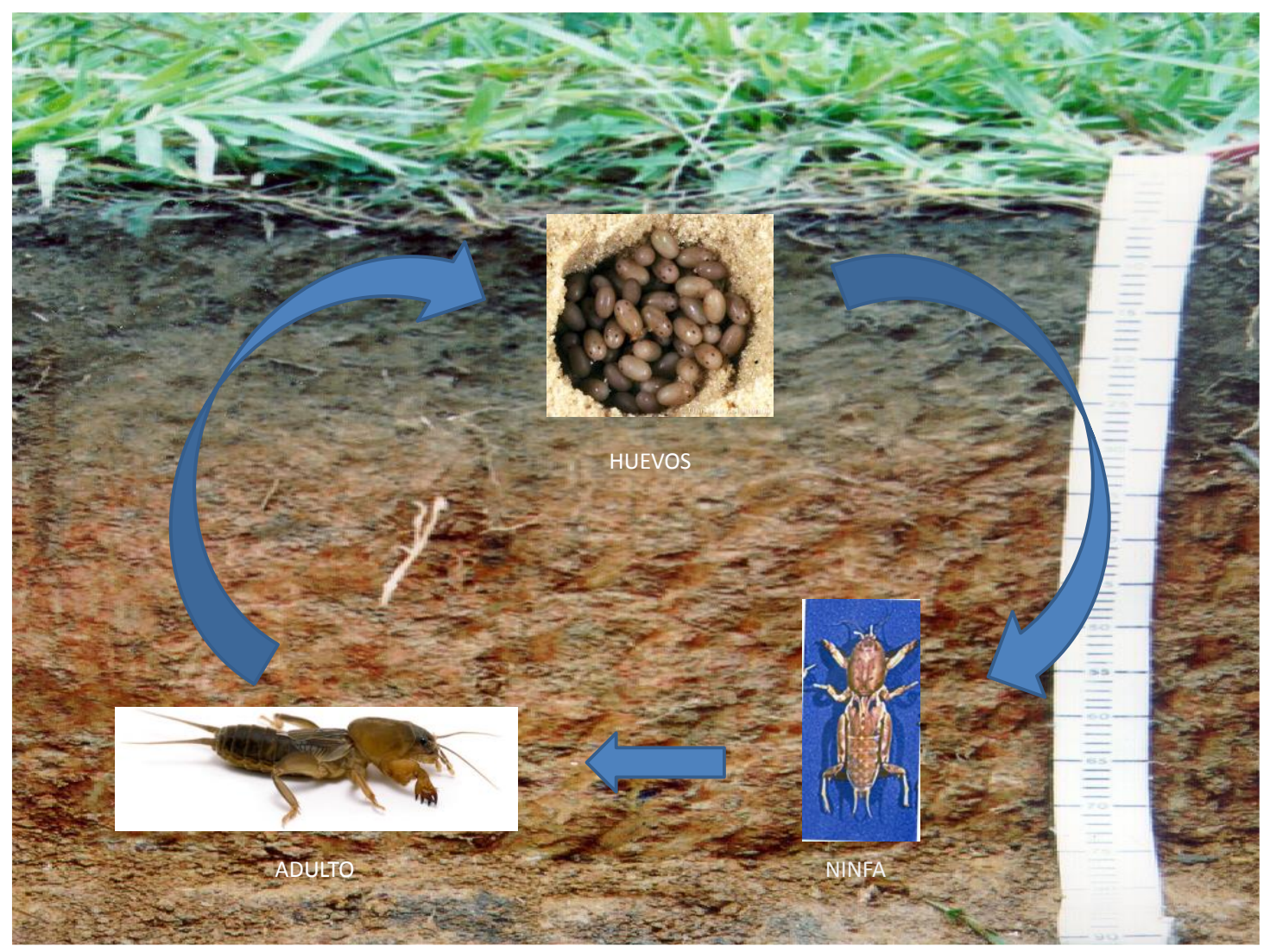

Figura 10. Ciclo de vida de N. claraziana

\section{Daños}

Excavan galerías en el suelo afectando a los órganos subterráneos de la planta, como raíces, tubérculos y bulbos (Fig. 12). Provocan la "caída de plántulas" al cortar la planta recién emergida por el cuello. En cultivos aprovechables por sus órganos subterráneos como la papa, los daños provocan la pérdida comercial de la cosecha (Hayslip, 1943). 


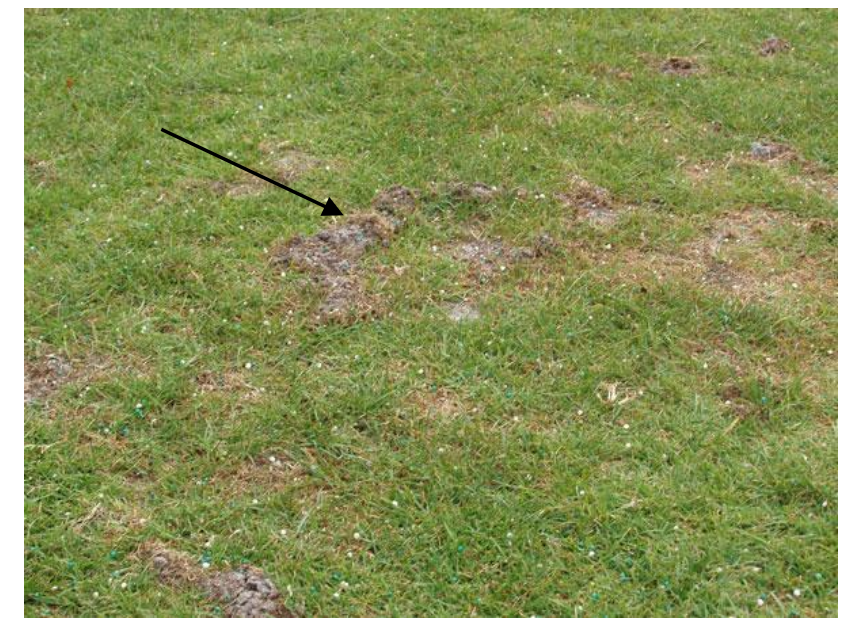

Figura 11. Daños ocasionados por N. claraziana (extraído de http://www.breamslandscapinginc.com/common-florida-pests.html)

\section{AREA DE ESTUDIO}

La Pampa húmeda es una subregión de $600.000 \mathrm{~km}^{2}$ de praderas que se encuentra en todo Uruguay, Río Grande do Sul (Brasil) y parte de Argentina, dentro del régimen pluviométrico superior a la isohieta de $500 \mathrm{~mm} / \mathrm{año}$. Junto con la Pampa seca forma la región pampeana.

El paisaje en la región es llano, sin embargo en las cercanías de los grandes ríos se vuelve ligeramente ondulado, con una red de drenaje poco definida, existiendo grandes cuencas arreicas caracterizadas por la presencia de lagunas permanentes o temporarias y amplias zonas afectadas por la salinización.

La llanura pampeana, se extiende por la Provincia de Entre Ríos, la mitad sur de Santa Fe, gran parte de Córdoba, La Pampa, casi toda la provincia de Buenos Aires y el sureste de San Luis. Predomina en esta llanura el clima templado y húmedo, donde las precipitaciones disminuyen hacia el sur y hacia el oeste (Cabrera, 1971). 


\section{SITIOS DE MUESTREO}

Los muestreos fueron realizados en estaciones experimentales, parques y espacios de recreación de la ciudad de La Plata y el Gran La Plata, Provincia de Buenos

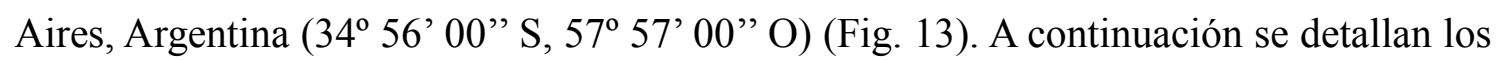
sitios en donde fueron efectuados:

1) Parque Ecológico: ubicado sobre el camino Centenario en la localidad de Villa Elisa, a 13 kilómetros de la ciudad de La Plata. Es de estepa graminosa y cuenta con 200 hectáreas (Figura 14).

2) Chacra Experimental de Gorina: ubicada a $10 \mathrm{~km}$ al noroeste de la ciudad de La Plata. Entre las actividades realizadas se pueden mencionar la producción de plantines, identificación de plagas, planes fitosanitarios, ensayo de bioinsumos, entre otros (Figura 15).

3) Estación Experimental Julio Hirschhorn: el establecimiento se ubica en el barrio de Los Hornos situado al oeste del casco urbano de La Plata, entre las calles 66 a 72 y 167 a 173, con frente sobre la Avenida 66, con una superficie aproximada de 65 hectáreas (Figura 16).

4) Plaza San Martín: se encuentra ubicada en la ciudad de La Plata. Está situada entre las calles 50, 54, 6 y 7. Consta de un césped herbáceo de tipo natural. (Figura 17).

5) Plaza Belgrano: localizada en la ciudad de La Plata. Entre las calles 12, 14, 39 y 40. Consta de un césped herbáceo de tipo natural (Figura 18).

6) Plaza Rocha: se encuentra en el cruce de las avenidas 7 y 60 junto con las diagonales 73 y 78 en la ciudad de La Plata. Consta de un césped herbáceo de tipo natural (Figura 19).

7) Paseo del bosque: el Paseo del Bosque es el mayor espacio verde de la 
ciudad de La Plata. Está emplazado donde antiguamente se hallaban los bañados de la estancia Martín Iraola, expropiada con motivo de la fundación de La Plata. Se sitúa entre las calles 50, 60, 115 y 122; tiene una extensión aproximada de 60 hectáreas y su forestación es de lo mas variada, contando con más de cien especies diferentes de árboles (Figura 20).

8) Rambla de calle 32: se muestreó el tramo que va desde calle 11 hasta calle 13. Provista de césped herbáceo de tipo natural (Figura 21).

9) Plazoleta "Eduardo Daniel Giosue" de diag. 113 y 64. Provista de césped herbáceo de tipo natural (Figura 22). 


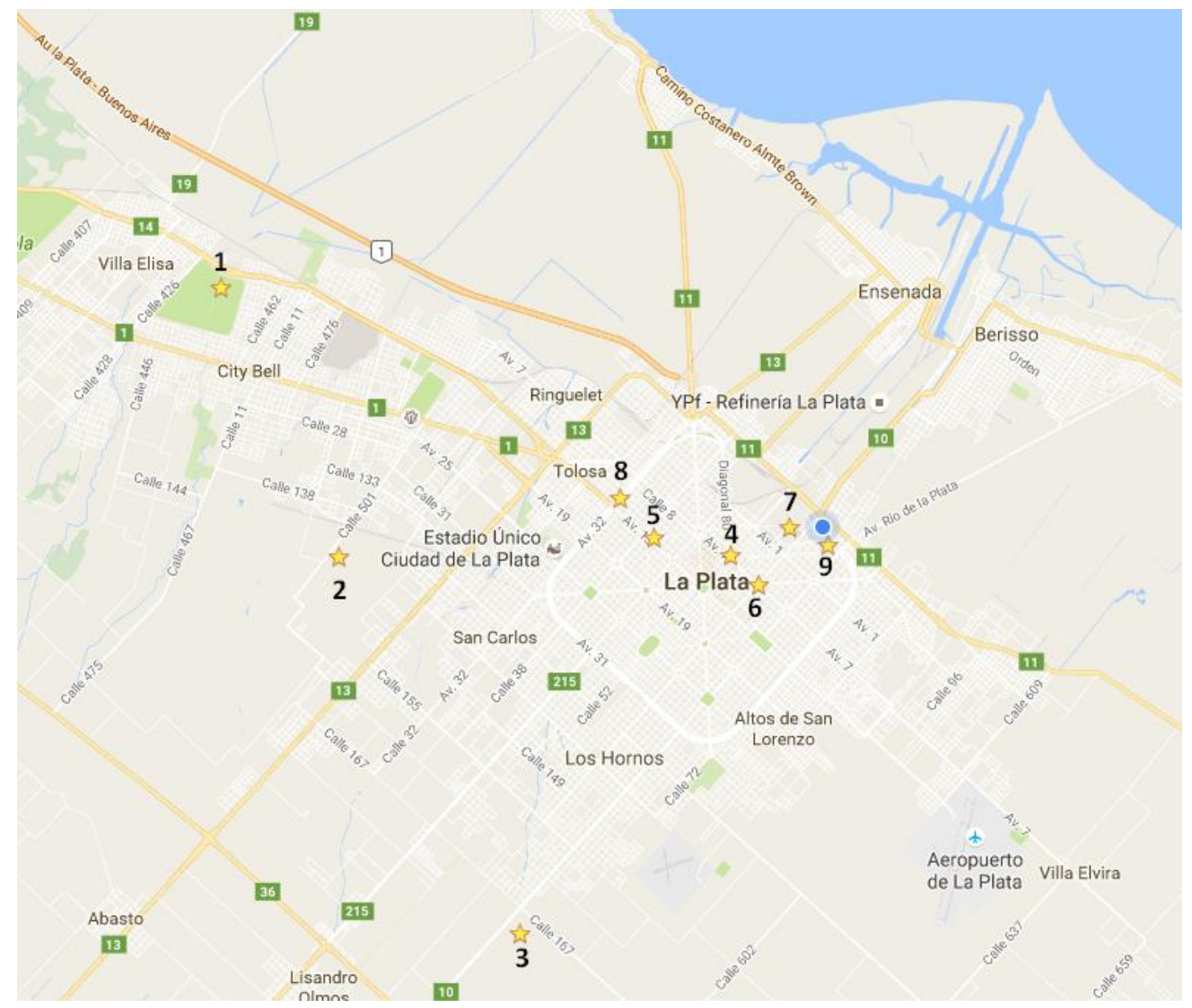

Figura 12. Lugares de muestreo (estrellas) en la zona de La Plata y Gran La Plata 


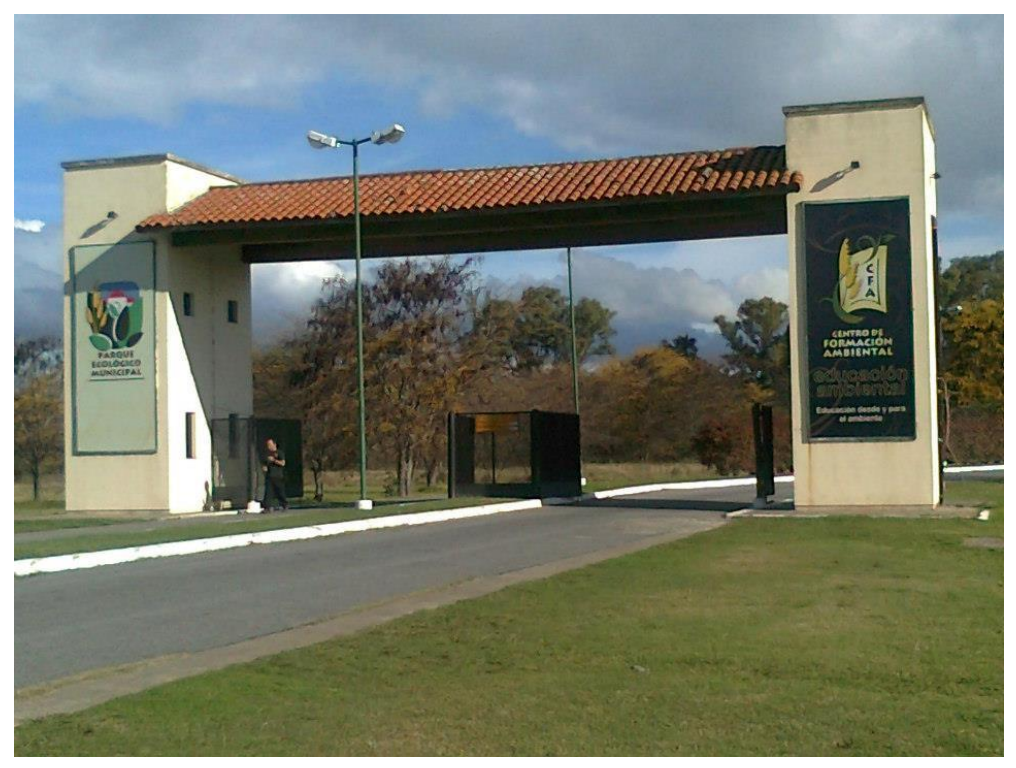

Figura 13. Parque Ecológico

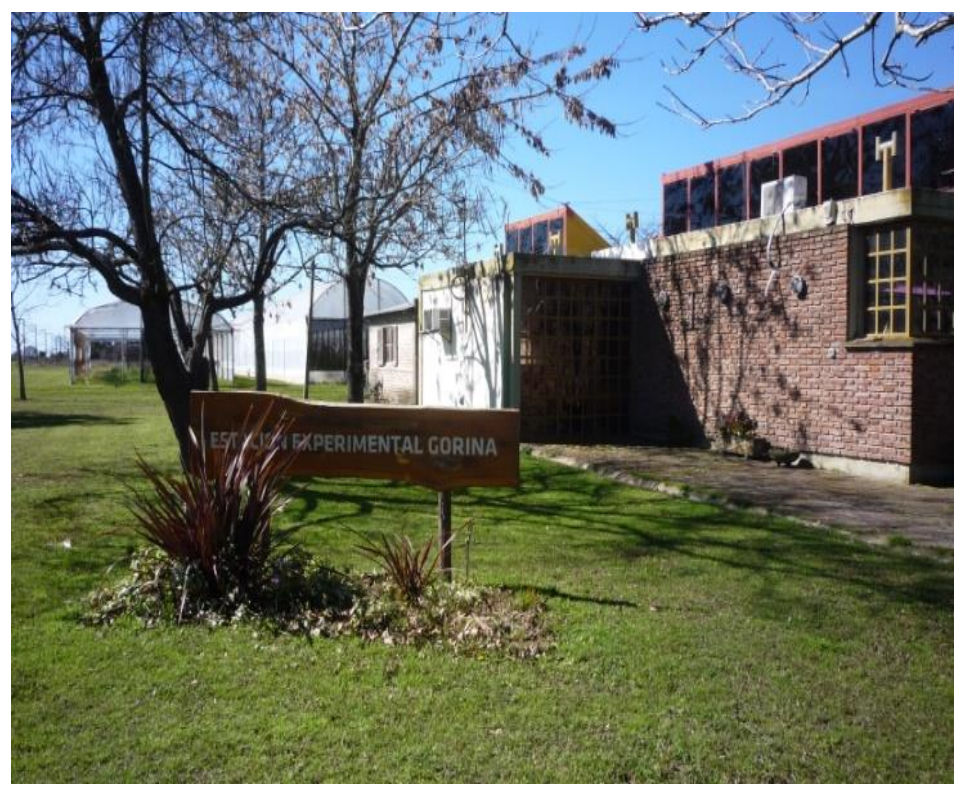

Figura 14. Estación Experimental de Gorina 


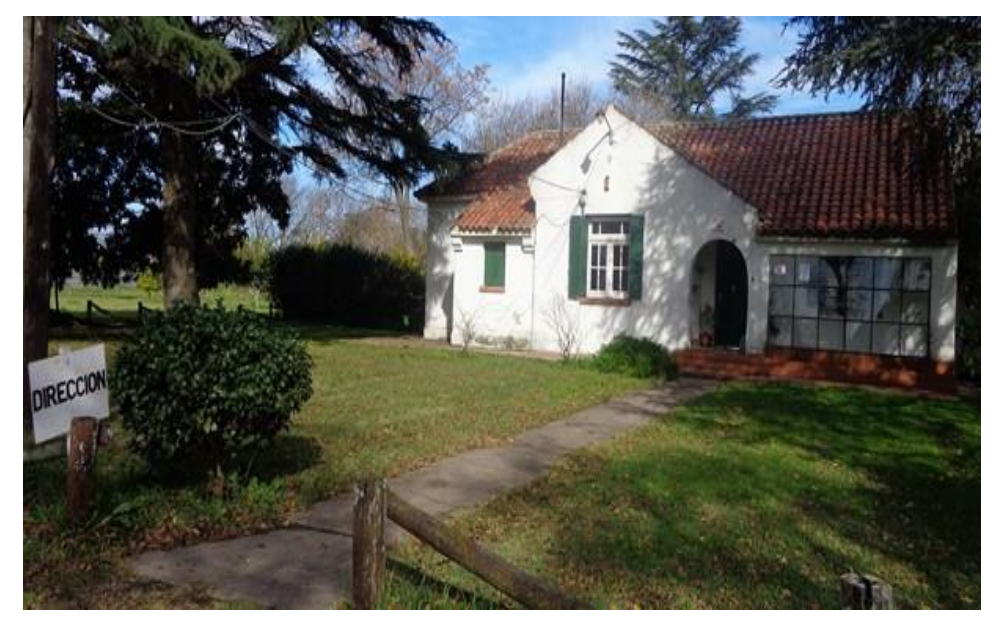

Figura 15. Estación Julio Hirschhorn

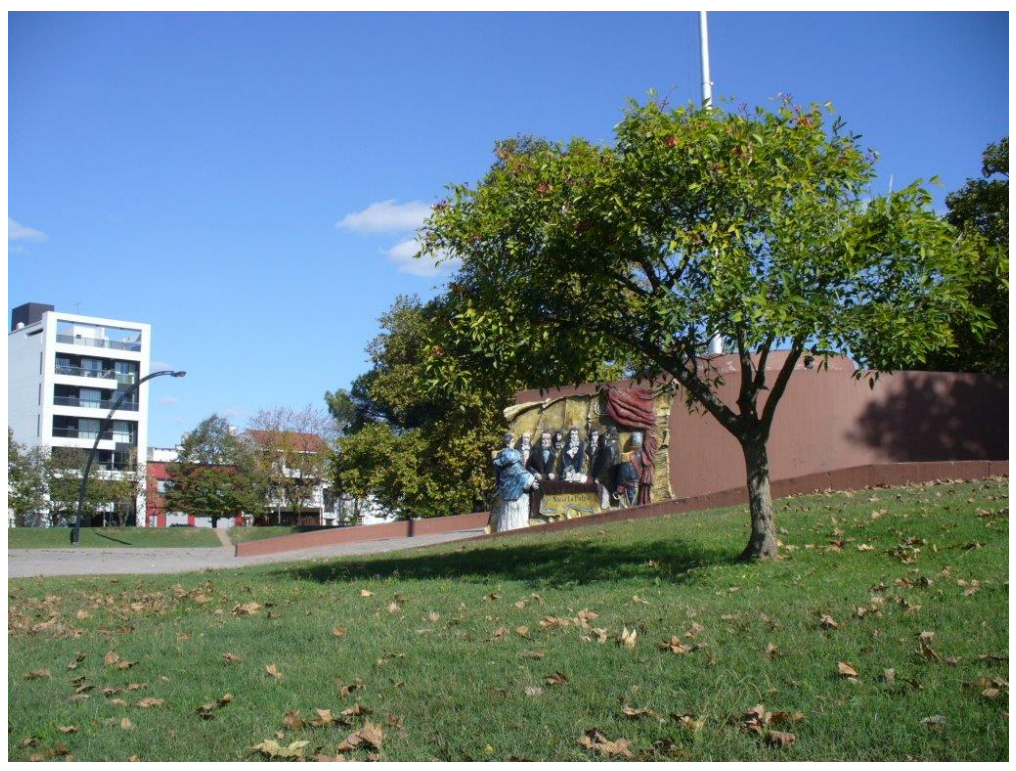

Figura 16. Plaza Belgrano 


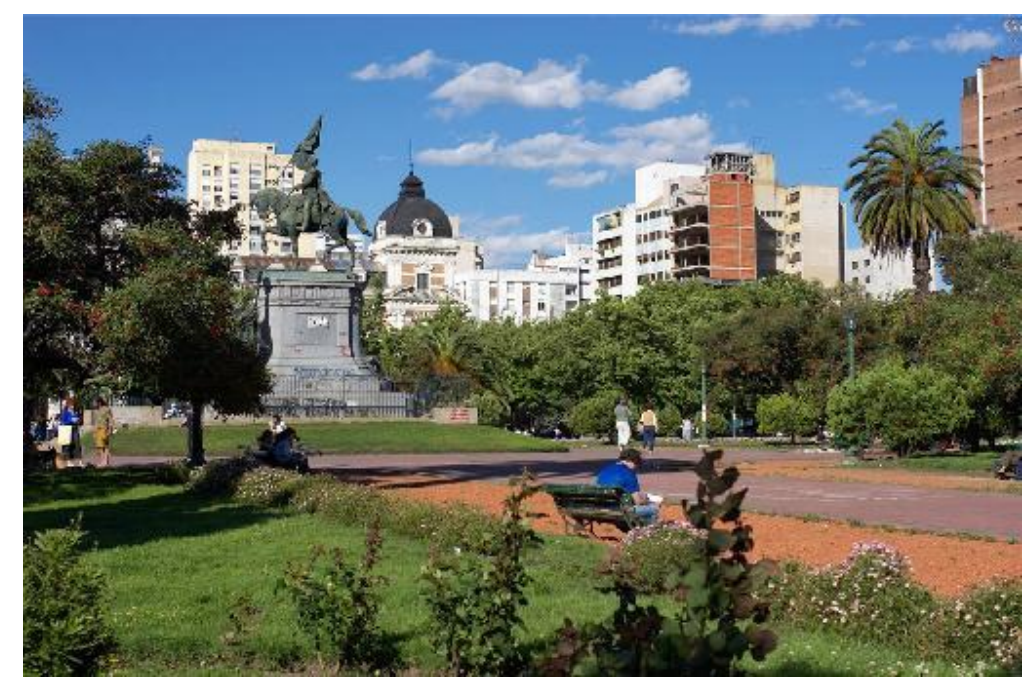

Figura 17. Plaza San Martín

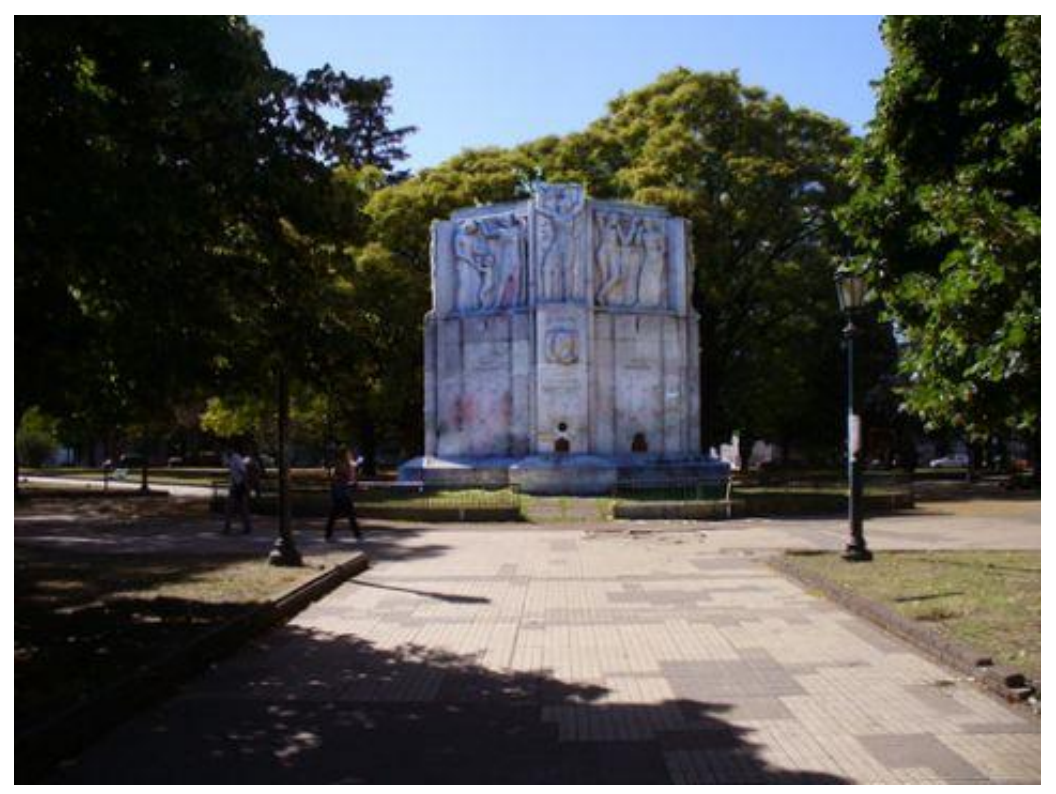

Figura 18. Plaza Rocha 


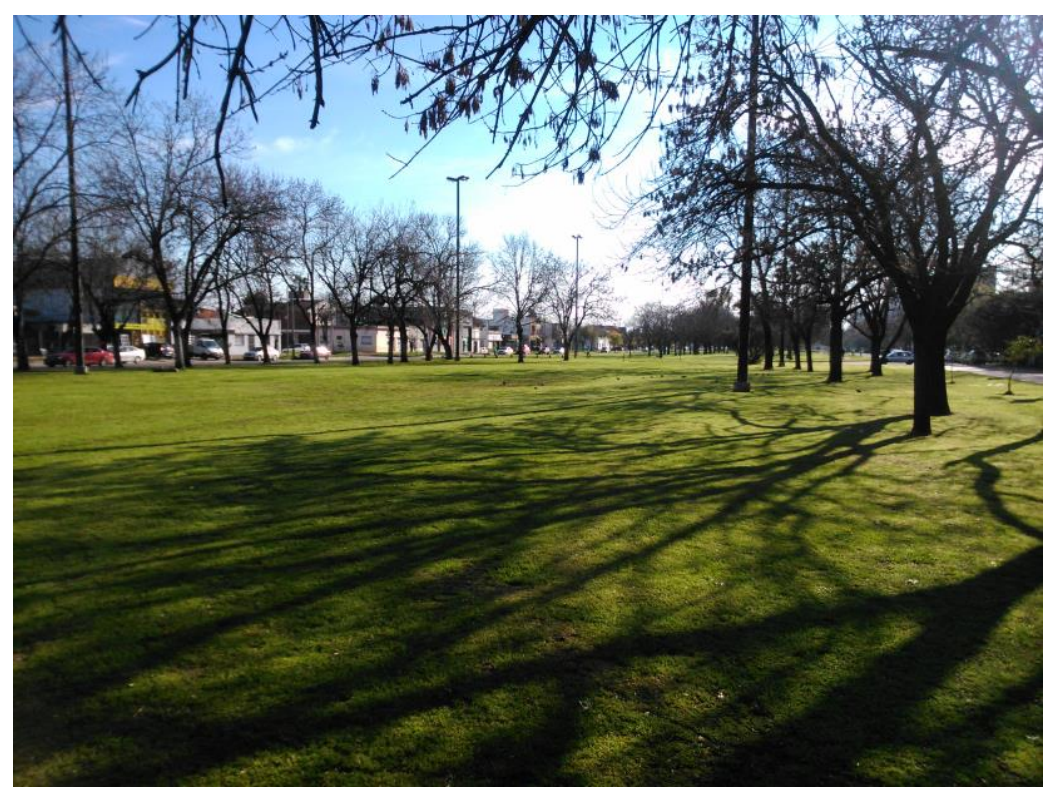

Figura 19. Rambla de calle 32

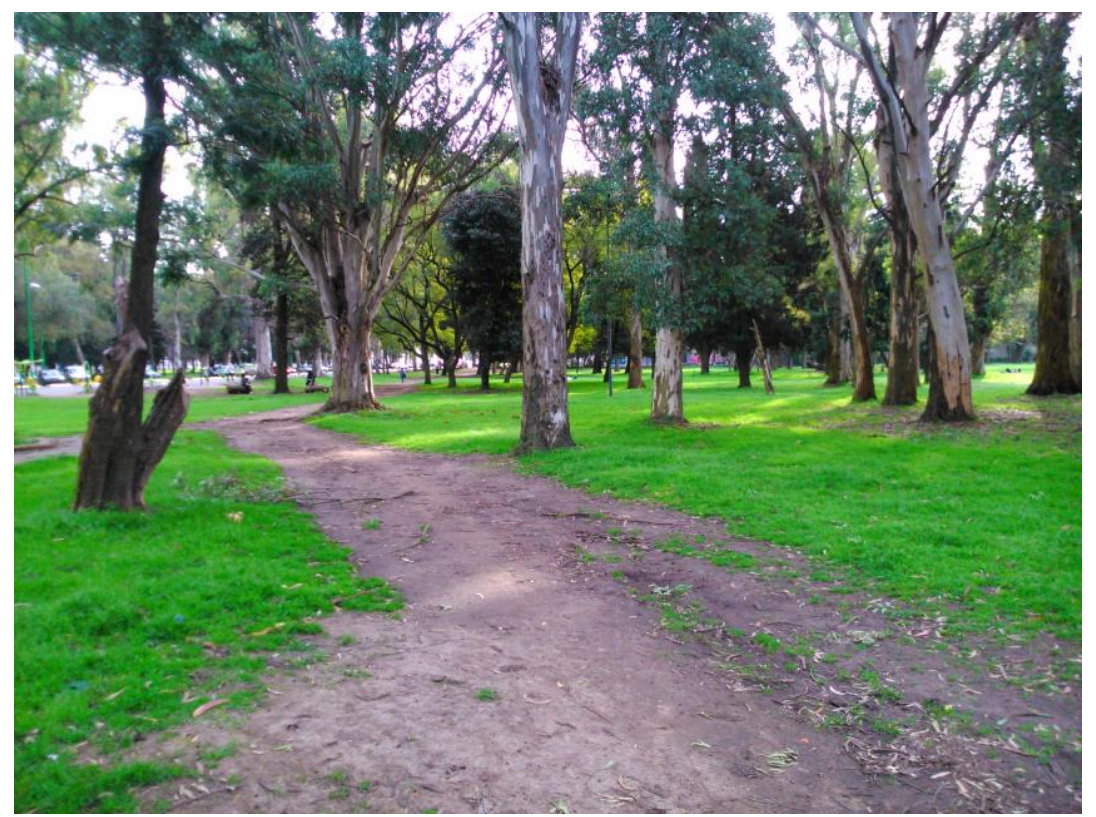

Figura 20. Paseo del Bosque 


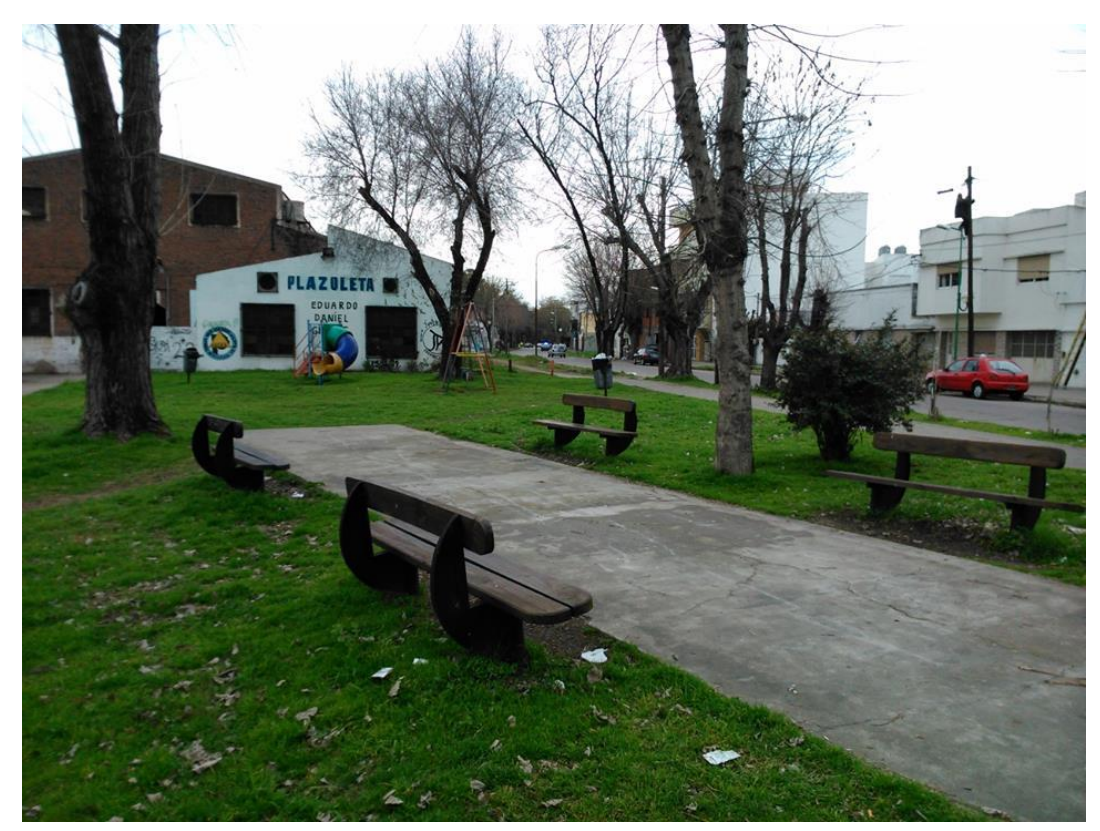

Figura 21. Plazoleta_Eduardo Daniel Giosue

\section{RECOLECCIÓN Y PROCESAMIENTO DE LOS ENTOMONEMATODOS}

\section{A PARTIR DE MUESTRAS DE SUELO (ENTOMOPATÓGENOS)}

\section{Tareas de campo}

Para el aislamiento de nemátodos a partir del estadio infectante en el suelo (JI o larva dauer), se tomaron muestras del mismo $\left(500 \mathrm{~cm}^{3}\right)$ y se colocaron en bolsas plásticas. Se transportaron al laboratorio en heladera a temperatura entre 12 y $15{ }^{\circ} \mathrm{C}$ (Beeding y Akhurst, 1975). La recolección de las muestras se realizó con pala, haciendo orificios de 15 a $20 \mathrm{~cm}$ de diámetro y $15 \mathrm{~cm}$ de profundidad.

\section{Tareas de laboratorio}

La técnica utilizada para la obtención de las formas infectantes a partir del suelo consiste en colocar la muestra de suelo tomada en cápsulas de Petri con larvas de 
Tenebrio molitor L., 1758 (Coleoptera, Tenebrionidae) durante una semana. En caso de hallarse nematodos estos parasitarán a los insectos, los cuales se observarán muertos y con una coloración rojiza a parda, dependiendo de la especie del nematodo. Los cadáveres se extraen y se lavan en agua destilada para colocarse posteriormente en una "trampa blanca" o "white trap" (Kaya y Stock, 1997). Esta consiste en una cápsula de Petri, dentro de la cual se coloca un vidrio de reloj invertido con un papel de filtro embebido en agua destilada, con las larvas muertas por encima. Los nematodos migrarán de los cadáveres al agua alrededor de una semana después de la infección (Fig. 22).

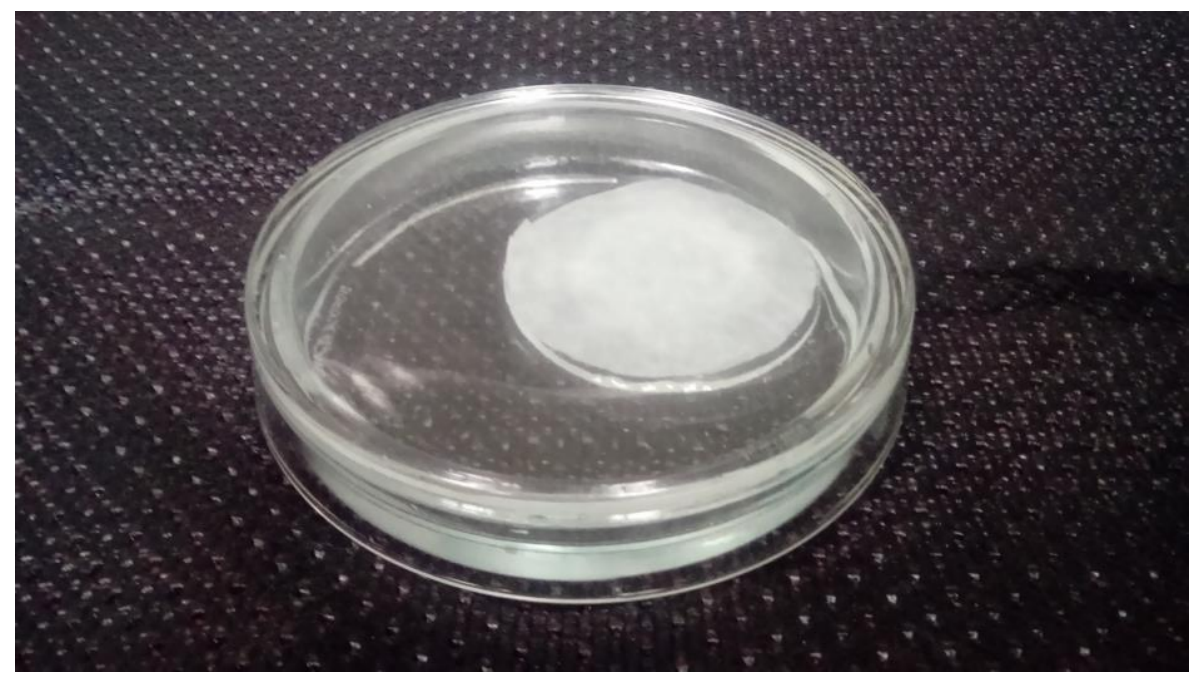

Figura 22. Trampa de White 


\section{A PARTIR DE INSECTOS}

\section{RECOLECCIÓN, PROCESAMIENTO E IDENTIFICACIÓN DE LOS HOSPEDADORES}

Los muestreos se efectuaron durante el período comprendido entre Mayo de 2013 y Diciembre de 2015, 48 horas posteriores a una precipitación. En caso de que esto no ocurriera, se relizaron los muestreos cada 15 días. La recolección de los grillos se llevó a cabo utilizando una solución tensioactiva (agua + detergente) y manualmente con una pala de jardinería. Esta solución fue vertida en las madrigueras (Fig. 23), haciendo que el grillo emerja a la superficie.

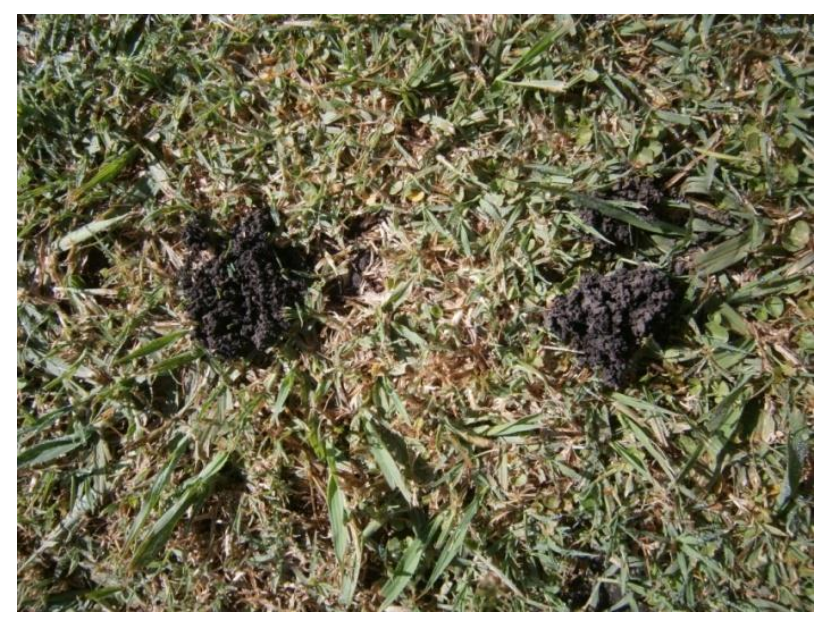

Figura 23. Imagen del aspecto exterior de las madrigueras

El material fue trasladado al laboratorio, analizado y procesado siguiendo los pasos que se detallan a continuación:

Los grillos y grillotopos fueron observados al microscopio estereoscópico con el fin de reconocer la especie. La clasificación sistemática de los mismos se hizo sobre la base de caracteres morfológicos, usando la información proporcionada por la página 
web Orthoptera Species File (2016) y trabajos de autores relacionados al tema (Liebermann, 1955; UF Entomology and Nematology Department, 2016).

\section{RECOLECCIÓN Y PROCESAMIENTO DE LOS ENTOMONEMATODOS}

Los insectos fueron mantenidos vivos en el laboratorio una semana antes de la disección con el fin de observar cualquier cambio de coloración, alteraciones producto del parasitismo, o bien la emersión de los nematodos (Poinar, 1976). Se los anestesió durante 10 minutos en un freezer $\mathrm{a}-15^{\circ} \mathrm{C}$ previo a la disección.

Para el análisis de los insectos se utilizó una cápsula de Petri de 6,9 cm de diámetro y 2 pinzas de disección (Kaya y Stock, 1997). Con una de las pinzas se sujetó al grillo por el extremo cefálico, mientras que con la otra se separó el abdomen del resto del cuerpo. Al tener el abdomen disociado, se extrajo el sistema digestivo cuidadosamente para la obtención de los nematodos (Fig. 24).

Para la recolección de los nematodos se revisaron, además, la cutícula, el sistema reproductor y la cavidad general de los insectos. 


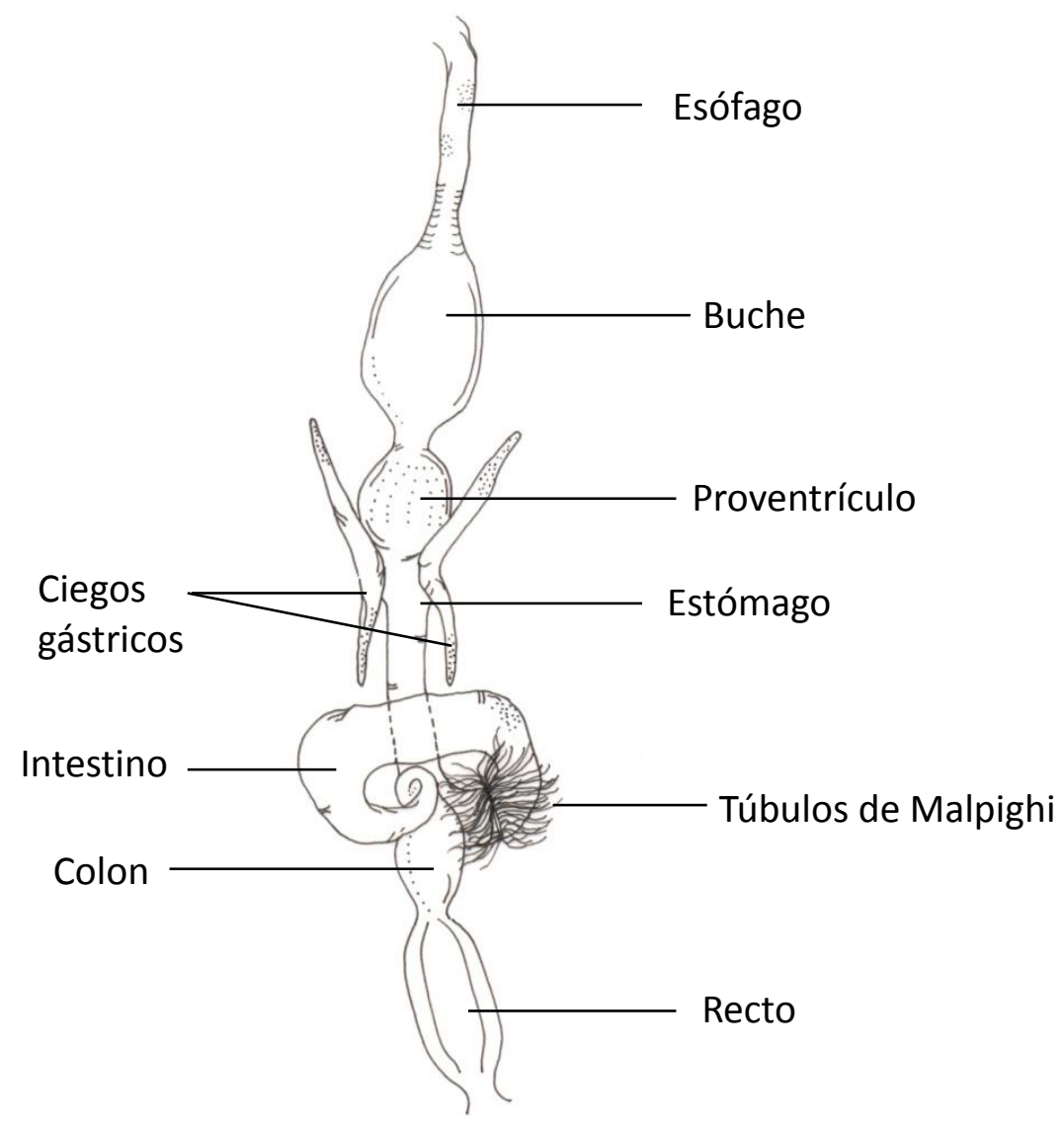

Figura 24. Esquema generalizado del sistema digestivo de un grillo/grillotopo

Una vez recolectados los nematodos, se los mató en agua destilada o solución Ringer a baño María a $60^{\circ} \mathrm{C}$ durante 2 minutos. Se agregó la misma cantidad de fijador T.A.F [(formol 40\% (7ml), trietanolamida $(2 \mathrm{ml})$, agua destilada $(91 \mathrm{ml})$ ] y luego de $24-$ 48 hs se los colocó en T.A.F puro (Courtney et al., 1955).

\section{IDENTIFICACIÓN DE LOS ENTOMONEMATODOS}

\section{Caracterización morfológica}

Las especies de nematodos se caracterizaron y describieron taxonómicamente 
sobre caracteres morfológicos estructurales y ultraestructurales. Esto incluyó dibujos con la cámara clara de un microscópio óptico Zeiss, fotografías con una cámara digital Olympus DP-71, procesamiento de imágenes computarizadas y fotografías con Microscopio Electrónico de Barrido.

La clasificación fue realizada siguiendo los criterios dados por Adamson y van Waerebeke (1992), Andrassy (1983), Basir (1956), Holovachov y De Ley (2006), Poinar (1977) y trabajos concernientes a cada especie.

\section{Preparación de muestras de nematodos para microscopía electrónica de barrido} (MEB)

Las muestras para microscopía de barrido fueron fijadas en T.A.F y posteriormente deshidratadas en una serie creciente de etanol (30\% a 100\%). Las muestras fueron secadas utilizando el método del Punto Crítico mediante un equipo BALTEC, modelo CPD-30. El microscopio electrónico de barrido usado fue un JEOL, modelo JSM-6360 LV. La metalización se llevó a cabo mediante un metalizador marca JEOL, modelo ION SPUTTER, Fine Coat, JFC 1100, que por el método de "sputtering" permite realizar depósitos delgados (de un espesor aproximado de 15-20 nm) de oro para brindar conductividad térmica y eléctrica a las muestras no conductoras (Kaya y Stock, 1997).

\section{Determinación de caracteres morfométricos}

Considerando las distintas familias de nematodos, se realizaron mediciones de los ejemplares con un ocular micrométrico y se determinaron los índices correspondientes principalmente en el estado adulto (longitud total, ancho a nivel de las papilas cefálicas, distancia del anillo nervioso al extremo anterior, largo del esófago, distancia de la base del bulbo/bulbo basal al extremo anterior, distancia del poro excretor al extremo anterior, ancho medio, ancho a nivel de la vulva, largo de la vulva, ancho de la vulva, V (longitud del cuerpo/ distancia entre el extremo cefálico y la vulva, x 100), ancho posterior, ancho a nivel del ano, longitud de la cola, longitud de los huevos, ancho de los huevos, largo y ancho de la espícula), se hace referencia al promedio de cada una de las medidas, el desvío estándar y el 
rango (entre paréntesis) . Todas las medidas están dadas en micras $(\mu)$, a excepción de la $\mathrm{V}$ que se expresa en porcentaje.

\section{ECOLOGÍA PARASITARIA}

1) Se determinó el número de nematodos (adultos y juveniles) por hospedador.

2) Se determinaron los indicadores de infección parasitaria para las especies de nematodos parásitos: prevalencia, intensidad promedio, abundancia y dominancia. A nivel comunidad, fueron determinados los valores de riqueza de especies, diversidad específica mediante el índice de Shannon-Weaver y el coeficiente de similaridad de Sørensen, para expresar el grado de semejanza entre hospedadores. Los términos están definidos por los criterios dados por Morales y Arelis-Pino (1987):

Prevalencia: número de individuos infestados por una especie parásita en particular, dividido el número total de hospedadores examinados. Se expresa en porcentaje.

$$
\mathrm{P}=\frac{\text { Número de hospedadores infestados }}{\text { Número de hospedadores examinados }} \times 100
$$

Intensidad media: número promedio de parásitos por el número total de hospedadores parasitados dentro de la muestra examinada.

$$
\mathrm{I}=\frac{\text { Número total de parásitos de una especie determinada }}{\text { Número de hospedadores positivos a dicho parásito }}
$$


Abundancia: número promedio de parásitos por cada hospedador examinado en una muestra (incluye a los no infestados). Este índice se corresponde con la media aritmética, ya que dicho valor se obtiene al dividir el número total de parásitos de una especie y el número de hospedadores examinados.

$$
\mathrm{A}=\frac{\text { Número total de parásitos de una especie }}{\text { Número total de hospedadores examinados }}
$$

Dominancia: proporción o porcentaje de una especie parásita en relación al conjunto de especies presentes en el o los hospedadores examinados.

Diversidad específica: puede ser definida como una medida de la composición en especies de un ecosistema, en términos del número de especies presentes y de sus abundancias relativas. El índice de Shannon-Weaver es uno de los más utilizados como medida de la diversidad en especies de una comunidad. El cálculo de dicho índice se puede hacer de forma práctica mediante la fórmula:

$$
\mathrm{ISh}=3,322\left[\log \mathrm{Q}-1 / \mathrm{Q} \sum\right. \text { qi Log qi] }
$$

En dicha fórmula, qi representa los efectivos estimados para cada especie encontrada, y Q la sumatoria de todos los efectivos estimados de todas las especies encontradas; los cálculos del índice de diversidad se hacen con logaritmos vulgares, o de base 10, y el resultado final es multiplicado por 3,322 para obtener el valor en bits.

Coeficiente de similaridad de Sørensen: se utiliza para expresar el grado de semejanza entre comunidades en términos porcentuales. Se determina según la siguiente fórmula:

$$
\mathrm{Css}=2 \cdot \mathrm{C} / \mathrm{S} 1+\mathrm{S} 2
$$


En donde:

Css $=$ Coeficiente de similaridad de Sørensen

$\mathrm{C}=$ Especies comunes a ambas comunidades

$\mathrm{S} 1$ y $\mathrm{S} 2=$ Número de especies presentes en la comunidad 1 (S1) y en la

comunidad 2 (S2)

\section{MORTALIDAD POR NEMATODOS ENTOMOPATÓGENOS (NEPs) EN ORTÓPTEROS DEL SUELO}

\section{Susceptibilidad de $\boldsymbol{A}$. muticus al nematodo Heterorhabditis bacteriophora Poinar, 1976 en el laboratorio}

Se efectuaron dos ensayos con el objetivo de evaluar la susceptibilidad del grillo A. muticus utilizando al nematodo entomopatógeno $H$. bacteriophora.

\section{Aplicación por suspensión}

Para medir la susceptibilidad en el laboratorio se aplicaron concentraciones de 5.000, 10.000 y 15.000 formas infectivas (JIs) de este nematodo a ninfas de la especie.

El ensayo consistió en colocar un ejemplar de $A$. muticus en un recipiente cilíndrico plástico (diam: $9 \mathrm{~cm}$, alto: $9 \mathrm{~cm}$ ) sobre un sustrato de $150 \mathrm{~cm}^{3}$ de tierra esterilizada en Autoclave (Fig. 25). Los ejemplares se colocaron individualmente para evitar el canibalismo. Se realizaron tres réplicas con tres repeticiones en el tiempo.

\section{Aplicación utilizando cadáveres de Tenebrio molitor infestados}

Un total de nueve ninfas de $A$. muticus se colocaron junto a un cadáver de una larva del coleóptero T. molitor infestado con H. bacteriophora (Fig. 26). Los ensayos se realizaron en recipientes cilíndricos plásticos (diam: $9 \mathrm{~cm}$, alto: $9 \mathrm{~cm}$ ) sobre un sustrato de $150 \mathrm{~cm}^{3}$ de tierra esterilizada en Autoclave donde se colocó un ejemplar de $A . m u$ ticus, totalizando nueve recipientes. 
A partir de la exposición, los grillos se observaron cada 24 hs durante la primera semana y los grillos muertos fueron posteriormente colocados en Trampas de White. Se contabilizó el número de JIs producidos por hospedador y el tiempo transcurrido hasta la emersión de los nematodos. Los insectos muertos en los cuales no se observó producción se disecaron para confirmar la infestación por el nematodo.

Los ensayos fueron realizados a $25^{\circ} \mathrm{C}$ y se usaron los correspondientes controles libres de nematodos.

Para determinar si existieron diferencias significativas entre los cuatro tratamientos se recurrió al test estadístico de Fisher. Se utilizó un nivel de significancia de $\alpha=0,05$. (Sokal y Rohlf, 1980). 


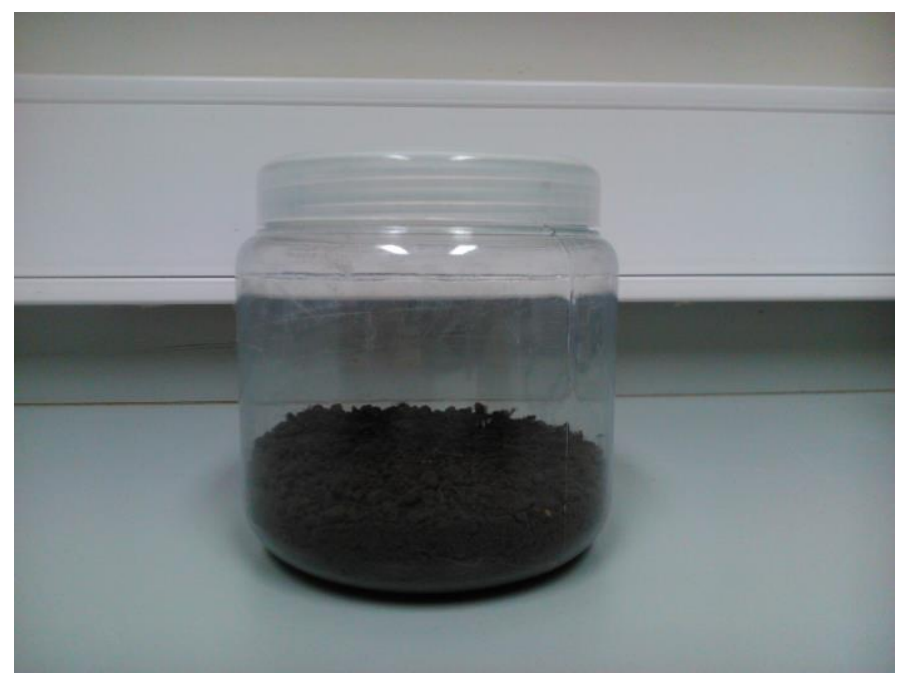

Figura 25. Recipiente utilizado para las infecciones con NEPs

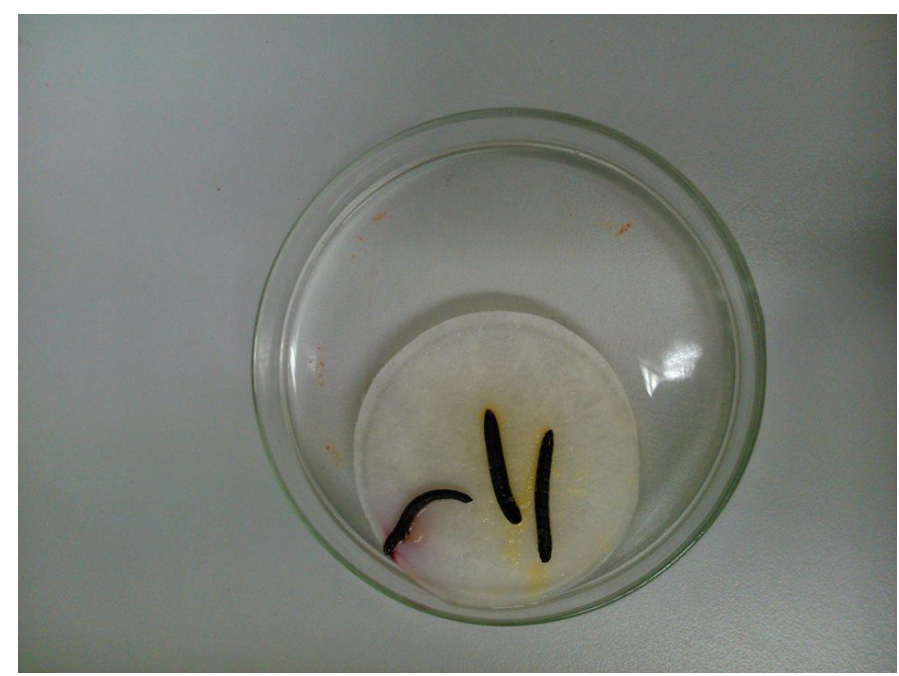

Figura 26. Cadáveres de tenebrios infectados en Trampas de White con H. bacteriophora 


\section{RESULTADOS}

\section{RELEVAMIENTO E IDENTIFICACIÓN DE INSECTOS ORTÓPTEROS (GRYLLIDAE y GRYLLOTALPIDAE)}

Se hallaron dos especies de ortópteros en los sitios de muestreo de la ciudad de La Plata y alrededores: 748 A. muticus (Gryllidae) y 317 N. claraziana (Gryllotalpidae) (Fig. 27). Neocurtilla claraziana se encontró solo en zonas agrícolas: 162 ejemplares en la Chacra Experimental de Gorina, 68 en el Parque Ecológico de Villa Elisa y 87 en la Estación Experimental Julio Hirschhorn. En lo referente a A. muticus, fue hallado en todos los sitios de muestreo: 516 grillos en el Paseo del Bosque, dos en Plaza Belgrano, dos en Plaza San Martín, tres en Plaza Rocha, 19 en la rambla de calle 32, 179 en la Plazoleta de diagonal 113 y 64, 8 en el Parque Ecológico, seis en la Estación Experimental Julio Hirschhorn y 13 en la Chacra Experimental de Gorina.

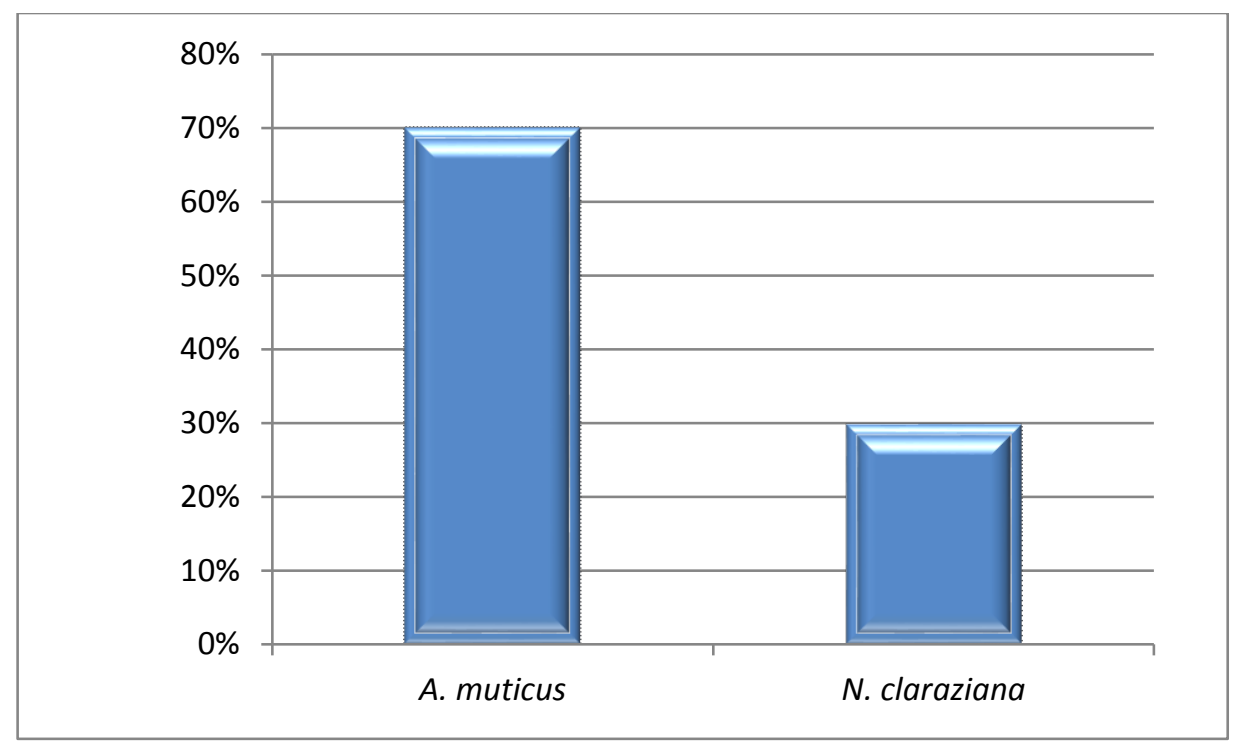

Figura 27. Porcentaje de grillos y grillotopos encontrados en el Gran La Plata 
Se hallaron nematodos en el $61,5 \%$ de los individuos examinados en $N$. claraziana, en tanto que para A. muticus solo el 16\% estaban parasitados (Fig.28).

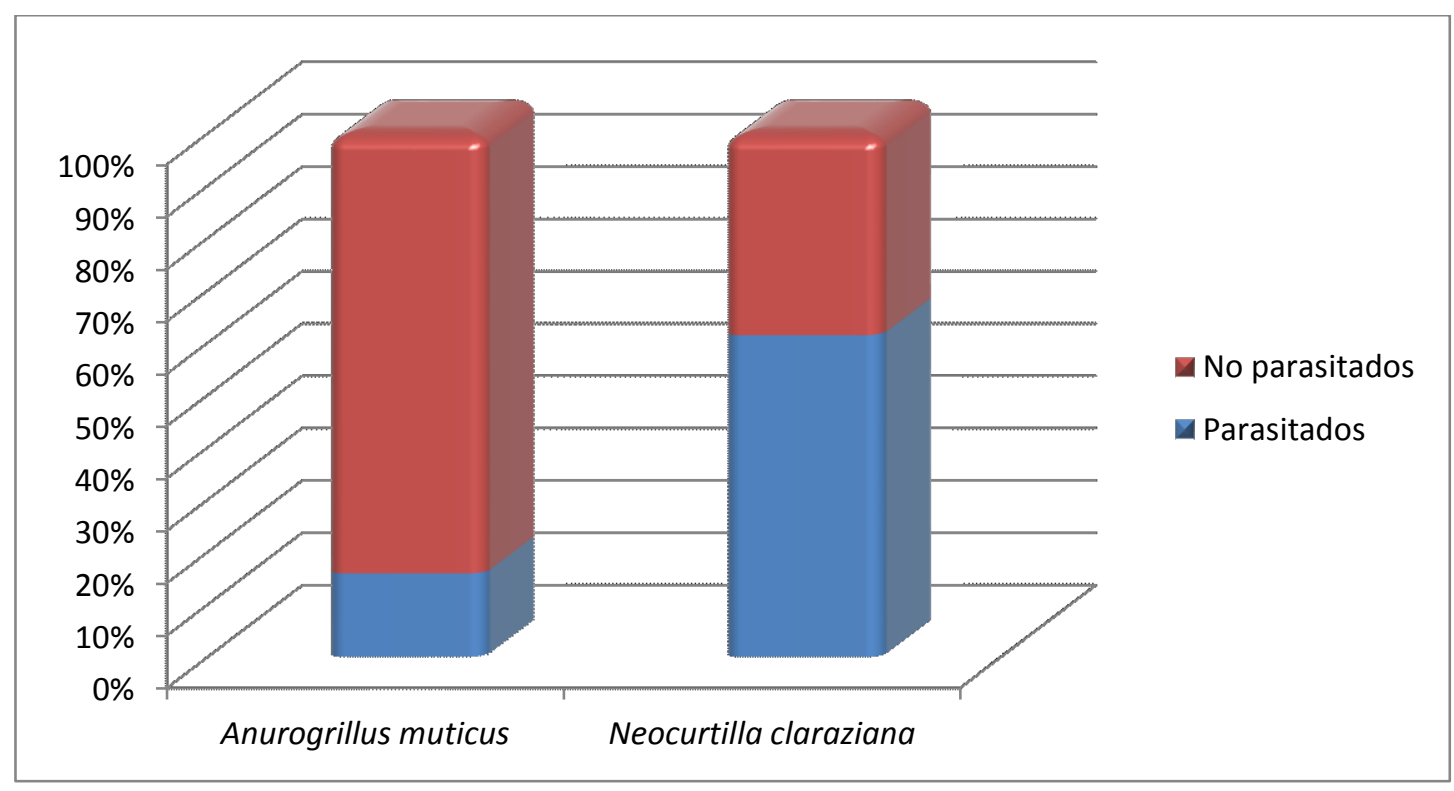

Figura 28. Porcentaje de Neocurtilla claraziana y Anurogryllus muticus parasitados y no parasitados.

\section{NEMATODOS ASOCIADOS A ORTÓPTEROS PLAGA DEL SUELO (GRYLLIDAE Y GRYLLOTALPIDAE) REGISTRADOS A PARTIR DE LOS LOS MUESTREOS}

Once especies de nematodos fueron halladas en este estudio, representantes de seis familias de tres órdenes diferentes. En $N$. claraziana se encontraron un total de siete especies pertenecientes a dos órdenes: Rhabditida y Oxyurida (más dos individuos juveniles de la familia Diplogasteridae); mientras que en $\mathrm{A}$. muticus, fueron halladas cuatro especies incluídas en los ordenes Rhabditida, Oxyurida y Plectida (Tabla 1). 


\begin{tabular}{|c|c|c|c|}
\hline Familia de ortópteros & Hospedador & Familia de nematodo & Especie de nematodo \\
\hline Gryllidae & Anurogryllus muticus & $\begin{array}{l}\text { Cephalobiidae } \\
\text { Plectidae } \\
\text { Thelastomatidae } \\
\text { Rhabditidae }\end{array}$ & $\begin{array}{l}\text { Cephalobium nitidum } \\
\text { Plectus parietinus } \\
\text { Blatticola cristovata } \\
\text { Cruznema tripartitum }\end{array}$ \\
\hline Gryllotalpidae & Neocurtilla claraziana & $\begin{array}{l}\text { Thelastomatidae } \\
\text { Travassosinematidae }\end{array}$ & $\begin{array}{l}\text { Blatticola cristovata } \\
\text { Cephalobellus magalhaesi } \\
\text { Gryllophila skrjabini } \\
\text { Cameronia } \text { n. sp. } \\
\text { Binema klossae } \\
\text { Binema bonaerensis } \\
\text { Binema } \text { sp. }\end{array}$ \\
\hline & & Diplogasteridae & No identificada \\
\hline
\end{tabular}

Tabla 1. Especies de nematodos encontrados en ortópteros plaga del suelo del Gran La Plata

\section{DESCRIPCIÓN DE LOS NEMATODOS ASOCIADOS A ORTÓPTEROS PLAGA DEL SUELO (GRYLLIDAE Y GRYLLOTALPIDAE)}

\section{Orden Rhabditida}

\section{Superfamilia Rhabditoidea}

\section{Familia Diplogasteridae}

No fue posible llegar a la determinación genérica debido a que solo se encontraron individuos en estadio juvenil $(n=2)$.

Los ejemplares obtenidos se caracterizaron por poseer labios débiles o ausentes. Estoma extremadamente variable, usualmente con uno o más dientes dirigidos hacia atrás. Esófago con procorpus y metacorpus distintivo (este último generalmente representado 
por un bulbo suctor muy poderoso), istmo y una región glandular piriforme. Bulbo basal del esófago sin aparato valvular esclerotizado. Cola filiforme. (Thorne, 1961). (Fig. 29).

\section{RESÚMEN TAXONÓMICO}

Sitio de colecta: Estación Experimental de Gorina.

Hospedadores infestados en este estudio: N. claraziana (adulto).

Localización: intestino posterior.

\section{COMENTARIOS}

Los diplogastéridos son más frecuentemente encontrados asociados con material vegetal en descomposición, a menudo apareciendo en gran número. Son comunes habitando estiércol de gallinero y son llevados al campo cuando es transportado. Muchas especies están asociadas con excremento de escarabajos de la subfamilia Scoltyinae, que viven en árboles muertos. Bovien (1937) observó que larvas de Diplogaster stercorarius y D. magnibucca eran llevados bajo el élitro del escarabajo Aphodius spp. Muchas especies son depredadoras de otros microorganismos, incluyendo nematodos, las hay también bacteriófagas y parásitas. Goodey y Triffitt (1927) y Bovien (1937) encontraron flagelados viviendo en el intestino de algunas especies (Thorne, 1961). 


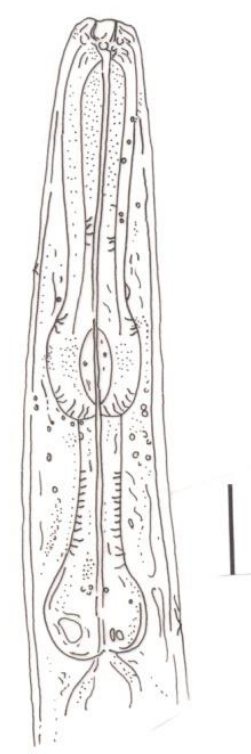

A

Figura 29. Diplogasteridae. A. Juvenil, región anterior (escala: $20 \mu \mathrm{m}$ )

\section{Familia Rhabditidae}

\section{Subfamilia Rhabditinae}

\section{Género Cruznema}

Cruznema tripartitum (Linstow, 1906), Zullini, 1982

\section{Caracterización general}

\section{Figura $30(\mathrm{~A}-\mathrm{G})$}

Cuerpo robusto. Cutícula transversalmente anillada y longitudinalmente estriada. Labios bien separados, globulares, con pequeñas papilas. Anfidios en forma de poro. Estoma dos veces el largo del diámetro de la cabeza. Cheilostoma cuticularizado. Esófago con bulbo medio bien desarrollado. Gónadas de las hembras no pareadas, prodélficas; vulva en el quinto posterior de la longitud corporal. Espículas simples, no fusionadas 
distalmente. Bursa pelodera, provista de nueve pares de papilas. Cola conoide, aquella de la hembra más larga que la del macho.

Hembras ( $\mathrm{n}=5)$ : longitud total: $1392 \pm 145,3$ (1200-1536), ancho a nivel de las papilas cefálicas: 16,5 \pm 3,5 (9-18), distancia del anillo nervioso al extremo anterior: -, ancho a nivel del anillo nervioso: -, longitud del esófago: 195,5 \pm 17,1 (171-225), distancia del bulbo al extremo anterior: 145,7 \pm 19,2 (108-180), distancia del poro excretor al extremo anterior: -, ancho medio: $108 \pm 10,3$ (99-117), ancho a nivel de la vulva: 76,5 \pm 9 (72-90), longitud de la vulva: 9, ancho de la vulva: 18, V: $83,03 \% \pm 3,1(80 \%-86,8 \%)$, ancho posterior: $99 \pm 10,3$ (90-108), longitud de la cola: $135 \pm 20,7$ (117-153), longitud de los huevos: 32,4 \pm 19,9 (18-45), ancho de los huevos: $27 \pm 12,7$ (18-36). (ver Anexo, tabla 2)

El macho se caracterizó por poseer 9 pares de papilas genitales con una distribución $2+2+5$ o $2+2+1+4$, lo que permitió diferenciar a esta especie de otras del mismo género.

Machos ( $\mathrm{n}=5)$ : longitud total: $932 \pm 83,2$ (816-1008), ancho a nivel de las papilas cefálicas: 10,5 $\pm 3,6$ (9-18), distancia del anillo nervioso al extremo anterior: -, ancho a nivel del anillo nervioso: -, longitud del esófago: $175 \pm 4,6$ (171-179), distancia del bulbo al extremo anterior: $129,5 \pm 4,04$ (126- 133), distancia del poro excretor al extremo anterior: -, ancho medio: $108 \pm 10,3$ (63-90), ancho a nivel del ano: 36, longitud de la espícula: $39 \pm 4,6$ (36-45), ancho de la espícula: 9, longitud de la cola: 40,5 \pm 7,5 (36-54) (ver Anexo, tabla 1).

\section{RESÚMEN TAXONÓMICO}

Sitio de colecta: Rambla de calle 32.

Hospedadores infestados en este estudio: ninfas de $A$. muticus.

Localización: intestino posterior. 


\section{COMENTARIOS}

Cruznema Artigas, 1927 es un género de nematodos bacteriófagos perteneciente a la familia Rhabditidae que suele estar asociado a cultivos, entre los que se pueden mencionar el ajo (Doucet, 1999), la papa (Desgarennes, 2009) y la caña de azúcar (Desgarennes, 2011). Sin embargo, cuatro especies han sido citadas asociadas a insectos: C. brevicaudatum Latheef y Seshadri, 1972 parasitando a Gryllotalpa africana, C. scarabaeum Sudhaus, 1978 en el escarabajo Scarabaeus sacer L., 1758, C. lincolnensis Reboredo y Camino, 1998 en el grillo Gryllodes laplatae, y C. campestris Reboredo y Camino, 2000 parasitando larvas del coleóptero Cyclocephala signaticolis.

Los ejemplares de Cruznema tripartitum hallados en este trabajo, constituyen el primer registro de esta especie asociada a insectos. 

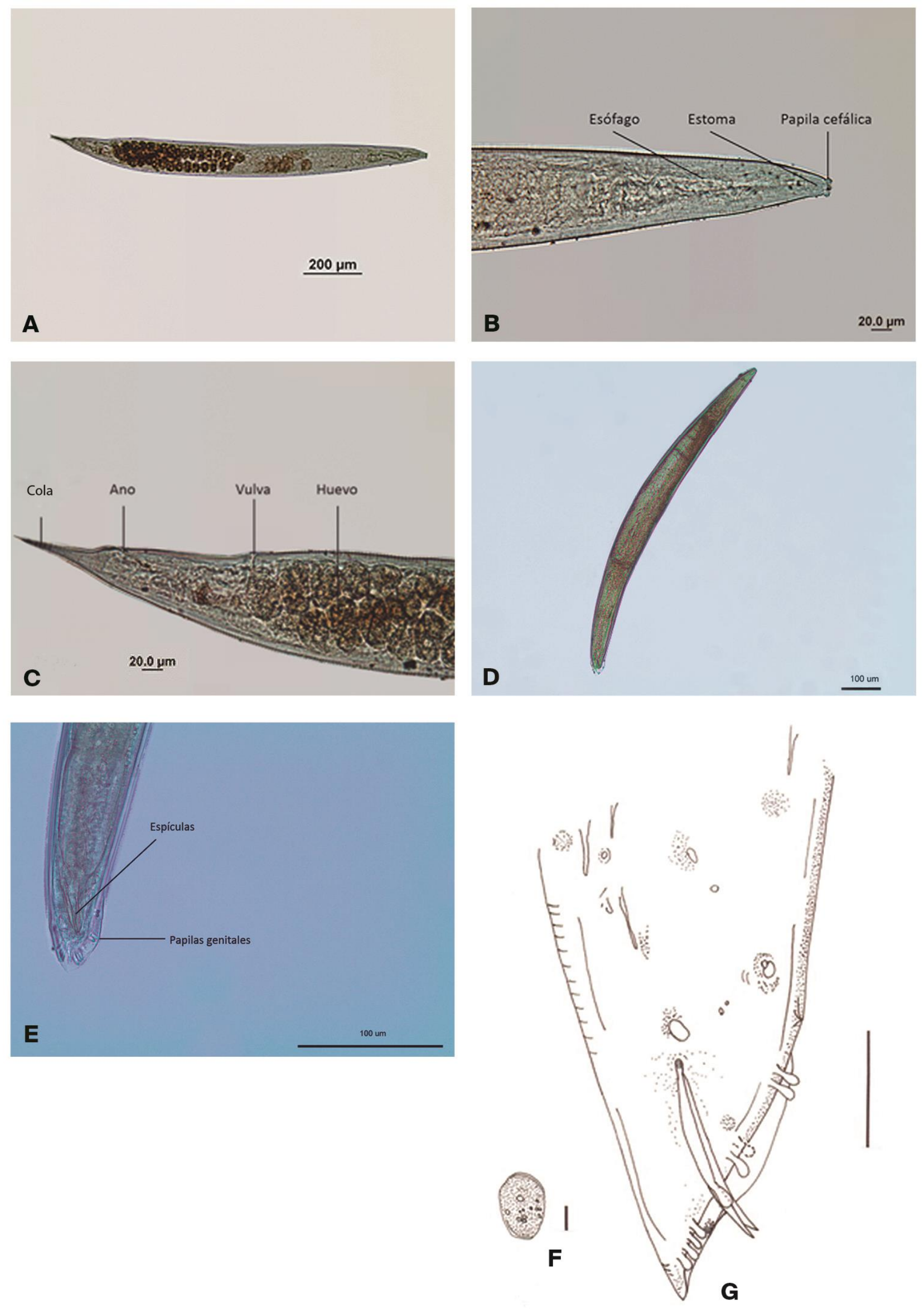
Figura 30. Cruznema tripartitum. A. Hembra, vista general. B. Región anterior. C. Detalle de la región posterior. D. Macho, vista general. E. Región posterior. Ilustraciones. F. Huevo (escala: $20 \mu \mathrm{m}$ ). G. Macho, región posterior. Se pueden apreciar las 9 papilas genitales de uno de los lados (escala: $10 \mu \mathrm{m}$ ).

Familia Cephalobidae

Subfamilia Cephalobinae

Género Cephalobium

Cephalobium nitidum Artigas, 1929

\section{Caracterización general}

Figura $31(\mathrm{~A}-\mathrm{F})$

Labios imperceptibles; boca pequeña; faringe en continuación con la cápsula bucal, presentando una porción anterior cilíndrica, limitada por anillos de quitina resistentes, rodeados a su vez por formaciones quitinosas discontinuas; desde esta porción se encontraba otra, separada de la primera por un segmento corto desprovisto de quitina; porción posterior también rodeada de un anillo quitinoso presentando un órgano de aspecto cordiforme, un aparato glotoideo, probablemente con función trituradora. Esófago tubuliforme en su porción anterior, con una ligera dilatación bulbar (desde esta dilatación existía una parte estrecha que unía al esófago e intestino). Intestino simple y sin inflexiones; cola larga afinandose gradualmente. Vulva media; ovarios en dirección opuesta a los úteros correspondientes, de tipo anfidélfico; huevos pequeños.

Los machos presentaron una formación buco-faríngea análoga a la de las hembras y el mismo tipo esofágico. Testículos simples y largos, dirigiéndose de adelante hacia atrás, tendiendo a comenzar por debajo del esófago. Dos espículas delgadas y 
resistentes, sustentadas por un gubernáculo reforzado de aspecto globoso, de 18,7 $\mu \mathrm{m}$ de largo. Un par de papilas caudales preanales y más de seis pares postanales.

Hembras ( $\mathrm{n}=154)$ : longitud total: $2844 \pm 412,2$ (2496-3432), ancho a nivel de las papilas cefálicas: 13,5 $\pm 5,1$ (9-18), distancia del anillo nervioso al extremo anterior: 290,2 $\pm 21,2$ (261-306), ancho a nivel del anillo nervioso: $81 \pm 12,7$ (63-90), longitud del esófago: 391,5 \pm 33,2 (342-414), distancia del bulbo al extremo anterior: 240,7 \pm 17,03 (216-256), distancia del poro excretor al extremo anterior: $339 \pm 5,19$ (333-342), ancho medio: $126 \pm 14,6$ (108-144), ancho a nivel de la vulva: 121,4 $\pm 22,04$ (99-144), longitud de la vulva: $22,5 \pm 5,1$ (18-27), ancho de la vulva: 13,5 \pm 5,1 (9-18), V: 46,6\% $\pm 0,02$ (44\%-57\%), ancho posterior: 78,7 $\pm 17,2$ (72-90), longitud de la cola: $276,7 \pm$ 11,3 (261-288), longitud de los huevos: $75 \pm 6,3$ (72-81), ancho de los huevos: $33 \pm 6,3$ (27-36) (ver Anexo, tabla 2) .

Machos ( $\mathrm{n}=84)$ : longitud total: $2192 \pm 49,9$ (2136-2232), ancho a nivel de las papilas cefálicas: 9 , distancia del anillo nervioso al extremo anterior: 137,5 \pm 8,02 (173-189), ancho a nivel del anillo nervioso: $69 \pm 10,3$ (63-81), longitud del esófago: $243 \pm 9$ (234252), distancia del bulbo al extremo anterior: 198,6 $\pm 8,02$ (191-207), distancia del poro excretor al extremo anterior: $279 \pm 9$ (270-288), ancho medio: $102 \pm 13,7$ (90-117), ancho a nivel del ano: $62 \pm 9,7$ (36-81), longitud de la espícula: $49 \pm 10,2$ (27-63), ancho de la espícula: 9, longitud de la cola: 174,7 $\pm 35,2$ (126-252) (ver Anexo, tabla 1).

\section{RESÚMEN TAXONÓMICO}

Sitios de colecta: Rambla de calle 32 y Estación Experimental Julio Hirschhorn.

Hospedadores infestados en este estudio: A. muticus (adultos).

Localización: intestino posterior. 


\section{COMENTARIOS}

El género Cephalobium fue establecido por Cobb (1920), basado en los caracteres morfológicos presentados por la especie C. microviborum Cobb, 1920, parásito del grillo Gryllus assimilis Fabricius. La característica esencial de este género es presentar el estoma constituído por dos partes: una anterior, rodeada por un anillo quitinoso, y una posterior, también rodeada de quitina y que posee una formación típica denominada "aparato glotoideo". Artigas (1929), describió a C. nitidum del intestino de Gryllotalpa sp., procedentes de los Estados de Rio y Sao Paulo (Brasil).

Los ejemplares aquí estudiados se diferencian de los descriptos por Artigas (1929) porque los machos son mayores (2,23 vs 1,65 mm), y por el menor ancho de los huevos $(33$ vs $45 \mu)$.

Cephalobium nitidum constituye el primer registro para la Argentina y amplía la lista de especies hospedadoras al haberse encontrado en Anurogrillus muticus (Gryllidae). 

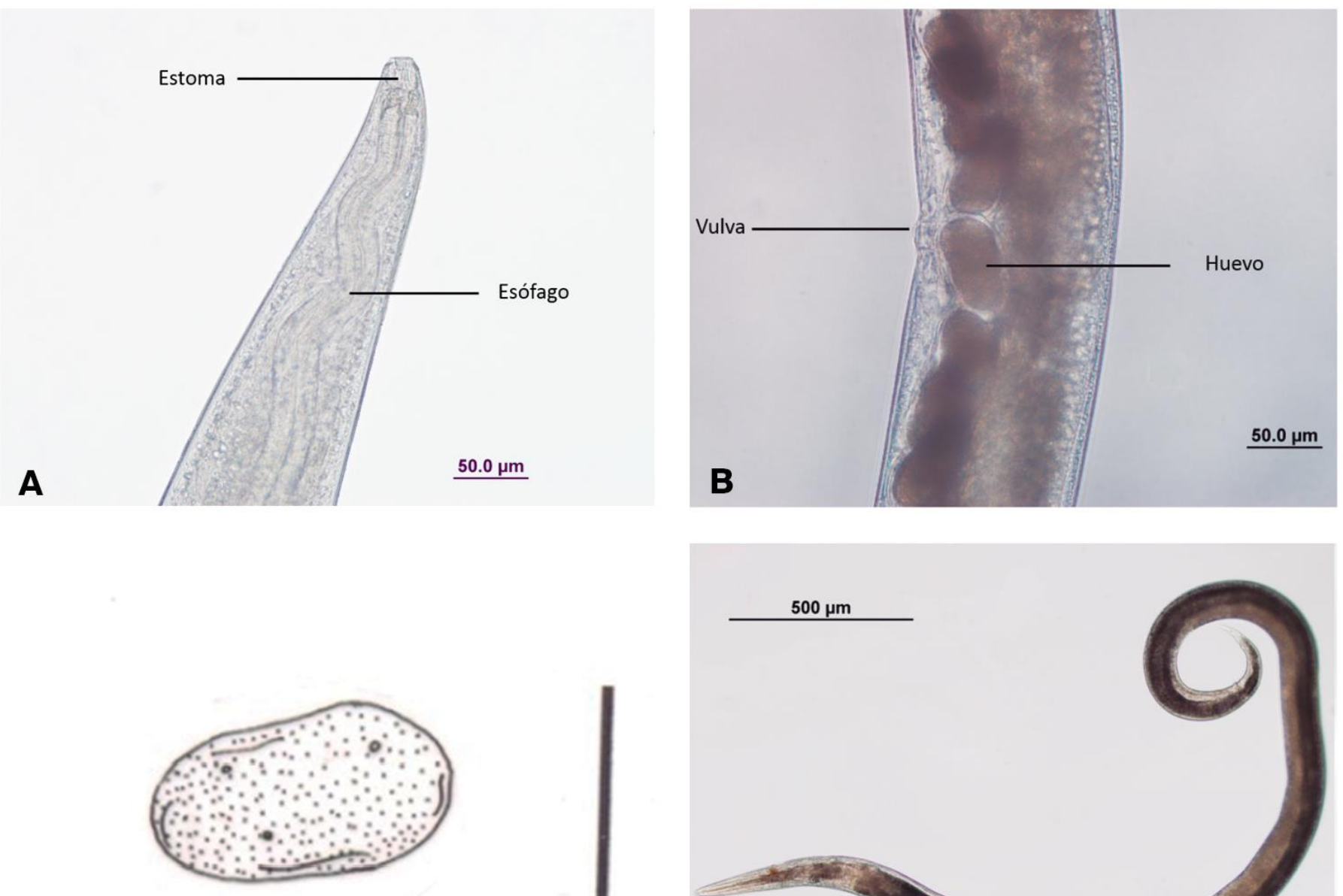

C
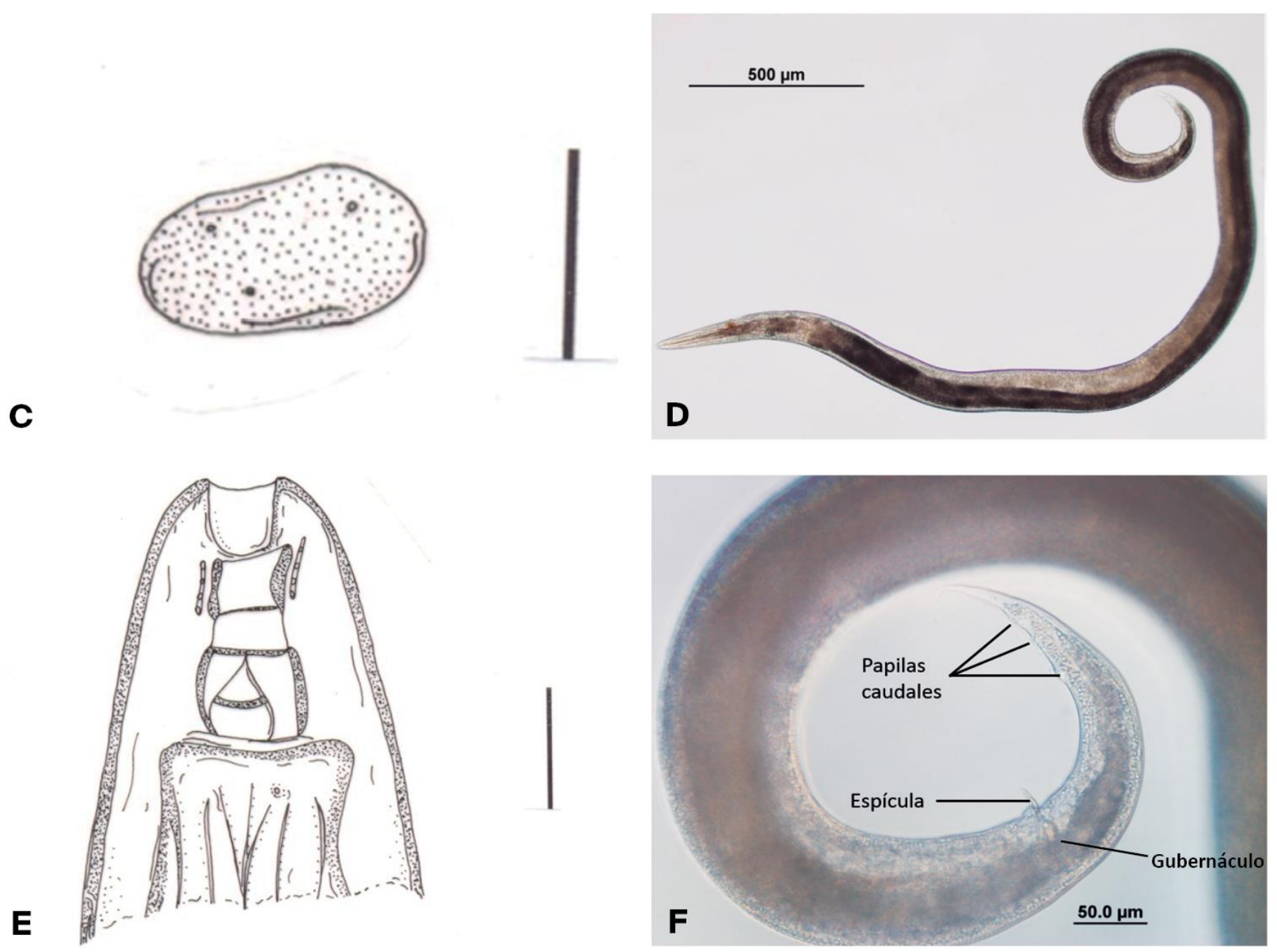
Figura 31. Cephalobium nitidum. (A-C). Hembra. A. Región cefálica. B. Detalle de la región vulvar, vista lateral. C. Huevo (escala: $50 \mu \mathrm{m}$ ). (D-F). Macho. D. Vista general. E. Extremo anterior, vista lateral (escala: $10 \mu \mathrm{m}$ ). F. Detalle de la región posterior, vista lateral.

\section{Orden Oxyurida}

\section{Superfamilia Thelastomatoidea}

\section{Familia Travassosinematidae}

\section{Género Binema}

Binema bonaerensis Camino y Reboredo, 1999

\section{Caracterización general}

\section{Figura $32(\mathrm{~A}-\mathrm{F})$}

Nematodos pequeños. Cutícula anillada a través de la longitud del cuerpo. Abertura de la boca prismoidal, rodeada por 8 papilas submedianas y 2 anfidios en forma de poro. Cavidad bucal corta y cilíndrica con 3 arcos esclerotizados. Esófago con un típico corpus cilíndrico, istmo corto y bulbo basal posterior. Poro excretor se ubicado inmediatamente posterior a la base del bulbo basal. Vulva situada posterior a la mitad del cuerpo. Vagina cilíndrica. Dos ovarios. Cola corta y cónica en hembras y machos. Huevos fertilizados ovales y pareados en el útero, con varios filamentos en cada polo.

El macho no fue encontrado en los muestreos realizados.

Hembras ( $\mathrm{n}=72)$ : longitud total: $1671 \pm 107,6$ (1575-1773), ancho a nivel de las papilas cefálicas: 22,5 $\pm 5,1$ (18-27), distancia del anillo nervioso al extremo anterior: 85,5 \pm 5,1 (81- 90), ancho a nivel del anillo nervioso: 110,2 $\pm 4,5$ (103-135), longitud del esófago: 346,5 \pm 15,5 (333-360), distancia del bulbo al extremo anterior: 244,2 $\pm 13,5$ (144-360), distancia del poro excretor al extremo anterior: 427,5 $\pm 44,5$ (396-495), ancho medio: $235,3 \pm 49,3$ (233-260), ancho a nivel de la vulva $=218,2 \pm 13,5$ (207- 
234), longitud de la vulva: $20,2 \pm 4,5$ (18-27), ancho de la vulva: 13,5 $\pm 5,1$ (9-18), V: $54,6 \% \pm 0,03$ (51,7\%-60\%), ancho posterior: 132,7 $\pm 18,5$ (108-153), longitud de la cola: $265,5 \pm 37,1$ (225-315), longitud de los huevos: 60,75 $\pm 4,5$ (54-63), ancho de los huevos: 33,75 \pm 4,5 (27-36) (ver Anexo, tabla 2).

\section{RESÚMEN TAXONÓMICO}

Sitio de colecta: Estación Experimental de Gorina.

Hospedadores infestados en este estudio: N. claraziana (adultos).

Localización: intestino posterior.

\section{COMENTARIOS}

La familia Travassosinematidae reúne un número de géneros que son parásitos de grillotopos y uno parásito de diplópodos. En 1958, Rao propone a esta familia para tres géneros (Pulchrocephala Travassos, 1925, Indiana Chakravarty, $1943 \mathrm{y}$ Travassosinema Rao, 1958) basándose en una modificación cuticular cefálica para la cual Hunt $(1981,1983)$ acuñó el término umbraculum cefálico. Adamson (1987) consideró a esta familia como monofilética, pero cuestionó su uso debido a la confusión que causaría con respecto a la ubicación taxonómica de géneros como Binema, Mirzaiella Basir, 1942 y Chitwoodiella Basir, 1948, relacionados a Pulchrocephala e Indiana pero que poco tienen en común con Travassosinema. El problema gira en torno a si el umbraculum cefálico es homólogo en los tres géneros en los que ocurre. El género Binema consta de un total de 11 especies distribuídas alrededor del mundo. Tewarson y Gupta (1978) describieron a B. thapari. Parveen y Jairajpuri (1985) describieron a B. parva. Singh y Singh (1990) hicieron lo propio con B. chauhani. Adamson y van Waerebeke (1992 b) citaron a 4 especies en su revisión de la familia Travassosinematidae (ver Anexo, tabla 6), entre ellas a $B$. ornata, esta última para Brasil. A nivel local existen 2 registros: B. klossae y B. bonaerensis. Posteriormente 
para la India, Singh y Malti (2003) describieron a la especie B. atrophicaudata. Un año más tarde, Shah y Rizvi (2004) describieron a B. annulinervus.

Camino y Reboredo (1999), describieron a B. bonaerensis del intestino de $N$. claraziana, procedentes de Gorina (Buenos Aires).

Los ejemplares aquí estudiados se diferencian de los descriptos por Camino y Reboredo (1999) porque los machos son menores (1,67 vs 1,78 mm), el porcentaje de "V" es menor (54,6 vs 64\%) y por un menor largo de los huevos $(60,75$ vs 84,6 $\mu$ ). 

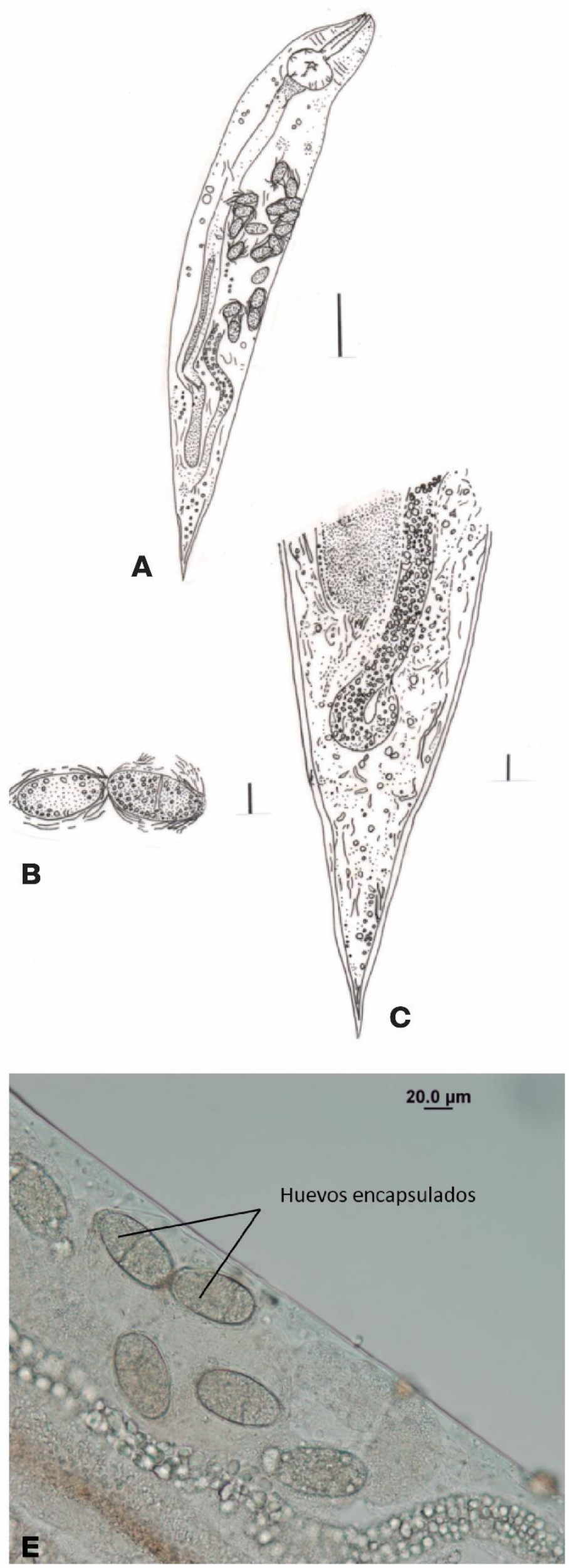

Figura 32. Binema bonaerensis. A. Hembra, vista general (escala: $100 \mu \mathrm{m}$ ). B. Huevos (escala: 50 $\mu \mathrm{m})$. C. Extremo caudal, vista lateral (escala: 20 $\mu \mathrm{m})$. D. Extremo cefálico, visto al M.E.B. E. Región vulvar. F. Huevos agrupados de a pares fuera de la hembra.
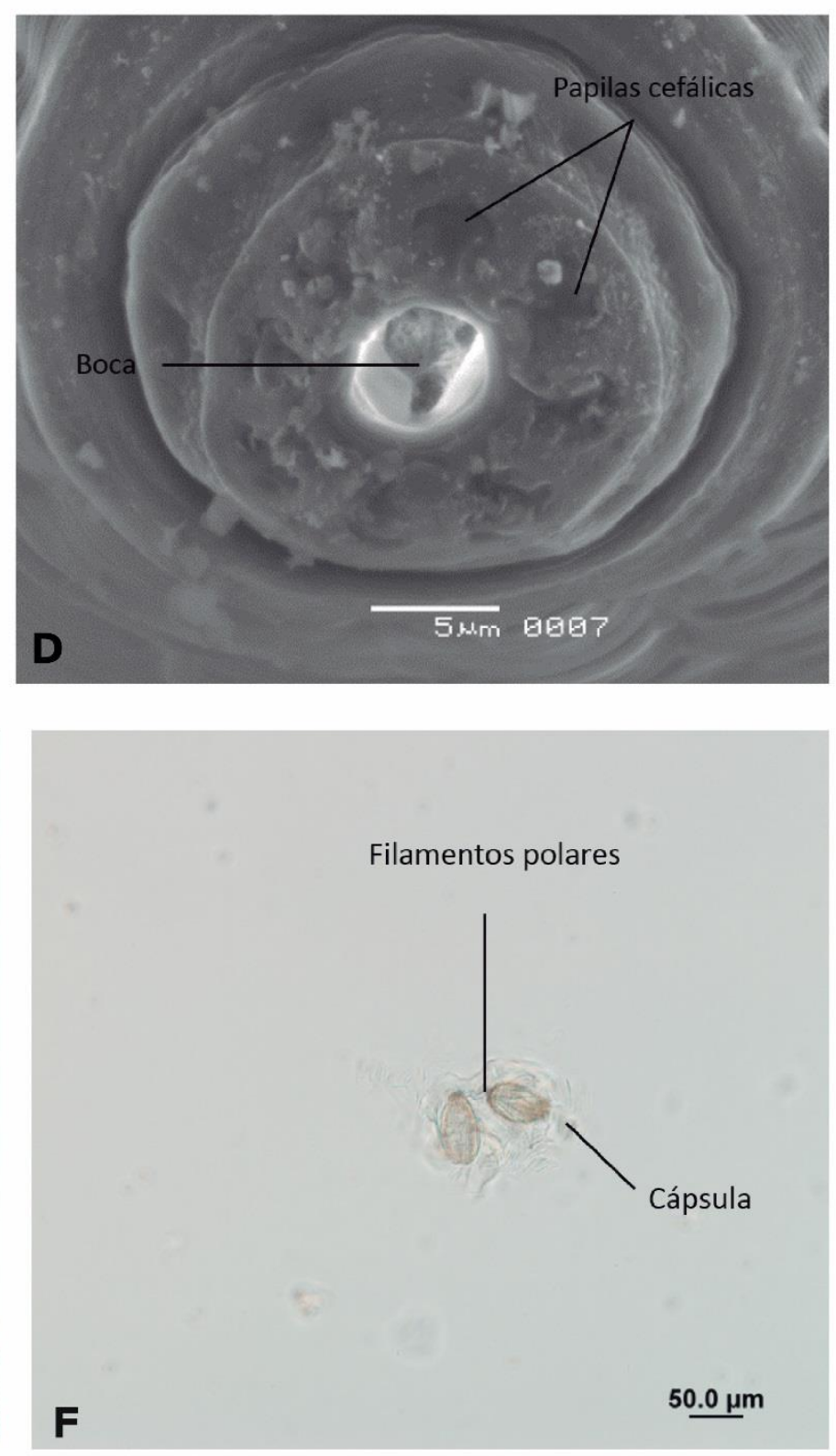


\section{Binema klossae (Marchissio y Miralles, 1993)}

\section{Caracterización general}

Figura $33(\mathrm{~A}-\mathrm{E})$

La hembra se distinguió por tener un cuerpo fusiforme, una boca rodeada por ocho papilas labiales y un par de anfidios. Cutícula anillada en la región cefálica, continuando lisa en el resto del cuerpo. Con ornamentación bucal. Estoma con paredes quitinosas. Esófago con un corpus bien diferenciado cuya porción anterior presentó paredes quitinosas, istmo muy desarrollado, largo y bulbo basal. Anillo nervioso situado en la mitad del corpus. Poro excretor ubicado posterior a la base del esófago. Intestino rectilíneo. Aparato reproductor didelfo anfidelfo. La vulva fue localizada en la mitad del cuerpo. Huevos grandes ovoides, provistos de filamentos polares que podían o no estar rodeados por una cápsula membranosa mucilaginosa. Con fasmidios. Cola cónica.

El macho no fue hallado.

Hembras ( $\mathrm{n}=3$ ): longitud total: $3504 \pm 475,1$ (3168-3840), ancho a nivel de las papilas cefálicas: $31,5 \pm 6,3$ (27-36), distancia del anillo nervioso al extremo anterior: $108 \pm$ 12,7 (99-117), ancho a nivel del anillo nervioso: $72 \pm 12,7$ (63-81), longitud del esófago: $352 \pm 11,3$ (344-360), distancia del bulbo al extremo anterior: $198 \pm 25,4$ (180216), distancia del poro excretor al extremo anterior: 508,5 $\pm 57,2$ (468-549), ancho medio: $315 \pm 63,6$ (270-360), ancho a nivel de la vulva: $288 \pm 76,3$ (234-342), longitud de la vulva: 18 , ancho de la vulva: $36, \mathrm{~V}: 52,3 \% \pm 1,15$ (51\%-53\%), ancho posterior: $180 \pm 63,6$ (135-225), longitud de la cola: $108 \pm 12,7$ (99-117), longitud de los huevos: 58,5 $\pm 6,3$ (54-63), ancho de los huevos: 31,5 $\pm 6,3$ (27-36) (ver Anexo, tabla 2) .

\section{RESÚMEN TAXONÓMICO}

Sitio de colecta: Estación Experimental de Gorina.

Hospedadores infestados en este estudio: $N$. claraziana (ninfa).

Localización: intestino posterior. 


\section{COMENTARIOS}

Esta especie fue descripta como Talpicola klossae Marchissio y Miralles, 1993 y posteriormente cambiada al género Binema.

Marchissio y Miralles (1993), describieron a Binema klossae del intestino de $N$. claraziana, procedentes de Carmen de Areco (Buenos Aires).

Los ejemplares estudiados en este trabajo se diferencian de los descriptos por Marchissio y Miralles (1993) porque el largo máximo de la hembra es menor (3,84 vs 4,20 mm), el largo máximo del esófago es menor (360 vs $420 \mu$ ), y la distancia máxima del bulbo al extremo anterior es también menor (549 vs $810 \mu)$. 

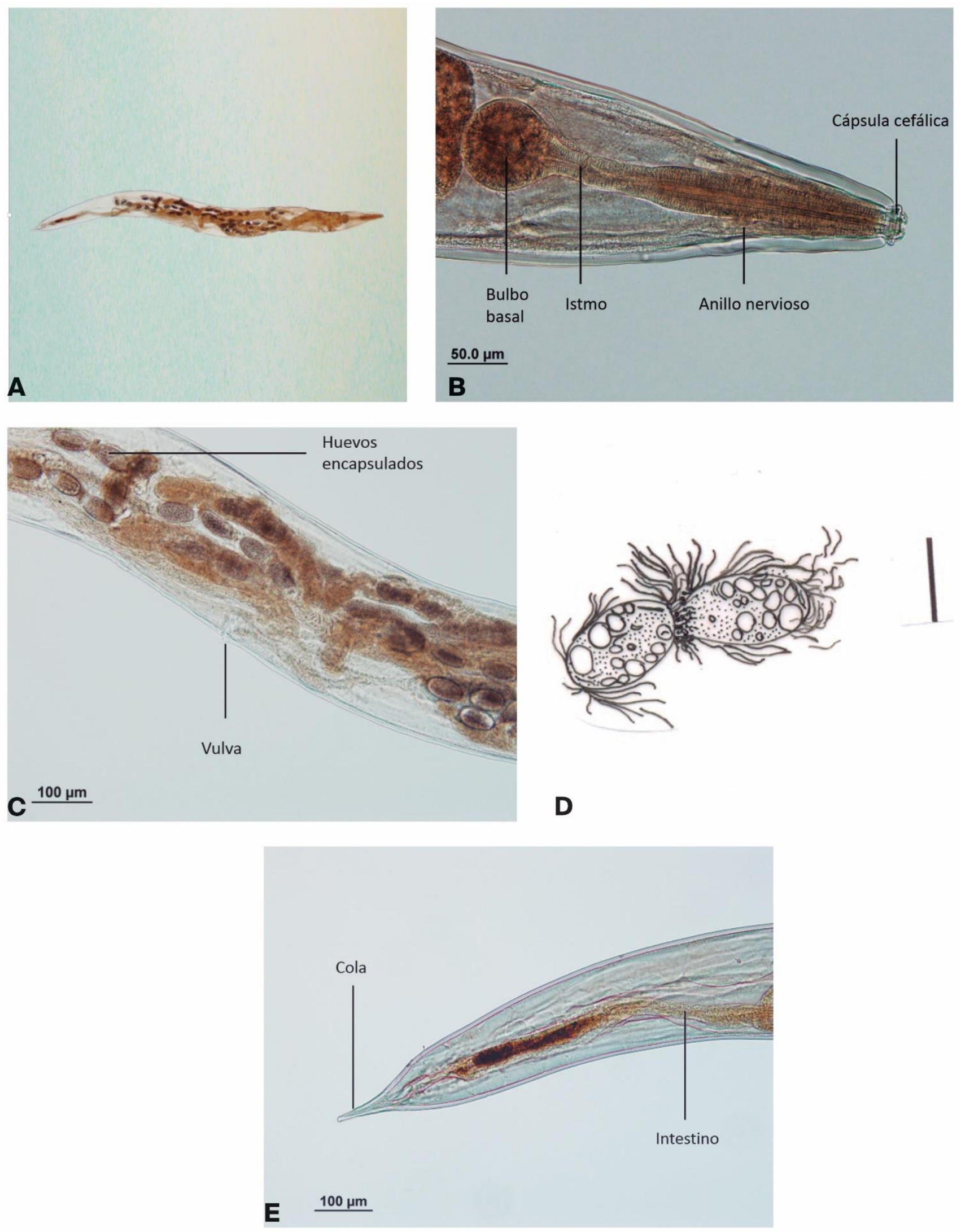

Figura 33. Binema klossae. A. Hembra, vista general (escala: $500 \mu \mathrm{m}$ ). B. Extremo cefálico, vista lateral. C. Región vulvar. D. Huevos (escala: $50 \mu \mathrm{m})$. E. Extremo caudal. 


\section{Descripción}

\section{Binema sp.}

Figura $34(\mathrm{~A}-\mathrm{E})$

\section{General}

La hembra presentó un cuerpo largo, angostándose hacia los extremos. Ala lateral ausente. Cabeza provista de dos anillos grandes sobresalientes. El cuerpo poseía pocas estrías, que se encontraban en la región cefálica y se extendían más allá del poro excretor. Cavidad bucal corta, de $9 \mu \mathrm{m}$ de largo aproximadamente. Esófago que consistió de un corpus, un istmo corto y un bulbo basal con 3 placas triangulares. Anillo nervioso cercano al tercio anterior del corpus. Poro excretor posterior a la base del esófago. Intestino con una dilatación anterior. Cola corta y cónica. La vulva se ubicó ligeramente posterior a la mitad del cuerpo, vagina dirigida anteriormente. Dos ovarios, uno dirigido hacia el extremo anterior y el otro al posterior. Huevos muy numerosos, cada uno con filamentos en los polos, encerrados de a pares en cápsulas.

El macho no fue localizado.

Hembras ( $\mathrm{n}=53)$ : longitud total: $3536 \pm 340,5$ (3168-3840), ancho a nivel de las papilas cefálicas: $30 \pm 5,1$ (27-36), distancia del anillo nervioso al extremo anterior: $90 \pm 7,3$ (81-99), ancho a nivel del anillo nervioso: $99 \pm 7,3$ (90-117), longitud del esófago: $373,3 \pm 11,6$ (360-387), distancia del bulbo al extremo anterior: 273,5 $\pm 11,6$ (216-324), distancia del poro excretor al extremo anterior: 416,2 $\pm 8,61$ (405-423), ancho medio: $346 \pm 9,3$ (342-360), ancho a nivel de la vulva: 331,5 $\pm 8,2$ (322-342), longitud de la vulva: 18 , ancho de la vulva: $36, \mathrm{~V}: 57,5 \% \pm 3(54 \%-59,5 \%)$, ancho posterior: $78,7 \pm$ 8,6 (72-90), longitud de la cola: 56,2 \pm 4,5 (54-63), longitud de los huevos: 52,8 $\pm 3,1$ (49,5-54), ancho de los huevos: $33 \pm 3,1$ (31,5-36) (ver Anexo, tabla 3). 


\section{RESUMEN TAXONÓMICO}

Sitio de colecta: Estación Experimental de Gorina.

Hospedadores infestados en este estudio: $N$. claraziana (adultos).

Localización: intestino posterior.

\section{COMENTARIOS}

Se comparó a la especie hallada con las restantes hembras del género y se encontraron diferencias a nivel morfológico y morfométrico. Este ejemplar registrado en la localidad de Gorina podría ser considerado una nueva especie ya que poseen los dos primeros anillos cefálicos sobresalientes, la vulva en posición media o ligeramente posterior $(\mathrm{V}=57,5 \%$ ) y la cola muy corta, aunque la falta de caracteres determinantes en la hembra y la ausencia de machos no permitió llegar a esta conclusión.

Estudios moleculares podrían llevarse a cabo para el esclarecimiento e identifcación de la especie. 

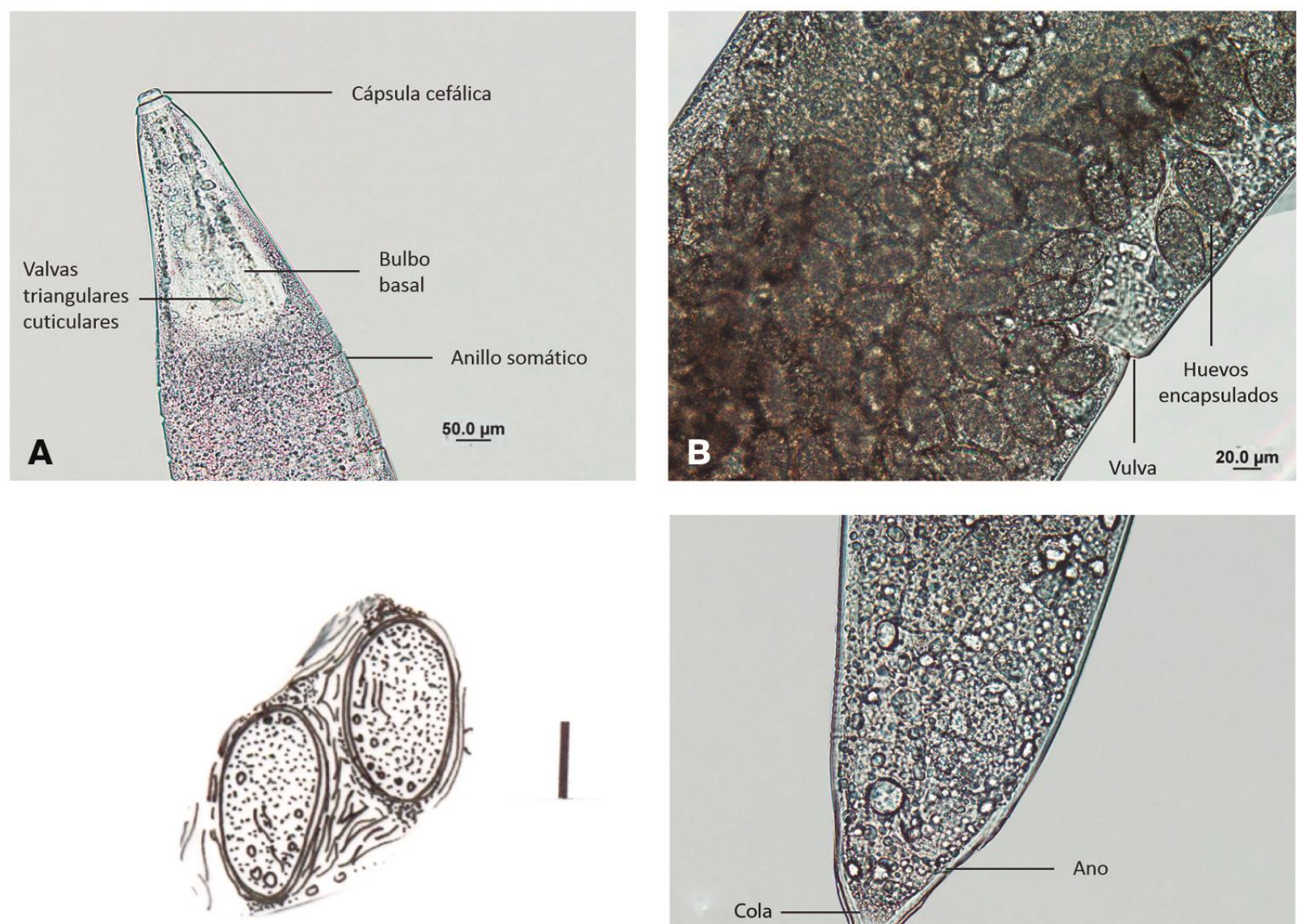

C
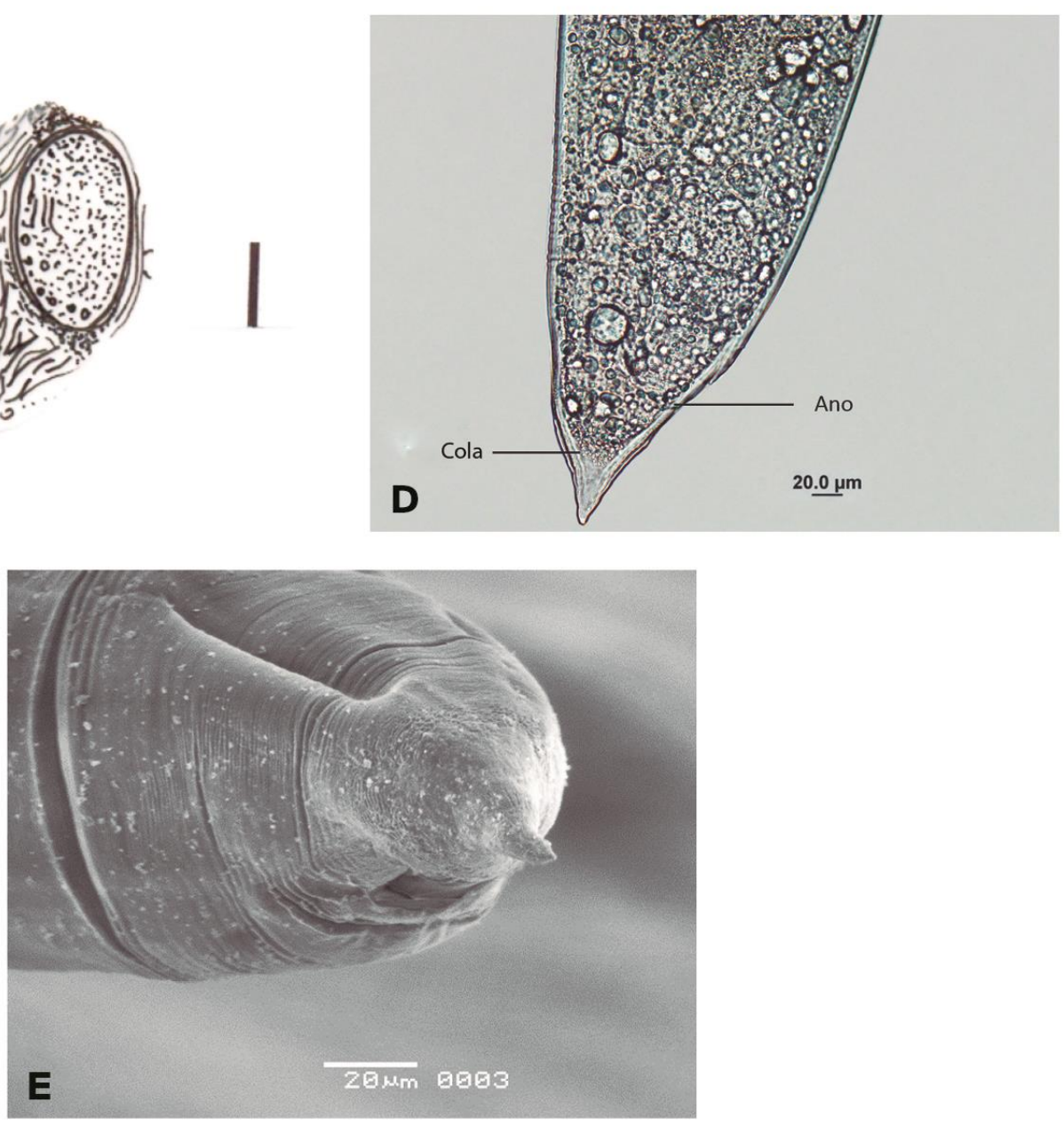

Figura 34. Binema sp. A. Hembra, extremo cefálico. B. Región vulvar. C. Huevos (escala: $20 \mu \mathrm{m}$ ). D. Extremo caudal. E. Extremo caudal visto al M.E.B 


\section{Familia Thelastomatidae}

\section{Subfamilia Thelastomatinae}

Género Cephalobellus

Cephalobellus magalhaesi (Schwenk, 1926)

\section{Caracterización general}

Figura 35 (A-E)

Cutícula transversalmente estriada hasta el nivel del esófago. Labios no salientes. Esófago provisto de un corpus cilíndico anterior, un istmo y un bulbo basal. Intestino dilatado anteriormente formando un cardia. Anillo nervioso situado alrededor del corpus. Poro excretor posterior a la base del esófago; cola larga, filiforme. Vulva aproximadamente en la mitad del cuerpo, o levemente posterior. Los ovarios yacían en dirección opuesta a sus correspondientes úteros y se replegaban cerca de sus terminaciones; úteros divergentes. Huevos elipsoidales.

El macho es desconocido.

Hembras ( $n=130)$ : longitud total: $5862 \pm 413,08$ (5520-6456), ancho a nivel de las papilas cefálicas: $22,5 \pm 5,19$ (18-27), distancia del anillo nervioso al extremo anterior: $261 \pm 12,7$ (252-270), ancho a nivel del anillo nervioso: $126 \pm 12,7$ (108-135), longitud del esófago: 569,2 \pm 11,3 (558-585), distancia del bulbo al extremo anterior: 469,3 \pm 11,3 (458-485), distancia del poro excretor al extremo anterior: $774 \pm 7$ (767-781), ancho medio: 292,5 $\pm 21,4$ (270-315), ancho a nivel de la vulva: 272,2 $\pm 4,5$ (270-279), longitud de la vulva: $29,2 \pm 4,5$ (27-36), ancho de la vulva: 11,2 $\pm 4,5$ (9-18), V: 50,8\% $\pm 3,4$ (46,5\%-55\%), 
ancho posterior: $195,7 \pm 13,5$ (189-216), longitud de la cola: $270 \pm 5,7$ (263-277), longitud de los huevos: $57 \pm 6,3$ (54-63), ancho de los huevos: $42 \pm 6,3$ (36-45) (ver Anexo, tabla 2).

\section{RESÚMEN TAXONÓMICO}

Sitio de muestreo: Estación Experimental Julio Hirschhorn.

Hospedores infestados en este estudio: $N$. claraziana (adultos).

Localización: intestino posterior.

\section{COMENTARIOS}

En la actualidad se reconocen 31 especies como miembros válidos del género Cephalobellus, parasitando a un amplio rango de hospedadores como por ejemplo blattodeos, ortópteros (Gryllidae), coleópteros y miriápodos. Veintiocho de estas especies fueron citadas por Adamson y van Waerebeke (1992 a) en su revisión de la familia Thelastomatidae (ver Anexo, tabla 7), a las cuales se agregan $C$. lobulata y $C$. cyclocephalae ambas para Argentina. Singh et al. (2014) describieron a C. orientalis para la India.

Cephalobellus magalhaesi fue hallada en Brasil en una especie no identificada de cucarachas y transferida del género Bulhoesia por Schwenk en 1926 (Basir, 1956). Este hallazgo constituye la tercer especie del género encontrada en Argentina, extendiendo su registro a la familia Gryllotalpidae (N. claraziana). 


\section{José Matías Rusconi 2017}

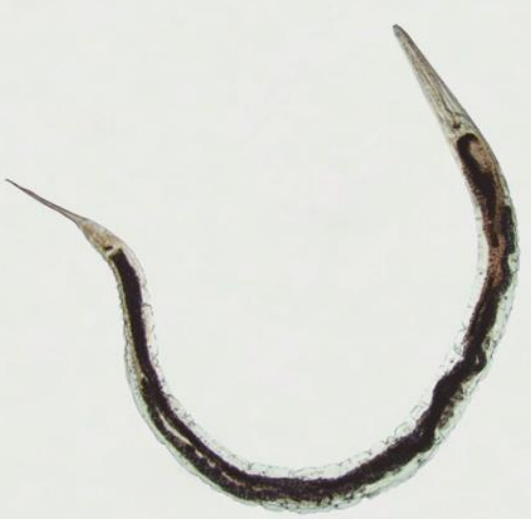

A
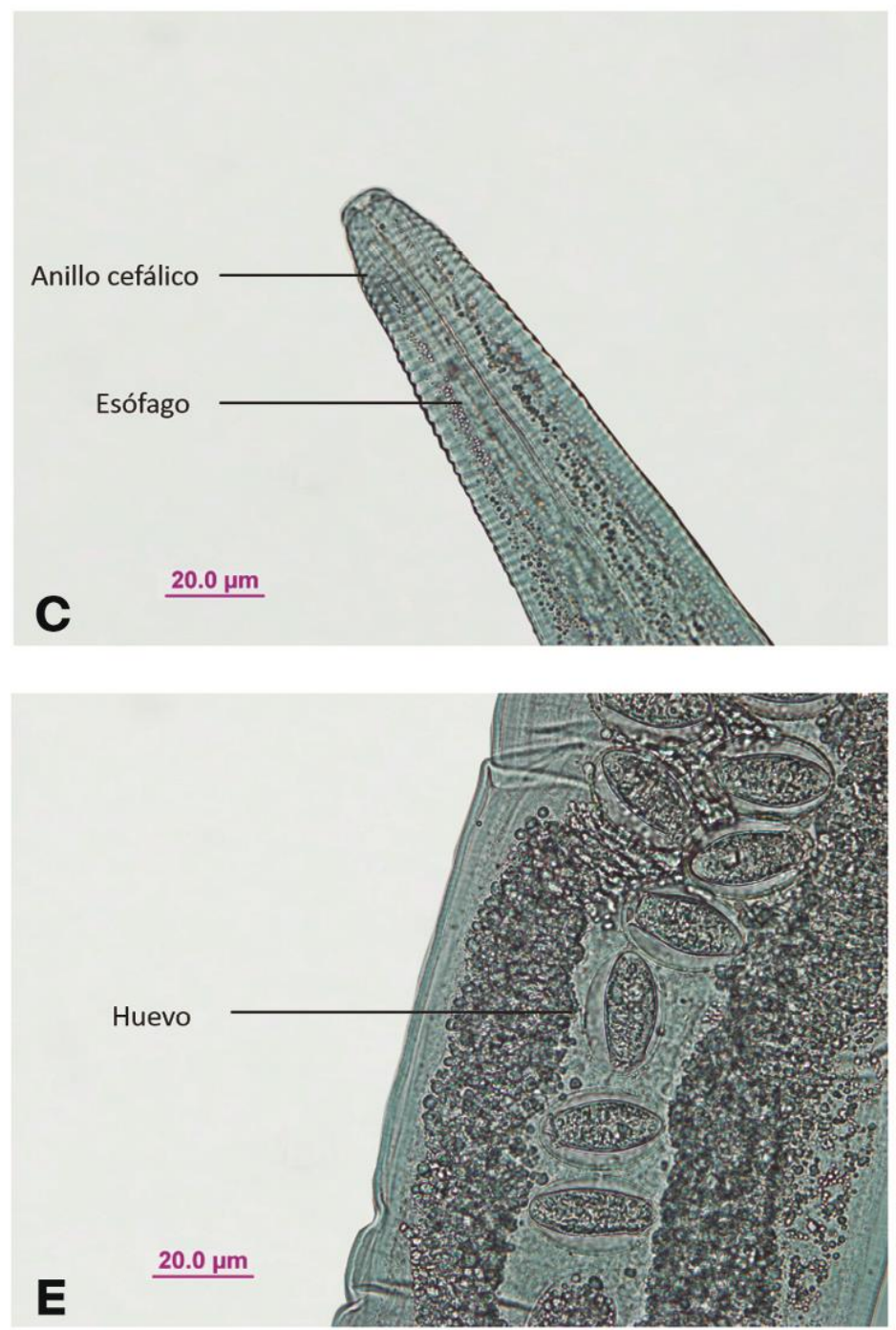
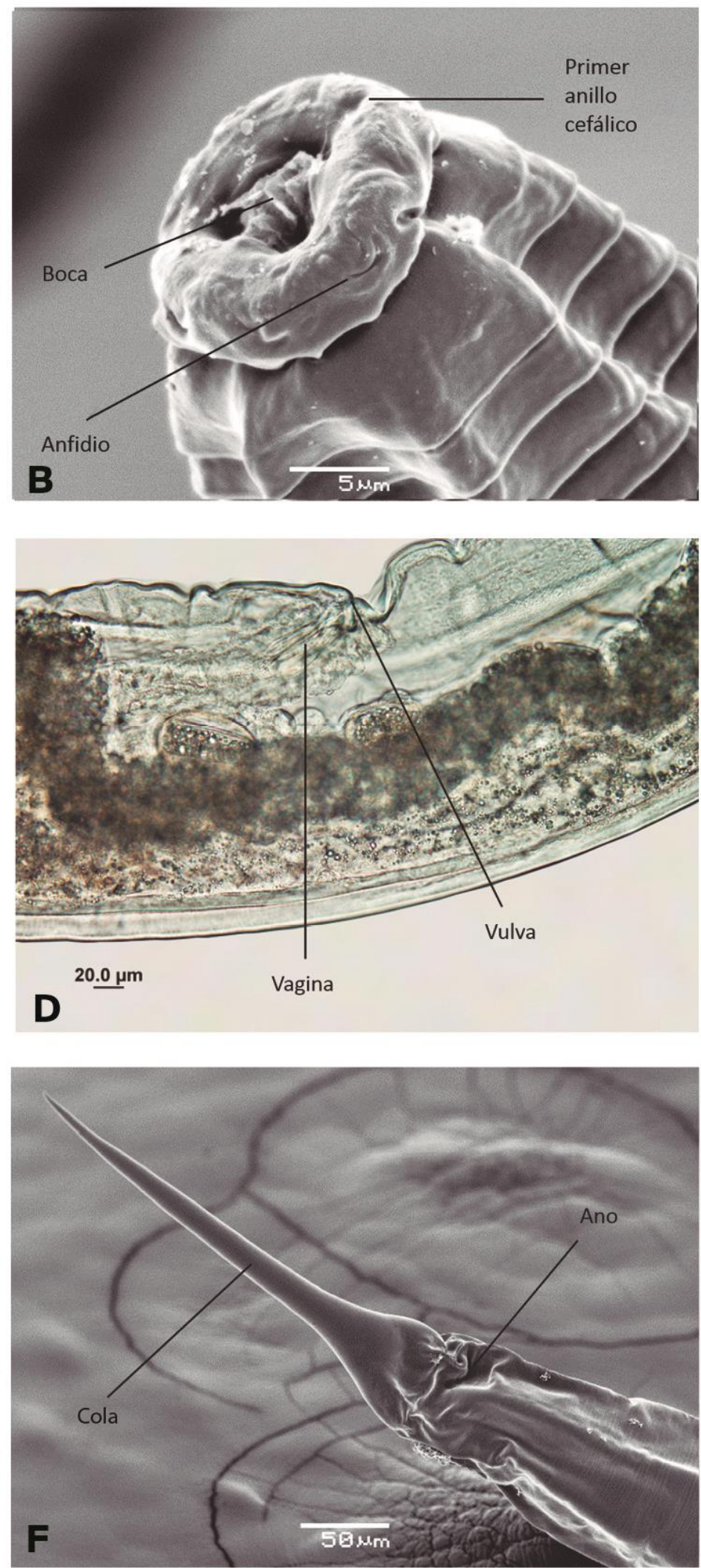

Figura 35. Cephalobellus magalhaesi. A. Hembra, vista general. B. Región anterior, vista al M.E.B. C. Extremo cefálico. D. Región vulvar, vista lateral. E. Huevos dentro de la hembra. F. Extremo caudal, visto al M.E.B. 


\section{Género Blatticola}

Blatticola cristovata Achinelly y Camino, 2007

\section{Caracterización general}

Figura $36(\mathrm{~A}-\mathrm{H})^{*}$

La hembra con la cutícula anillada a lo largo del cuerpo. El segundo anillo más largo que los demás. El primer anillo posee pequeños anfidios, con forma de poro, aberturas anfidiales pequeñas y circulares. Boca hexagonal rodeada de 8 papilas. Estoma más largo que ancho, sin dientes, con paredes esclerotizadas gruesas, formando 3 pares de placas alineadas en 2 filas. Esófago tripartito, indistintamente esclerotizado en la parte anterior, con un corpus ladeado paralelamente, expandido posteriormente; istmo corto y bulbo basal valvado. Anillo nervioso situado anterior a la articulación corpus-istmo. Poro excretor posterior al extremo anterior del intestino. Intestino ancho, disminuyendo posteriormente. Vulva localizada posteriormente, con un labio más desarrollado; vagina larga y angosta. Útero simple, dirigido anteriormente desde la vagina, cerca del extremo anterior del intestino formaba un bucle, que luego iba hacia el extremo posterior del intestino donde formaba otro y ascendía hasta el nivel de la vulva. Ovario simple dirigido anteriormente. Huevos ovales, cáscara suave, con un lado recto y el otro con una cresta con bandas longitudinales. Cola corta, cónica y puntiaguda.

Los machos son más pequeños que las hembras. Cutícula suavemente anillada a lo largo del cuerpo. Anfidios pequeños con forma de poro. Estoma más largo que ancho, con paredes esclerotizadas y dos filas con 3 pares de placas, sin dientes. Esófago e intestino similares a los de la hembra. Anillo nervioso localizado anterior al corpus y a la articulación del istmo. Testículo simple, extendido anteriormente, replegado posteriormente hacia la mitad del cuerpo. Vaso deferente evidente. Espícula simple, recta. Capítulo y gubernáculo ausentes. Papilas genitales con arreglos ventrolaterales en un par preanal, un par adanal y 2 pares postanales. Cola corta y cónica (Achinelly y Camino, 2007). 
Hembras $(n=341)$ : longitud total: $3834 \pm 222,02$ (3552-4080), ancho a nivel de las papilas cefálicas: $15 \pm 4,5$ (9-18), distancia del anillo nervioso al extremo anterior: $266,5 \pm 4,9$ (263-270), ancho a nivel del anillo nervioso: 135,2 $\pm 12,7$ (126-144), longitud del esófago: $547 \pm 25,6$ (531-585), distancia anterior al bulbo: 447,5 $\pm 25,3$ (431-485), distancia del poro excretor al extremo anterior: 913,5 \pm 19,09 (900-927), ancho medio: $297 \pm 19,4$ (270-315), ancho a nivel de la vulva: $201 \pm 5,1$ (198-207), longitud de la vulva: $27 \pm 9$ (18-36), ancho de la vulva: $12 \pm 5,1$ (9-18), V: 82,8\% $\pm 3,2$ (79\%-85,3\%), ancho posterior: 200,2 $\pm 23,6$ (180-234), longitud de la cola: $94,5 \pm 5,1$ (90-99), longitud de los huevos: $51 \pm 6,3$ (45-54), ancho de los huevos: $36 \pm 12,7$ (2745) (ver Anexo, tabla 3).

Machos (n=5): longitud total: $1824 \pm 191,5$ (1656-2040), ancho a nivel de las papilas cefálicas: 12,6 \pm 4 (9-18), distancia del anillo nervioso al extremo anterior: 105,7 $\pm 22,6$ (81-117), ancho a nivel del anillo nervioso: 49,5 \pm 9 (36-54), longitud del esófago: $250,2 \pm 21,5$ (225-279), distancia del bulbo al extremo anterior: 174,2 $\pm 27,8$ (134-207), distancia del poro excretor al extremo anterior: -, ancho medio: $99 \pm 19,7$ (81-135), ancho a nivel del ano: 48,6 \pm 10,2 (36-63), longitud de la espícula: 36, ancho de la espícula: 9, longitud de la cola: $72 \pm 15,05$ (54-99) (ver Anexo, tabla 1).

\section{RESÚMEN TAXONÓMICO}

Sitios de colecta: Rambla de calle 32, Estación Experimental de Gorina, Plaza Rocha, Plaza San Martín, Plaza Belgrano, Paseo del Bosque, Estación Experimental Julio Hirschhorn, Parque Ecológico de Villa Elisa, Plazoleta de diag. 113 y 64.

Hospedadores infestados en este estudio: $N$. claraziana (ninfas y adultos) y $A$. muticus (ninfas y adultos).

Localización: intestino posterior. 


\section{COMENTARIOS}

Trece especies pertenecientes al género Blatticola fueron descriptas en el mundo. Once de ellas fueron citadas por Adamson y van Waerebeke (1992 a) (ver Anexo, tabla 5), mientras que 2 fueron descriptas para Argentina: B. cristovata y B. biannulata.

Los ejemplares aquí estudiados se diferencian de los descriptos por Achinelly y Camino, 2007 porque el largo máximo de hembras $(3,83$ vs 4,21 $\mu)$ y de machos $(1,82$ vs $2,11 \mu$ ) es menor, la distancia del poro excretor al extremo anterior en la hembra es mayor $(913,5$ vs 875,3 $\mu$ ), la medida a nivel del ancho medio es menor (297 vs 453,3), al igual que la longitud de los huevos (51 vs 84).

Los registros de los trabajos realizados por Achinelly y colaboradores para esta especie corresponden a la localidad de Villa Elisa. En este estudio, se amplía el registro a las localidades de La Plata, Gorina y Los Hornos. 

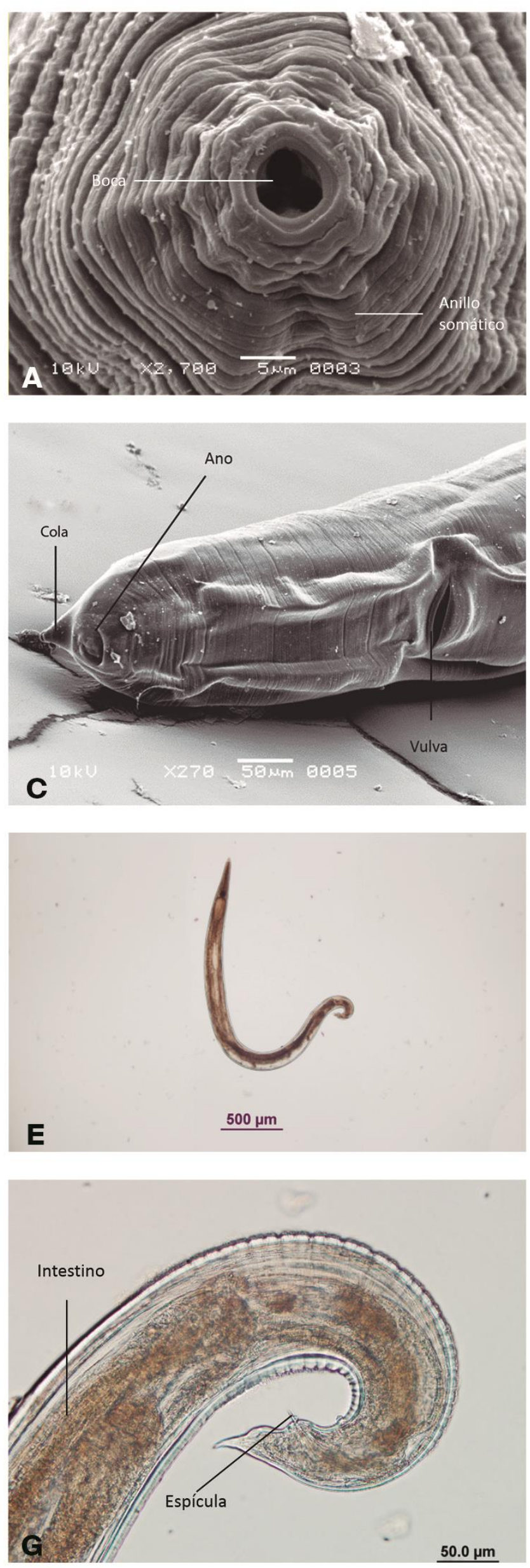
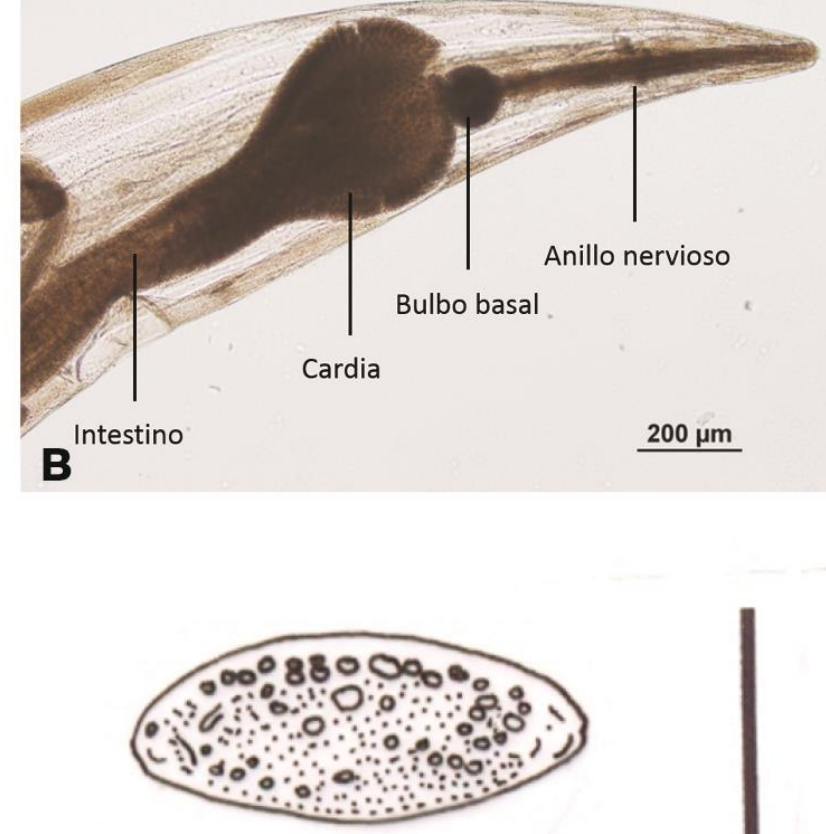

D
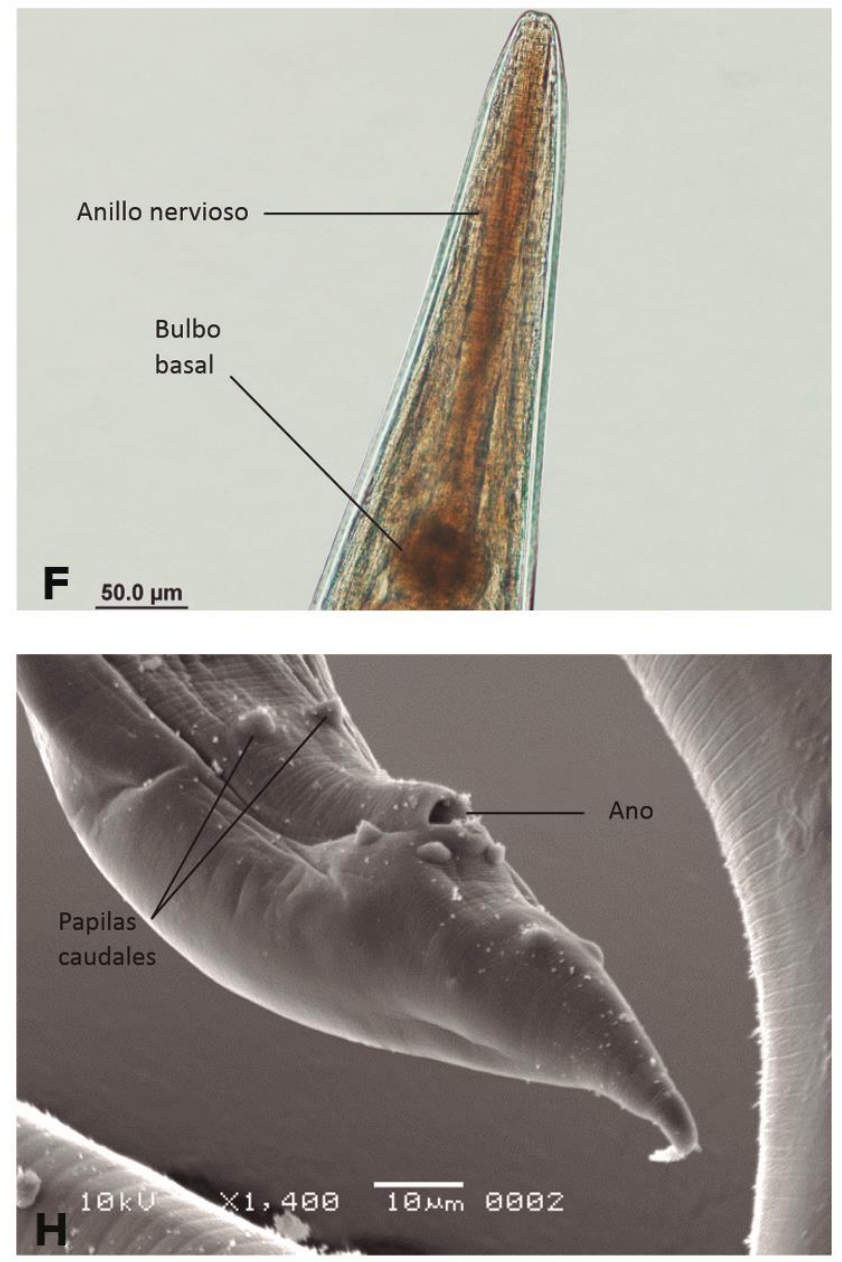
Figura 36. Blatticola cristovata. (A-D). Hembra. A. Detalle de la región bucal vista al M.E.B. B. Extremo cefálico. C. Detalle de la vulva y el ano, vistos al M.E.B. D. Huevos (escala: $20 \mu \mathrm{m}$ ). (E-F). Macho. E. V ista general. F. Extremo cefálico. G. Extremo caudal, vista lateral. H. Extremo caudal, visto al M.E.B. *Figuras A, C y H, extraídas de Achinelly y Camino, 2007.

\section{Género Cameronia}

\section{Descripción}

\section{Cameronia n. sp.}

Figura $37(\mathrm{~A}-\mathrm{I})$

\section{General}

La hembra se caracterizó por poseer una cutícula anillada a lo largo de todo el cuerpo, mayormente pronunciada en la región cefálica. El segundo anillo cefálico de mayor tamaño que el primero. Cavidad bucal corta. Estoma provisto de 2 dientes cuticulares desarrollados al nivel del segundo anillo cefálico. Esófago largo, formado por un corpus, un istmo y un bulbo basal valvado. Poro excretor situado en una posición muy posterior al bulbo basal. Vulva ubicada en el tercio posterior del cuerpo. Vagina dirigida posteriormente. Cola cónica. Huevos elongados, con forma elíptica y sin filamentos polares que se disponían en tríadas o tétradas. Cada una de estas tríadas y tétradas se hallaron fusionadas a lo largo de sus superficies achatadas.

El macho no se encontró en los muestreos efectuados.

Hembras ( $\mathrm{n}=3$ ): longitud total: $3012 \pm 186,6$ (2880-3144), ancho a nivel de las papilas cefálicas: 18, distancia del anillo nervioso al extremo anterior: 112,5 \pm 6,36 (108-117), ancho a nivel del anillo nervioso: 85,5 $\pm 6,36$ (81-90), longitud del esófago: $351 \pm 12,7$ (342-360), distancia del bulbo al extremo anterior: $279 \pm 12,7$ (270-288), distancia del poro excretor al extremo anterior: 499,5 $\pm 6,36$ (495-504), ancho medio: 184,5 $\pm 6,36$ (180-189), ancho a nivel de la vulva: 175,5 $\pm 6,36$ (171-180), longitud de la vulva: 9, ancho de la vulva: $18, \mathrm{~V}: 74,6 \% \pm 0,01(73,5 \%-75,8 \%)$, ancho posterior: $108 \pm 13,7$ (99-117), longitud de la cola: $225 \pm 25,4$ (207-243), longitud de los huevos: $120 \pm 6,3$ (117-126), ancho de los huevos: 40,5 $\pm 6,3$ (36-45) (ver Anexo, tabla 3) 


\section{RESÚMEN TAXONÓMICO}

Sitio de colecta: Parque Ecológico de Villa Elisa.

Hospedadores infestados en este estudio: $N$. claraziana (ninfas).

Localización: intestino posterior.

\section{COMENTARIOS}

El género Cameronia está representado por 12 especies a nivel mundial. En 1984 Parveen y Jairajpuri describieron a C. klossi. Marchissio y Miralles (1987) describieron a C. arecoensis. Adamson y van Waerebeke (1992 a) citaron a 6 especies en su revisión de la familia Thelastomatidae (ver Anexo, tabla 4). Reboredo y Camino (2001) describieron a C. laplatae mientras que Rizvi y Jairajpuri (2002) a C. basiri. Por último, Shah (2007) describió a C. manipurensis y a C. triovata, esta última basándose solo en la morfología de la hembra.

Cameronia $\mathrm{n}$. sp. se diferencia de C. triovata porque la primera posee dos dientes cuticulares en el estoma y por sus huevos grandes y elípticos sin filamentos polares, fusionados de a tres (tríadas) o de a cuatro (tétradas) a lo largo de sus caras aplanadas. Si bien fue similar en la morfología del esófago, la cola y la posición de la vulva, difirió de ésta en la disposición de los huevos (en C. triovata estaban agrupados solo de a 3 y constaban de filamentos polares). Aunque Cameronia n. sp. y $C$. multiovata son similares en la morfología de la cola, la segunda especie mencionada posee cinco o más huevos en grupo, unidos unos sobre otros. A pesar de que la distancia del poro excretor al extremo anterior de Cameronia sp es similar a la de C. biovata (499,5 vs $500 \mu$ ), las dos especies pueden diferenciarse por el largo del esófago (351 vs $440 \mu$ ), la distancia del anillo nervioso al extremo anterior $(112,5 v s 200 \mu)$ y por el largo de la cola (225 vs $190 \mu$ ). La nueva especie hallada se asemeja a C. laplatae en el ancho de los huevos $(40,5 v s 40 \mu)$, pero se diferencian en la longitud total del cuerpo (3012 vs $4230 \mu$ ), longitud del esófago ( 351 vs $582 \mu$ ), distancia del poro excretor al extremo anterior (499,5 vs $982 \mu$ ) y largo de los huevos (120 vs $98 \mu$ ). Cameronia n. sp. puede ser diferenciada de C. arecoensis por la longitud del esófago (351 vs $600 \mu)$, distancia del anillo nervioso al extremo anterior $(112,5$ vs $270 \mu)$, la posición del poro 
excretor respecto al extremo anterior $(499,5$ vs $870 \mu)$, y el largo del huevo (120 vs 194

$\mu)$.
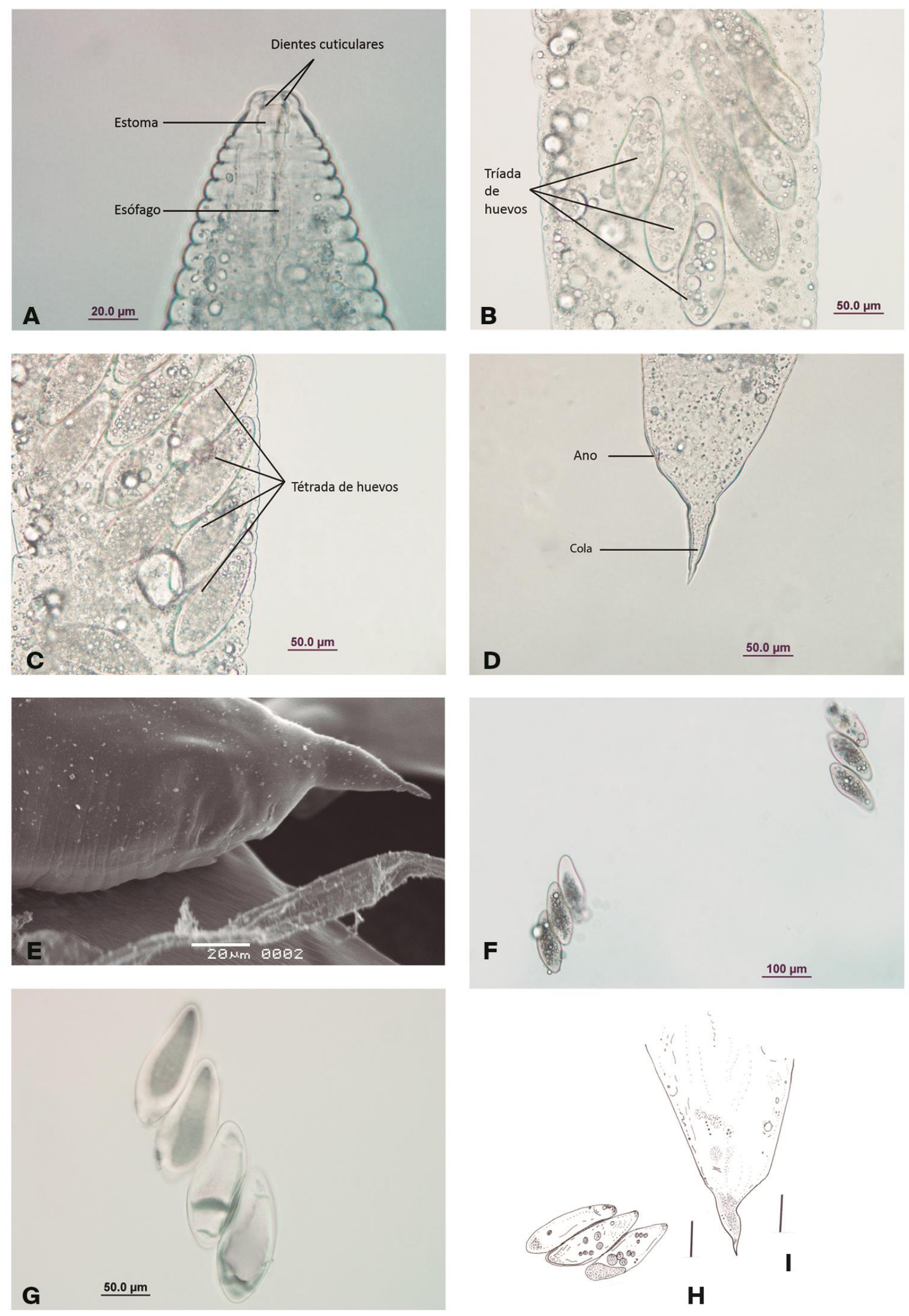
Figura 37. Cameronia n. sp. A. Hembra, extremo cefálico. B. Huevos dispuestos en tríadas en el útero. C. Huevos dispuestos en tétradas en el útero. D. Extremo caudal. E. Extremo caudal, visto al M.E.B. F. Huevos agrupados en tríadas fuera de la hembra. G. Huevos agrupados en tétradas fuera de la hembra. Ilustraciones. H. Huevos (escala: 50 $\mu \mathrm{m})$. I. Extremo caudal (escala: $50 \mu \mathrm{m}$ ).

\section{Género Gryllophila}

Gryllophila skrjabini Sergiev, 1923

\section{Caracterización general}

Figura $38(\mathrm{~A}-\mathrm{G})$

Cutícula visiblemente estriada; el primer anillo de $17 \mu \mathrm{m}$ de ancho; el ancho de los anillos siguientes se incrementó regularmente hasta el noveno que midió $50 \mu \mathrm{m}$; posterior al noveno anillo se mantuvo un ancho de 30 a $40 \mu \mathrm{m}$ regularmente; por detrás de la vulva pudieron decrecer a $10 \mu \mathrm{m}$ solamente. Abertura oral subtriangular, rodeada por una elevación circumoral y ocho labiopapilas; anfidios presentes. Cavidad bucal cilíndrica. Esófago un corpus, un istmo y un bulbo basal. Anillo nervioso ubicado cerca de la finalización del corpus. Poro excretor muy posterior a la base del esófago, cerca de $1 / 3$ de la longitud del cuerpo desde el extremo anterior. Intestino dilatado anteriormente formando un cardia abultado, que se angosta repentinamente en un delgado intestino. Cola cónica atenuada. Vulva situada en el tercio posterior del cuerpo. Dos ovarios, ambos conectados con su respectivo útero al nivel del poro excretor. Útero paralelo en dirección posterior, uniéndose apenas por detrás del nivel de la vulva dando lugar a un útero simple, el cual se dirige anteriormente llegando al nivel del poro excretor donde se replega y corre hacia atrás hasta que encuentra la vagina; vagina larga. Huevos elipsoidales de gran tamaño, con una cáscara gruesa con excrecencias en forma de espinas, puestos en un estadio de dos células y encadenados por una estructura tubular formada probablemente por una secreción mucosa del oviducto. 
El macho no fue recuperado en los muestreos correspondientes.

Hembras ( $\mathrm{n}=3)$ : longitud total: $3451,5 \pm 27,5$ (3432-3471), ancho a nivel de las papilas cefálicas: 18, distancia del anillo nervioso al extremo cefálico: 184,5 \pm 6,36 (180-189), ancho a nivel del anillo nervioso: 202,5 \pm 6,36 (198-207), longitud del esófago: $446 \pm$ 7,07 (441-451), distancia del bulbo al extremo anterior: $329 \pm 7,07$ (324-334), distancia del poro excretor al extremo anterior: 948,5 $\pm 4,9$ (945-952), ancho medio: $445 \pm 5,6$ (441-449), ancho a nivel de la vulva: $322 \pm 9,8$ (315-329), longitud de la vulva: 18, ancho de la vulva: $36, \mathrm{~V}: 74 \% \pm 1$ (73\%-75\%), ancho posterior: 265,5 $\pm 6,3$ (261-270), longitud de la cola: $337,5 \pm 6,3$ (333-342), longitud de los huevos: 147,6 \pm 7,7 (144155), ancho de los huevos: $96 \pm 6,3$ (90-99) (ver Anexo, tabla 3).

\section{RESÚMEN TAXONÓMICO}

Sitio de colecta: Parque Ecológico de Villa Elisa.

Hospedadores infestados en este estudio: N. claraziana.

Localización: intestino posterior.

\section{COMENTARIOS}

El género Gryllophila está representado por cinco especies en el mundo, siendo todas parásitas de grillotopos: Gryllophila skrjabini, G. gryllotalpae Farooqui, 1970, G. nihali Rizvi et al., 2002, G. basiri Malti, 2014 y G. cephalolobulata Camino y Maiztegui, 2002 esta última para Argentina.

Los caracteres de importancia diagnóstica para la clasificación de las especies de este género incluyen una posición del poro excretor muy posterior a la base del esófago, intestino dilatado anteriormente formando un cardia voluminoso, vulva en el tercio posterior del cuerpo, y huevos muy grandes, elipsoidales, con o sin excrecencias en forma de espinas. 
Gryllophila skrjabini constituye el primer registro para la Argentina y amplía la lista de especies hospedadoras al haberse encontrado en Neocurtilla claraziana (Gryllotalpidae).
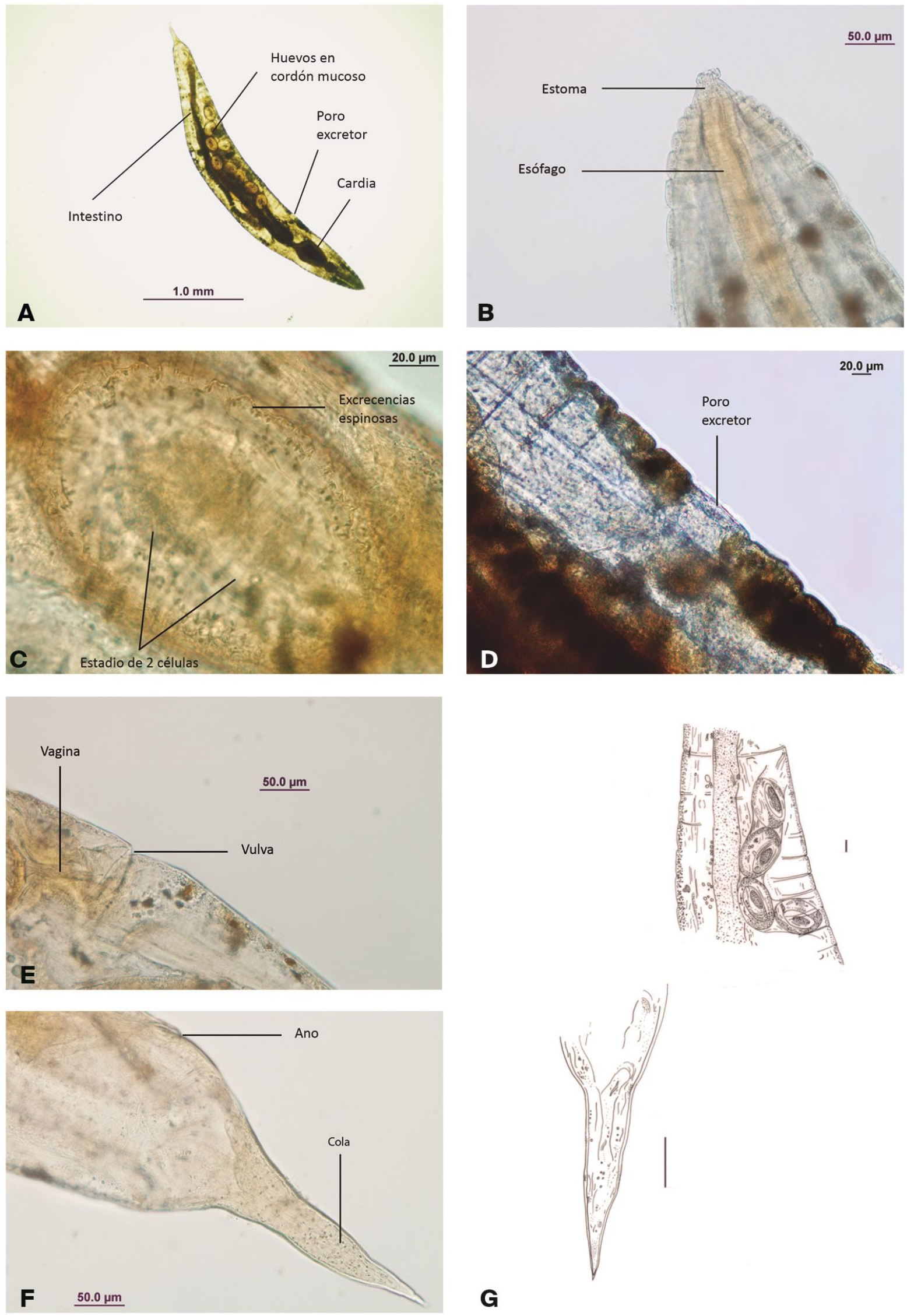
Figura 38. Gryllophila skrjabini. A. Hembra, vista general. B. Extremo cefálico. C. Detalle del huevo, con proyecciones en forma de espinas. D. Detalle del poro excretor.

E. Región vulvar. F. Región caudal. Ilustraciones. G. Huevos dentro de la hembra (escala: $20 \mu \mathrm{m}$ ) y extremo caudal (escala: $20 \mu \mathrm{m}$ ).

\section{Orden Plectida}

\section{Superfamilia Plectoidea}

\section{Familia Plectidae}

\section{Subfamilia Plectinae}

\section{Género Plectus}

Plectus parietinus Bastian, 1865

\section{Caracterización general}

Figura 39 (A-D)

Cuerpo grande y robusto, ventralmente arqueado. Cutícula gruesa, especialmente en la región cefálica. Campos laterales aproximadamente de 1/8 del ancho del cuerpo. Glándulas hipodermales grandes y numerosas. Cabeza separada por una constricción, labios conoides separados. Seta cefálica corta, dirigida anteriormente. Anfidios muy grandes. Estoma de 24-26 $\mu \mathrm{m}$ de largo. Esófago con un bulbo fuerte. Recto tan largo como el diámetro del ano. Cola corta, 2,4-3 veces del diámetro a nivel del ano.

El macho no fue encontrado en los muestreos realizados.

Hembra ( $\mathrm{n}=1)$ : longitud total: 1056, ancho a nivel de las papilas cefálicas: 9 , longitud del esófago: 243, distancia anterior al bulbo: 216, ancho medio: 54, ancho a nivel de la vulva: 36, longitud de la vulva: 9, ancho de la vulva: 9, V: 51\%, ancho posterior: 36 , longitud de la cola: 81 (ver Anexo, tabla 3). 


\section{RESÚMEN TAXONÓMICO}

Sitio de muestreo: Plazoleta de diag. 113 y 64.

Hospedadores infestados en este estudio: A. muticus (ninfa).

Localización: intestino medio.

\section{COMENTARIOS}

Dentro del orden Plectida, el género Plectus es el más ampliamente distribuído con 79 especies válidas y 24 de estatus incierto. Está distribuído por todo el mundo, tanto en hábitats terrestres como de agua dulce, suelos húmedos y arenosos cerca de la playa (Holovachov y Bolstrom, 2010).

Según Maggenti, 1991 la familia Plectidae establece relaciones foréticas con insectos, generalmente cuando los miembros de ambos grupos ocupan el mismo nicho ecológico. No existen registros de parasitismo hasta el momento.

Respecto a este género, durante los muestreos, un ejemplar de $P$. parietinus fue hallado en el intestino de un A. muticus. Debido a que las especies de Plectus son de vida libre, se piensa que el hecho de haber sido encontrado en el intestino de un grillo podría deberse o a un evento azaroso durante la alimentación del insecto, o a un caso de foresis interna lo cual no pudo ser comprobado durante el desarrollo de este estudio. 

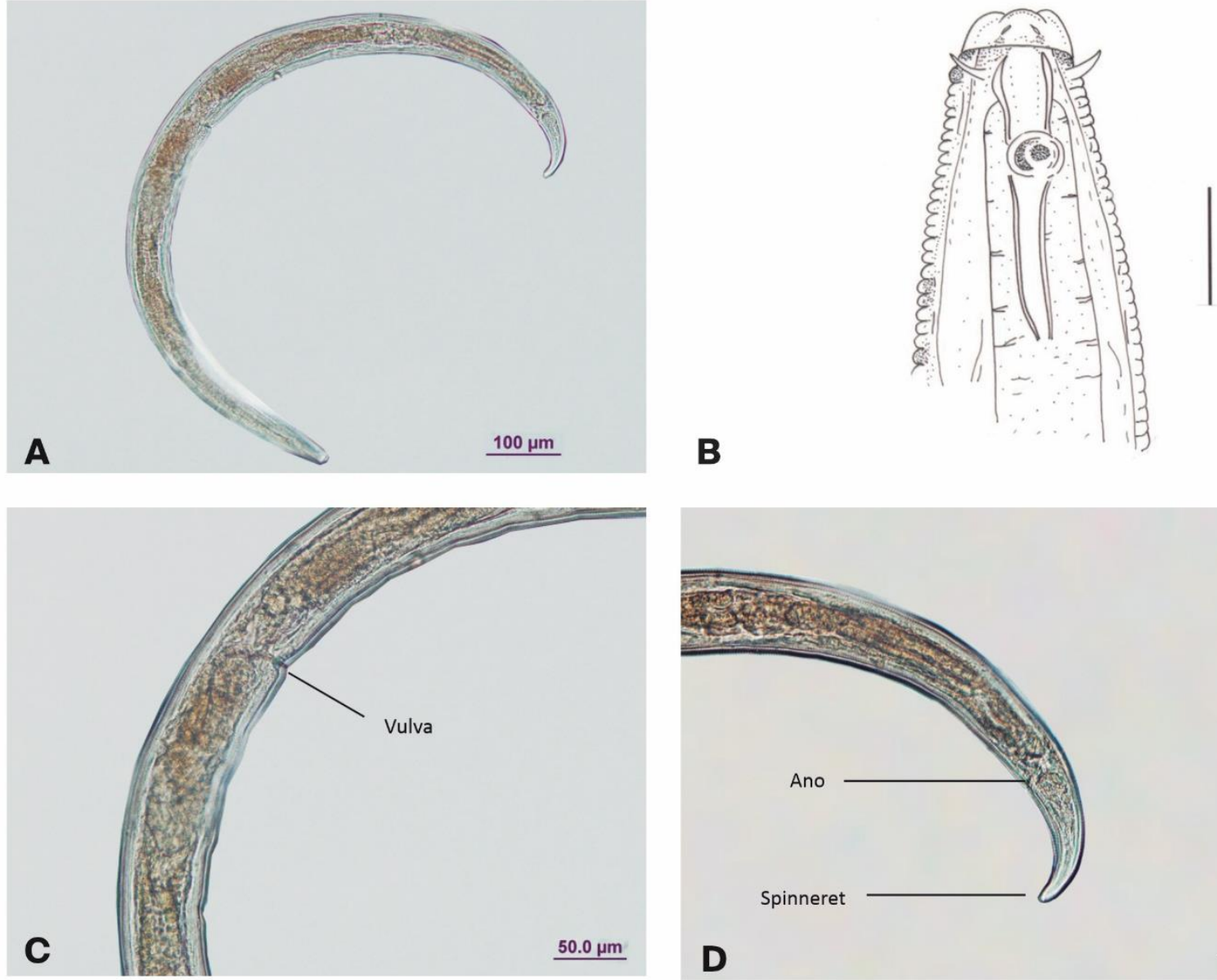

B

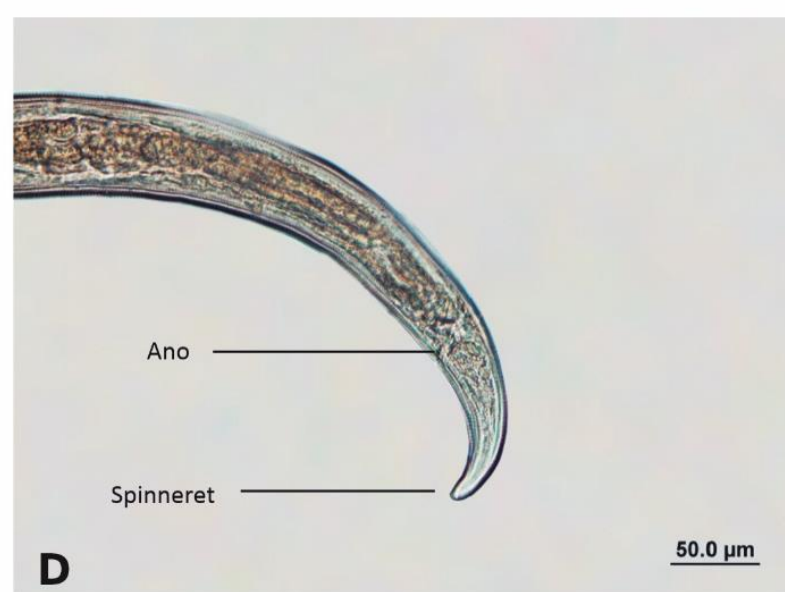

Figura 39. Plectus parietinus. A. Hembra, vista general. B. Extremo cefálico (escala: $10 \mu \mathrm{m})$. C. Detalle de la región vulvar, vista lateral. D. Extremo posterior.

\section{RESUMEN DEL MATERIAL HALLADO}

Phylum: Nematoda Rudolphi, 1808

Clase: Secernentea Linstow, 1905

Orden: Rhabditida Chitwood, 1933

Superfamilia: Rhabditoidea (Oerley) Travassos, 1920

Familia: Diplogasteridae Steiner, 1929

Familia: Rhabditidae Oerley, 1880 
Subfamilia: Rhabditinae (Oerley, 1880), Micoletzky, 1922

Género: Cruznema Artigas, 1987

$\checkmark$ Especie: Cruznema tripartitum (Linstow, 1906), Zullini, 1982

Familia: Cephalobidae Chitwood y McIntosh, 1934

Subfamilia: Cephalobinae Filipjev, 1934

Género: Cephalobium Cobb, 1920

Especie: Cephalobium nitidum Artigas, 1929

Orden: Oxyurida

Superfamilia: Thelastomatoidea

Familia: Travassosinematidae Rao, 1958

Género: Binema Travassos, 1925

$\checkmark$ Especie: Binema bonaerensis Camino y Reboredo, 1999

$\checkmark \quad$ Especie: Binema klossae Marchissio y Miralles, 1993

$\checkmark \quad$ Especie: Binema sp.

Familia: Thelastomatidae Travassos, 1929

Subfamilia: Thelastomatinae Travassos, 1920

Género: Cephalobellus Cobb, 1920

$\checkmark$ Especie: Cephalobellus magalhaesi Schwenk, 1926

Género: Blatticola Schwenk, 1926

$\checkmark$ Especie: Blatticola cristovata Achinelly y Camino, 2007

Género: Cameronia Basir, 1948

$\checkmark \quad$ Especie: Cameronia n. sp. 
Género: Gryllophila Basir, 1942

$\checkmark$ Especie: Gryllophila skrjabini Sergiev, 1923

Orden Plectida Malakhov, 1982

Superfamilia Plectoidea Orley, 1880

Familia Plectidae Orley, 1880

Subfamilia Plectinae

Género Plectus Bastian, 1865

Especie: Plectus parietinus Bastian, 1865

\section{MORTALIDAD POR NEMATODOS ENTOMOPATÓGENOS (NEPS) EN ORTÓPTEROS DEL SUELO}

\section{Aplicación por suspensión}

Los grillos infectados con $H$. bacteriophora presentaron una coloración rojiza que contrastó con el color verde-amarronado de aquellos no infectados (Fig. 40). Se obtuvo un valor de $10 \%$ de mortalidad con la suspensión de $5.000 \mathrm{JIs} /$ recipiente, 55,5\% con $10.000 \mathrm{JIs} /$ recipiente y $22,3 \%$ con $15.000 \mathrm{JIs}$ por recipiente. Los grillos murieron aproximadamente 4 días después de efectuada la infección para los tres tratamientos.

La producción promedio de nematodos obtenida por concentración fue de 96.600 JIs (5000 JIs/recipiente), 55.145 JIs (10.000 JIs/recipiente) y 79.880 JIs (15.000).

Aplicación utilizando cadáveres

Se detectaron grillos infectados que también presentaron la coloración rojiza característica (Fig. 41). La mortalidad obtenida fue de un 55,5\% y los grillos murieron entre 3 y 5 días luego de realizada la infección. La producción promedio de nematodos obtenida fue de $28.220 \mathrm{JIs}$ con un rango entre 25.000 y 30.000 . 
En ambas aplicaciones realizadas, los nematodos pudieron completar su ciclo biológico. Fueron observados tanto formas infectivas como adultos (Figs. 42, 43, 44 y 45).

Bajo ambos tratamientos, los nematodos fueron capaces de completar su ciclo biológico.

Se compararon de a pares, todas las combinaciones posibles de las dosis utilizando un test de Fisher exacto. Los resultados fueron los siguientes:

$\begin{array}{lc}\text { COMPARACIÓN } & \text { P-VALOR } \\ \text { C 5000-C 10000 } & 0,131 \\ \text { C 5000-C 15000 } & 1,000 \\ \text { C 10000-C 15000 } & 0,335 \\ \text { C 5000-Cadáveres } & 0,131 \\ \text { C 10000-Cadáveres } & 1,000 \\ \text { C 15000- Cadáveres } & 0,335\end{array}$

Al mostrar cada una de las comparaciones $p$-valores mayores a $\alpha=0,05$, no fue posible encontrar diferencias significativas entre ellas. 


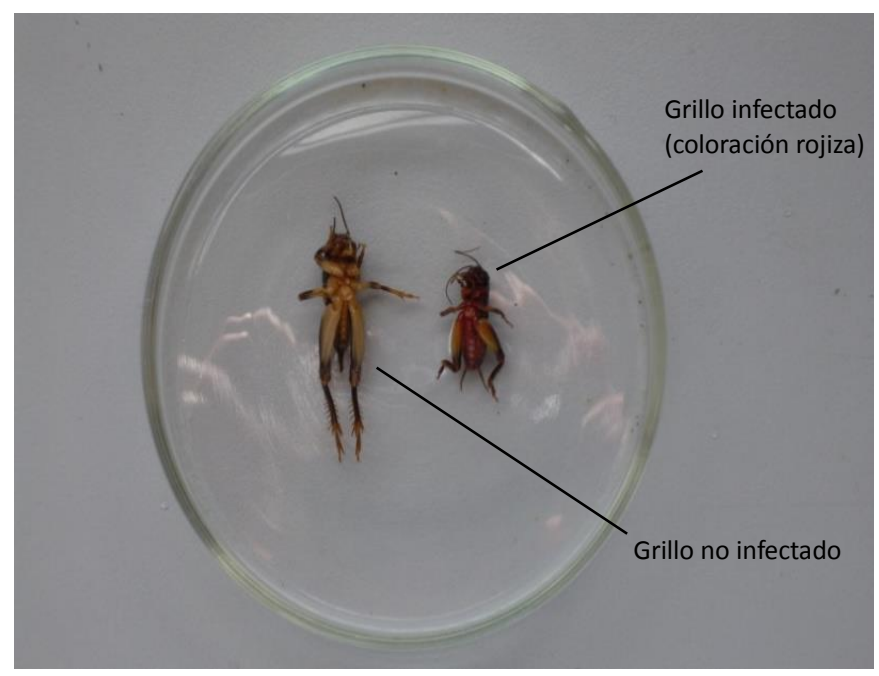

Figura 40. Comparación entre un grillo infectado y uno no infectado

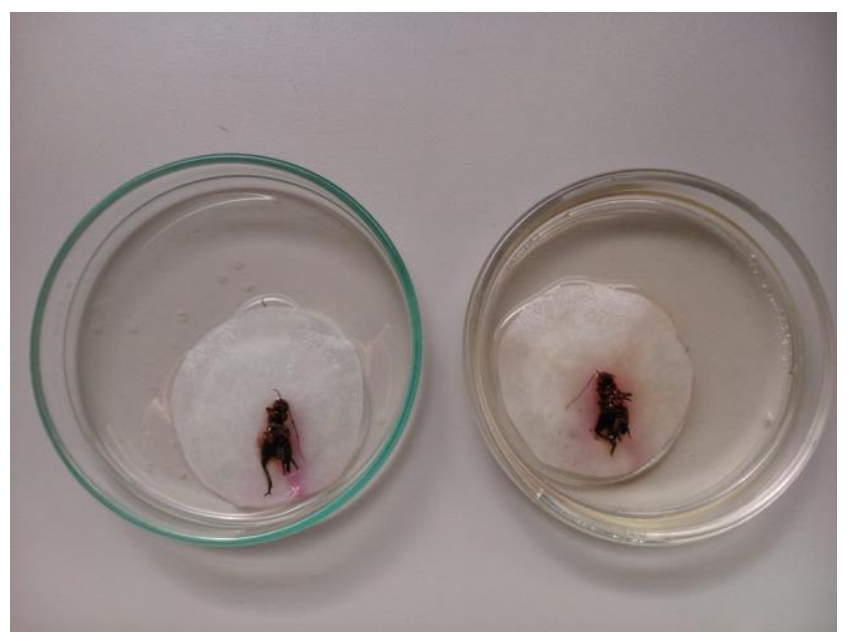

Figura 41. Grillos infectados con H. bacteriophora en Trampa de White 


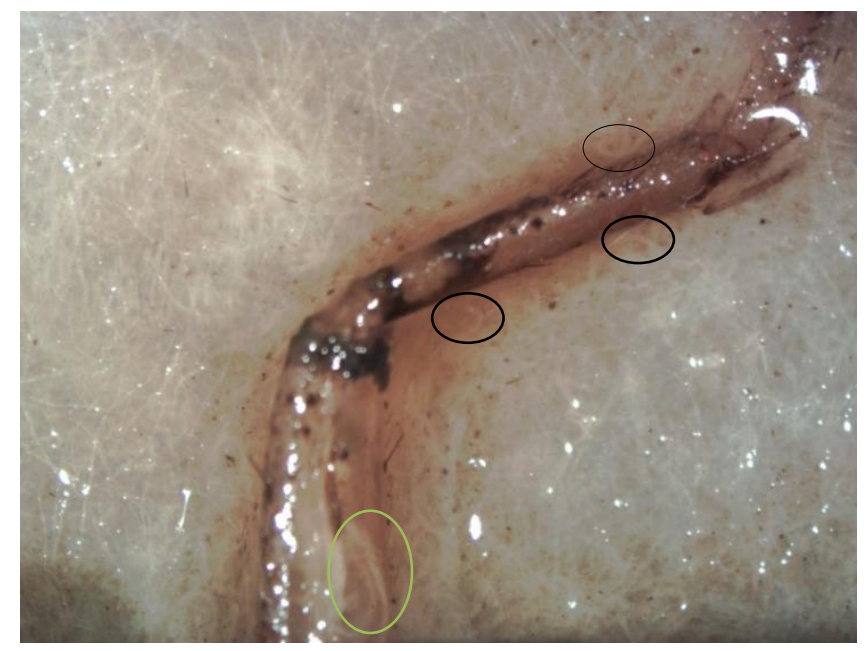

Figura 42. Formas infectivas de H. bacteriophora emergiendo del hospedador (óvalos negros) y adultos (óvalo verde)

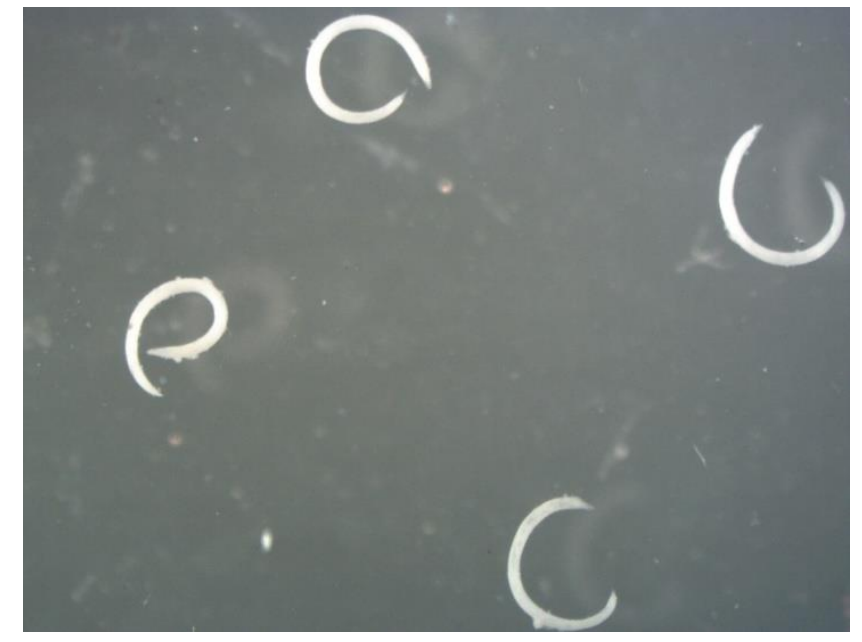

Figura 43. Hembras de H. bacteriophora 


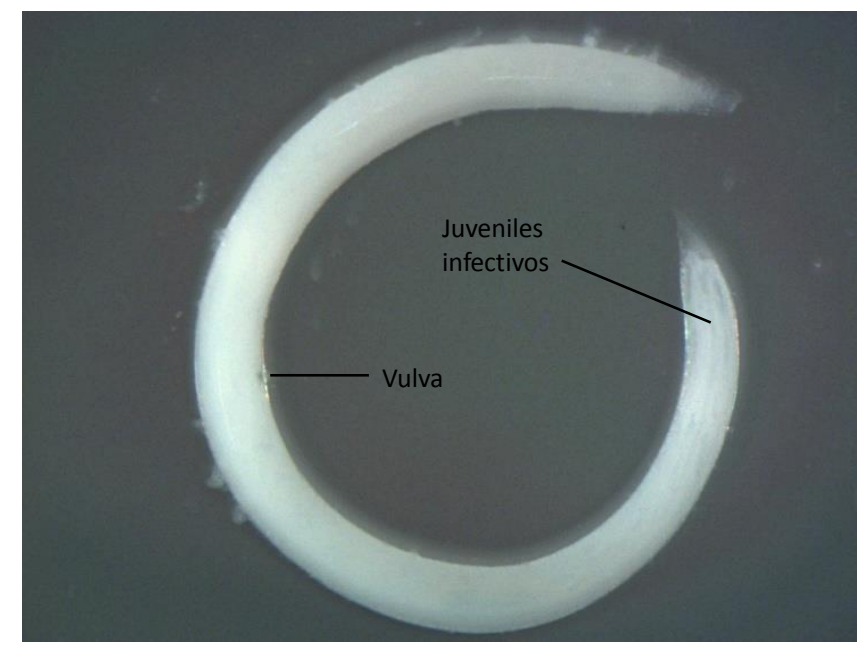

Figura 44. Hembra portando los juveniles (matricida)

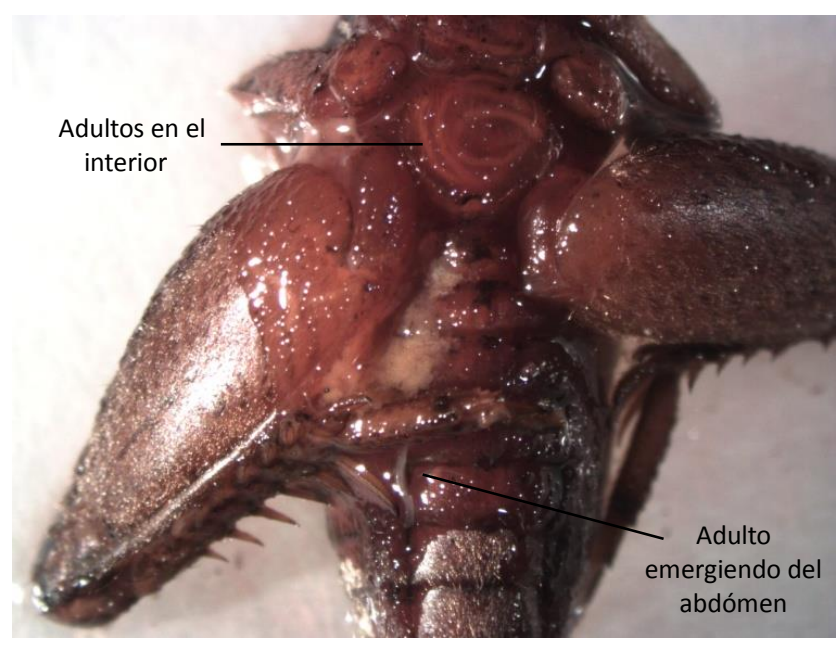

Figura 45. H. bacteriophora en tórax y abdómen

\section{CARACTERIZACIÓN ECOLÓGICA DE LOS EJEMPLARES ENCONTRADOS}

Once especies de nematodos fueron halladas en ambos hospedadores de las cuales tres se registraron en $A$. muticus, siete en $N$. claraziana y una compartida, $B$. cristovata. La mayoría de los individuos registrados pertenecieron a los órdenes Oxyurida y Rhabditida (una especie al orden Plectida), siendo parásitos del tracto digestivo y no mostrando letalidad para sus hospedadores. 


\section{$\underline{\text { Nematodos adultos }}$}

En las tablas 2 y 3 se muestran el total de nematodos adultos (machos y hembras) encontrados en las dos especies de ortópteros. El número de nematodos registrados asciende a 859. Como se puede apreciar la especie más abundante en ambos insectos fue Blatticola cristovata con un total de 346 individuos (Tablas 3 y 4), seguido de Cephalobium nitidum con 238 en A. muticus, donde también se encontró a la especie Plectus parietinus, con el menor número de ejemplares $(\mathrm{n}=1)$ (Tabla 4$)$.

\begin{tabular}{|l|c|c|c|}
\hline Especie de nematodo encontrada en N. claraziana & Número de machos & Número de hembras & Total \\
\hline Blatticola cristovata & 2 & 221 & 223 \\
Binema klossae & & 3 & 3 \\
Binema sp & & 53 & 53 \\
Binema bonaerensis & & 72 & 72 \\
Cephalobellus magalhaesi & & 130 & 130 \\
Cameronia n. sp & & 3 & 3 \\
Gryllophila skrjabini & & 3 & 3 \\
& & & 487 \\
\hline
\end{tabular}

Tabla 2. Número total y sexo de nematodos adultos encontrados en N. claraziana

\begin{tabular}{|l|c|c|c|}
\hline Especie de nematodo encontrada en A. muticus & Número de machos & Número de hembras & Total \\
\hline Blatticola cristovata & 3 & 120 & 123 \\
Cephalobium nitidum & 84 & 154 & 238 \\
Cruznema tripartitum & 5 & 5 & 10 \\
Plectus parietinus & & 1 & 1 \\
& & & 372 \\
\hline
\end{tabular}

Tabla 3. Número total de nematodos adultos encontrados en A. muticus 
En la figura 46 se muestra el porcentaje total de nematodos adultos hallados. La especie más abundante correspondió a B. cristovata con un 40,61\% del total de especies de nematodos registradas.

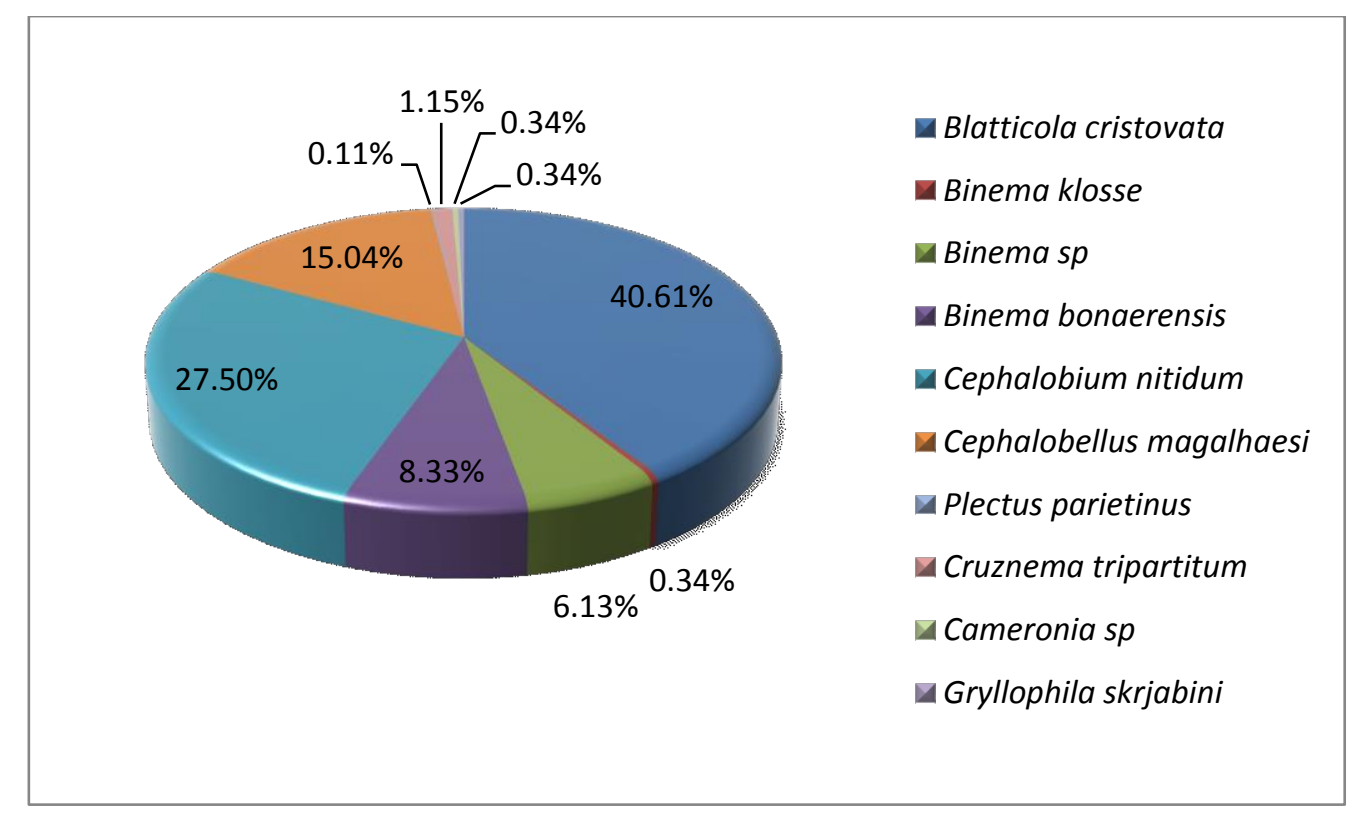

Figura 46. Porcentaje total de nematodos adultos

\section{$\underline{\text { Machos }}$}

En la figura 47 se muestran los porcentajes de los machos correspondientes a las especies encontradas. Fueron evidenciados machos en tres especies: B. cristovata, $C$. nitidum y C. tripartitum. Cephalobium nitidum tuvo el más alto porcentaje (89,33\%), seguido de B. cristovata (5,30\%) y C. tripartitum (5,30\%). 


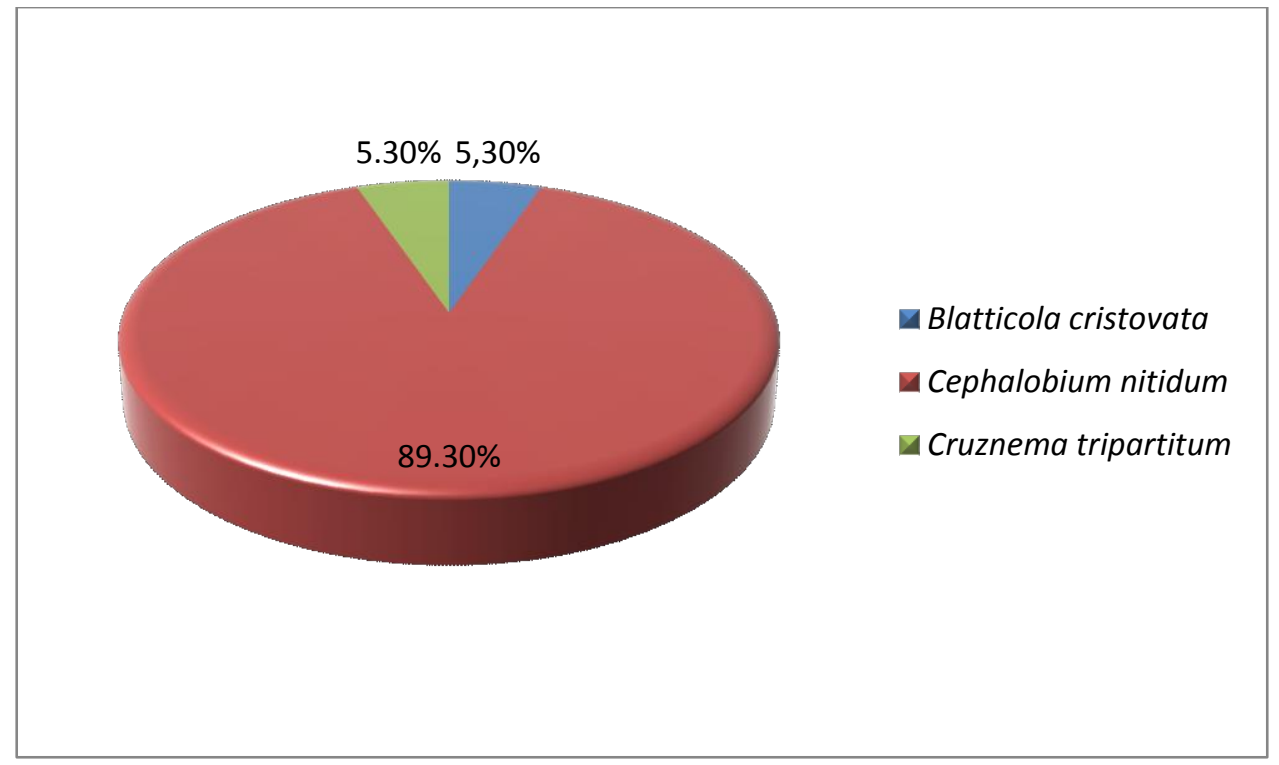

Figura 47. Porcentaje de machos hallados en los muestreos

\section{$\underline{\text { Hembras }}$}

La figura 48 muestra el porcentaje de hembras que corresponden a las especies encontradas. Blatticola cristovata fue la más numerosa con un $45,42 \%$, seguida de $C$. nitidum con $20,02 \%$. Con $0,13 \%$, la especie P. parietinus mostró los valores más bajos. 


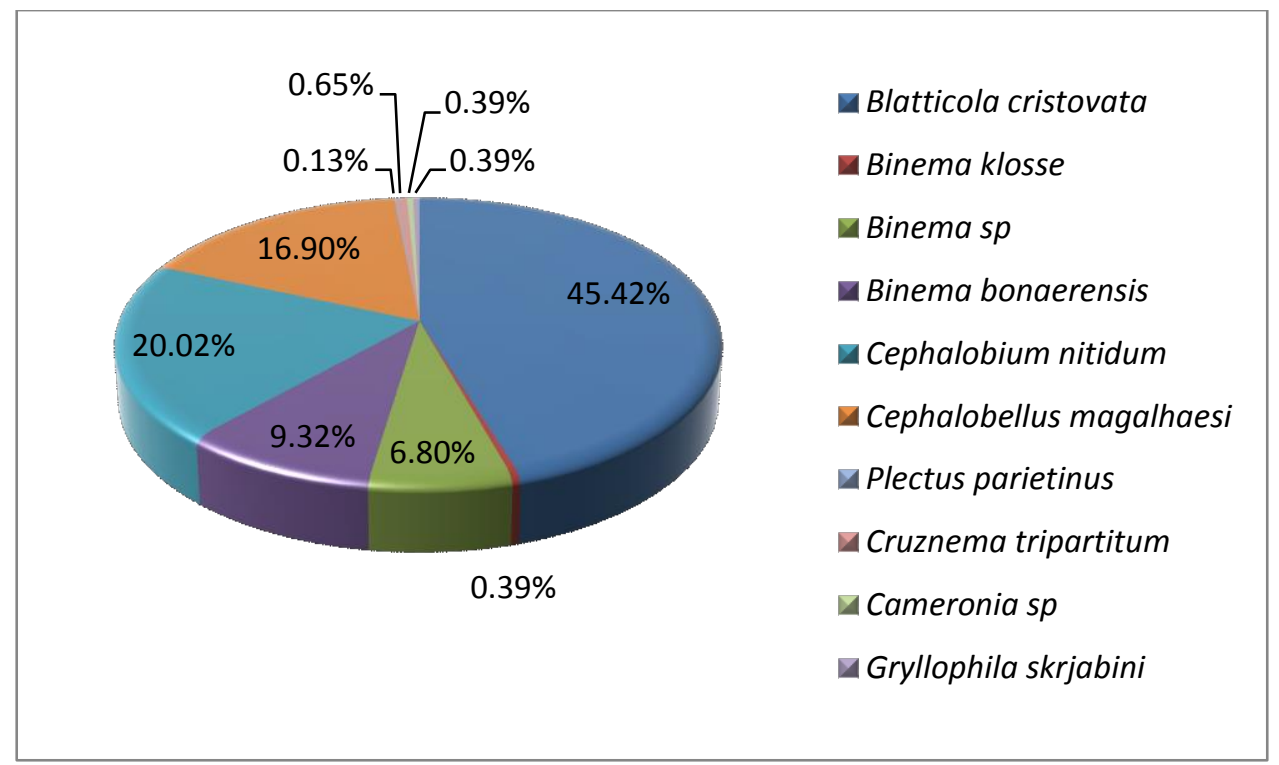

Figura 48. Porcentaje de hembras halladas en los muestreos

\section{$\underline{\text { Juveniles }}$}

Las tablas 4 y 5 proporcionan información acerca del número total de juveniles hallados en grillos y grillotopos. Se hallaron juveniles en tres especies de nematodos $(C$. nitidum, C. magalhaesi y B. cristovata) y en la familia Diplogasteridae. Cephalobium nitidum fue la especie con el número más alto de individuos juveniles, con un total de 42.

\begin{tabular}{|l|c|}
\hline Juveniles encontrados en N. claraziana & Número \\
\hline Blatticola cristovata & 3 \\
Diplogasteridae & 2 \\
\hline
\end{tabular}

Tabla 4. Número de juveniles encontrados en N. claraziana

\begin{tabular}{|l|c|}
\hline Juveniles encontrados en A. muticus & Número \\
\hline Cephalobium nitidum & 42 \\
Cephalobellus magalhaesi & 16 \\
\hline
\end{tabular}

Tabla 5. Número de juveniles encontrados en A. muticus 
La figura 49 refleja el porcentaje de juveniles de las especies halladas en ambc hospedadores. Cephalobiumm nitidum presentó el mayor porcentaje (61\%), mientras qu los representantes de la familia Diplogasteridae, el menor con un 3\%.

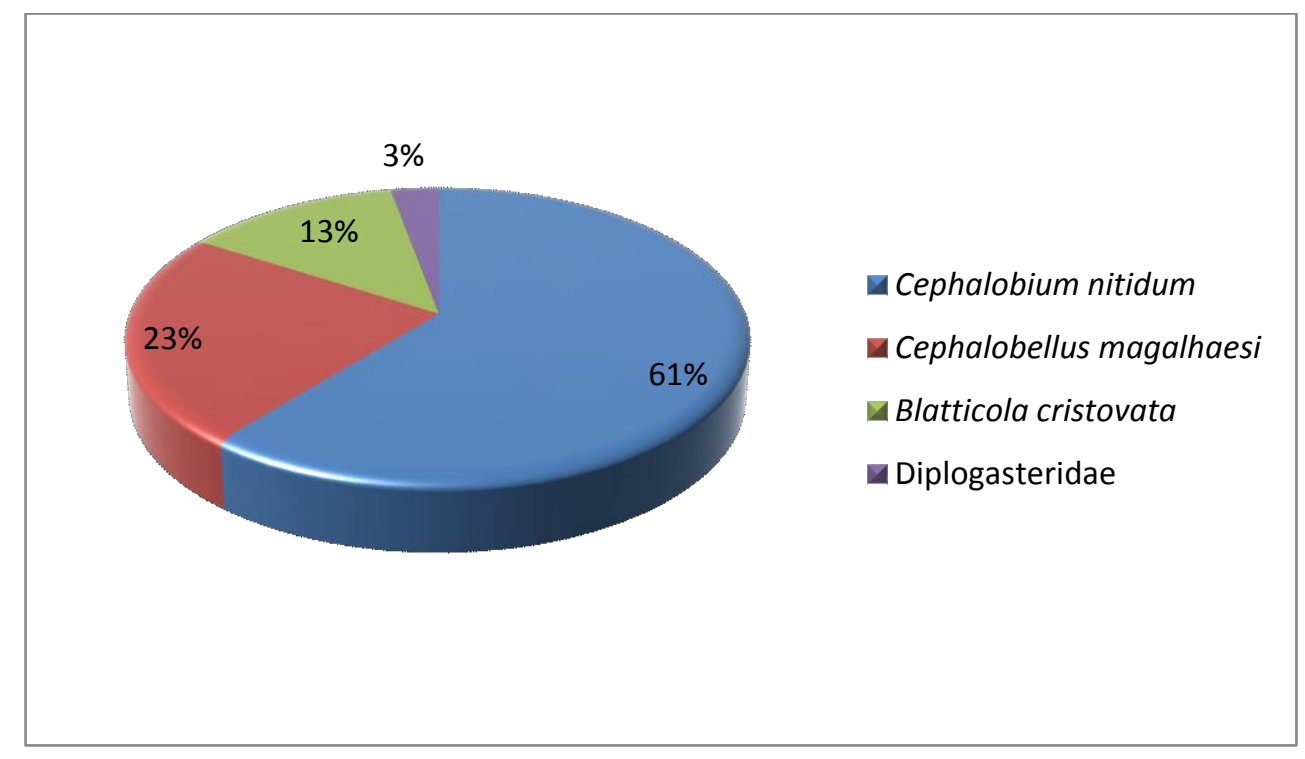

Figura 49. Porcentaje de juveniles hallados en los muestreos

\section{$\underline{\text { Índices parasitarios }}$}

La Tabla 6 muestra los índices parasitarios para las dos especies de hospedadores. En A. muticus la especie C. nitidum fue la que presentó los valores más altos de abundancia $(0,31)$, dominancia $(63,91 \%)$ e intensidad media $(59,5)$, mientras que Blatticola cristovata mostró los valores más elevados de prevalencia (14,8\%). Por otra parte, en $N$. claraziana la especie $B$. cristovata evidenció los valores más elevados de prevalencia con un 22,71\%, una dominancia de 45,6\% y una abundancia de 0,70. Binema bonaerensis mostró la intensidad media más elevada $(3,42)$. Los valores mínimos de dominancia en $N$. claraziana se dieron en los juveniles de la familia Diplogasteridae $(0,40 \%)$, los de intensidad en Binema sp. $(1,29)$, los de prevalencia en Cameronia n. sp, G. skrjabini, B. klossae y en los juveniles de los diplogastéridos $(0,31 \%)$ y finalmente los de abundancia en los juveniles de la familia Diplogasteridae $(0,006)$. 


\begin{tabular}{|c|c|c|c|c|c|c|c|c|}
\hline & \multicolumn{4}{|c|}{ Gryllidae } & \multicolumn{4}{|c|}{ Gryllotalpidae } \\
\hline \multirow[t]{2}{*}{ Especies de nematodos } & \multicolumn{4}{|c|}{ Anurogryllus muticus } & \multicolumn{4}{|c|}{ Neocurtilla claraziana } \\
\hline & $\mathrm{P}$ & I & $\mathrm{A}$ & $\mathrm{D}$ & $\mathrm{P}$ & $\mathrm{I}$ & $\mathrm{A}$ & $\mathrm{D}$ \\
\hline \multicolumn{9}{|l|}{ Thelastomatidae } \\
\hline Blatticola cristovata & $14,8 \%$ & 1,10 & 0,16 & $33,06 \%$ & $22,71 \%$ & 3,09 & 0,70 & $45,6 \%$ \\
\hline Cephalobellus magalhaesi & & & & & $17,9 \%$ & 2,28 & 0,41 & $26,58 \%$ \\
\hline Gryllophila skrjabini & & & & & $0,31 \%$ & 3 & 0,009 & $0,61 \%$ \\
\hline Cameronia $\mathrm{n} . \mathrm{sp}$ & & & & & $0,31 \%$ & 3 & 0,009 & $0,61 \%$ \\
\hline \multicolumn{9}{|l|}{ Travassosinematidae } \\
\hline Binema bonaerensis & & & & & $6,62 \%$ & 3,42 & 0,22 & $14,72 \%$ \\
\hline Binema sp & & & & & $12,93 \%$ & 1,29 & 0,16 & $10,83 \%$ \\
\hline Binema klossae & & & & & $0,31 \%$ & 3 & 0,009 & $0,61 \%$ \\
\hline \multicolumn{9}{|l|}{ Cephalobidae } \\
\hline Cephalobium nitidum & $0,53 \%$ & 59,5 & 0,31 & $63,91 \%$ & & & & \\
\hline \multicolumn{9}{|l|}{ Rhabditidae } \\
\hline Cruznema tripartitum & $0,68 \%$ & 2 & 0,01 & $2,68 \%$ & & & & \\
\hline \multicolumn{9}{|l|}{ Plectidae } \\
\hline Plectus parietinus & $0,13 \%$ & 1 & 0,001 & $0,26 \%$ & & & & \\
\hline Diplogasteridae & & & & & $0,31 \%$ & 2 & 0,006 & $0,40 \%$ \\
\hline
\end{tabular}

Tabla 6. Indices parasitarios: P: prevalencia; I: intensidad media; A: abundancia; D: dominancia

El Coeficiente de similaridad de Sørensen, valor que expresa el grado de semejanza entre comunidades, otorgó un valor de 0,16. Este resultado indica que las comunidades de parásitos presentes en las dos especies de grillos son semejantes en un 16\%. El Indice de Shannon-Weaver arrojó un valor de 1,77 para N. claraziana y de 1,12 para A. muticus.

\section{$\underline{\text { Análisis de comunidad componente }}$}

Ninguna de las especies de nematodos superó una prevalencia del $23 \%$, por lo que no se podría hablar de especies centrales ni secundarias en este estudio según los criterios establecidos por Bush et al. (1997) (Figs. 50 y 51). 


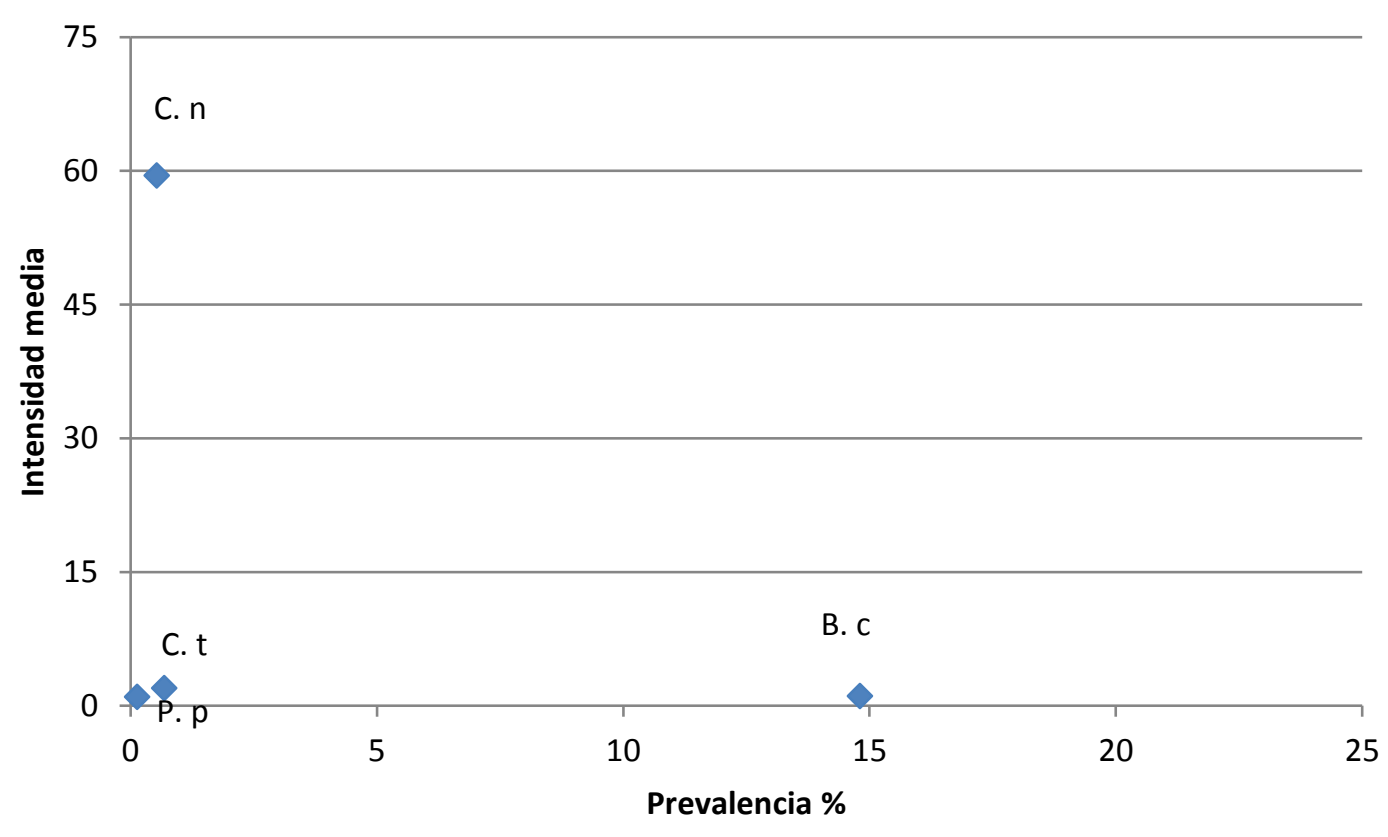

Figura 50. Intensidad media en relación a la prevalencia de las especies de nematodos en A. muticus. Ref: B. c: B. cristovata, C. n: C. nitidum, C. t: C. tripartitum, P. p: P. parietinus. 


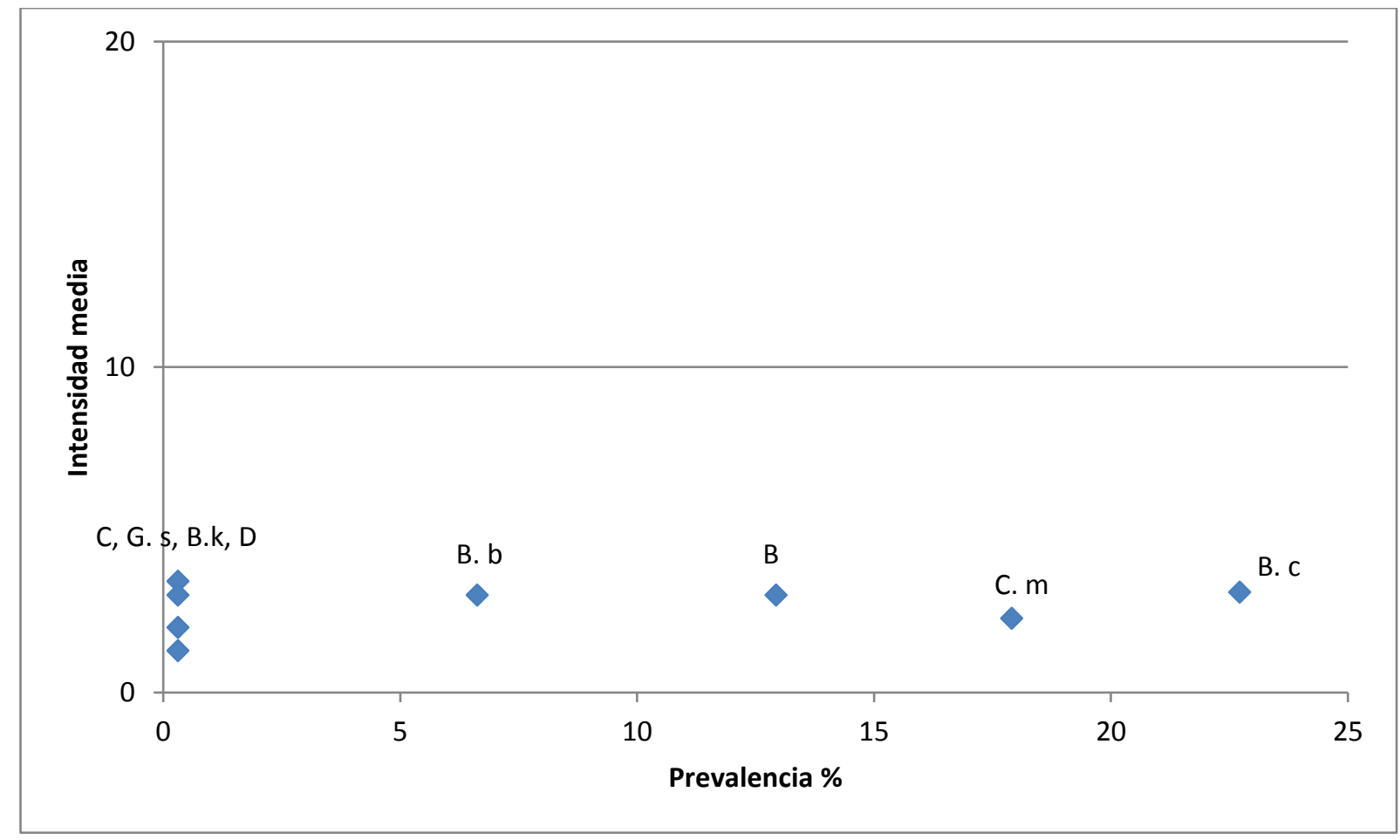

Figura 51. Intensidad media en relación a la prevalencia de las especies de nematodos en N. claraziana. Ref: B. c: Blatticola cristovata, B: Binema sp., B. b: Binema bonaerensis, B. k: Binema klossae, G. s: Gryllophila skrjabini, C: Cameronia n. sp., C. m: Cephalobellus magalhaesi, D: Diplogasteridae.

Durante los muestreos se recolectaron en las madrigueras relevadas de grillos y grillotopos ejemplares pertenecientes a las familias Lycosidae (Arachnida: Araneae) y Scarabaeidae (Insecta: Coleoptera). La especie correspondiente a la primera familia mencionada se identificó como Lycosa thorelli Keyserling, 1877. El representante de la familia Scarabaeidae fue identificado como la especie Diloboderus abderus Sturm, 1826. 


\section{DISCUSIÓN}

Once especies de nematodos pertenecientes a cinco familias fueron aisladas a partir de ninfas y adultos de grillos y grillotopos: Cruznema tripartitum, Cephalobium nitidum, Cephalobellus magalhaesi, Binema bonaerensis, Binema klossae, Binema sp., Blatticola cristovata, Cameronia n. sp., Gryllophila skrjabini y Plectus parietinus. Además, se encontraron dos individuos pertenecientes a la familia Diplogasteridae. Debido a que se trató de estadios juveniles, no fue posible su identificación a nivel específico. La mayoría de los individuos registrados pertenecieron al orden Oxyurida $(\mathrm{n}=629)$. Todas las especies, a excepción de C. tripartitum y P. parietinus, mostraron una asociación de tipo parasitaria con los hospedadores.

Thelastomatoidea es una de las dos superfamilias de este orden. Sus miembros parasitan invertebrados, especialmente artrópodos y su taxonomía ha sido tratada separadamente de aquellos que parasitan vertebrados (Oxyuroidea).

Thelastomatoidea presenta una gran diversidad, como puede apreciarse en trabajos realizados por Kloss (1960), Skrjabin et al. (1966) y Poinar (1978). Más recientemente, Adamson y van Waerebeke (1992 a, b, c) reconocen cinco familias dentro de esta superfamilia: Protrelloididae, encontrados solamente en cucarachas; Hystrignathidae, exclusivos de escarabajos pasálidos; Travassosinematidae, citados principalmente en grillotopos; Pseudonymidae, parásitos de escarabajos hidrofílidos y Thelastomatidae, con 31 géneros que parasitan a una gran diversidad de insectos.

La familia Thelastomatidae es sin dudas la más vasta de los Thelastomatoidea, la cual es considerada hasta el momento parafilética por Adamson y van Waerebeke (1992 a) quienes no pudieron encontrar una sinapomorfía que sugiera su monofilia. En el presente trabajo, se encontraron especies correspondientes a cuatro géneros de esta familia: Cephalobellus, Blatticola, Cameronia y Gryllophila. Gryllophila skrjabini y Cephalobellus magalhaesi constituyeron los primeros registros para Argentina, ampliando la lista de especies hospedadoras a $N$. claraziana (Gryllotalpidae). Se describió como nueva especie a Cameronia n. sp. en base a la morfología y disposición de los huevos, los cuales mostraron un patrón único dentro del género.

La familia Travassosinematidae reúne nematodos principalmente de grillotopos, mientras que sólo uno de los géneros (Travassosinema) fue encontrado en diplópodos. 
Tres especies del género fueron aisladas durante los muestreos realizados en la Estación Experimental de Gorina, una de ellas pudiendo ser considerada una nueva especie. Al no hallarse el macho y no tener la hembra caracteres determinantes, no fue posible otorgarle esta categoria taxonómica.

El orden Rhabditida incluye un gran número de nematodos que abarcan un amplio rango de hábitats y que divergen morfológica y ecológicamente, existiendo especies terrestres de vida libre, parásitos de plantas, vertebrados e invertebrados pertenecientes a varias familias (Manzanilla-Lopez y Marbán-Mendoza, 2012).

Entre ellas, los representantes de la familia Cephalobidae son típicamente habitantes de suelo y de residuos de plantas en descomposición. Se alimentan de materia orgánica asociada a bacterias y tal vez de otros microorganismos. A menudo son encontrados en el tejido de plantas suculentas y en hojas de trigo (Thorne, 1961), mientras que algunos géneros como Cephalobium, son parásitos de artrópodos, alojándose en el sistema digestivo. En este sentido, C. nitidum fue hallada asociada al tubo digestivo de ejemplares de $A$. muticus en los muestreos realizados para la localidad de Los Hornos, siendo el primer registro para la Argentina.

La familia Rhabditidae constituye uno de los grupos de nematodos pertenecientes al orden Rhabditida mejor representados. Los representantes de esta familia son de vida libre, generalmente especializados en la alimentación de bacterias (materia orgánica en descomposición) y a menudo se los vincula a animales como hospedadores (Andrassy, 1983).

Cruznema tripartitum es un nematodo de suelo, de vida libre, aislado de $A$. muticus. La foresis es una relación simbiótica en la cual no hay interacción trofica entre los organismos, y en general siendo uno utilizado como medio de transporte (Bush, et al., 2001). Al haberse encontrado machos y hembras de esta especie en el hospedador, sumado a que hay casos de parasitismo dentro del género y a que no se sabe con certeza si hay interrelación trófica entre estos organismos, no sería correcto hablar de este tipo de asociación. El hallazgo en este estudio constituyó el primer registro de esta especie asociada a insectos, por lo cual debería ser analizado en mayor detalle para corroborar el tipo de asociación existente entre nematodo/hospedador. 
Cabe destacar que en ninguna de las asociaciones mencionadas anteriormente se observó coexistencia entre especies de nematodos.

En cuanto a los índices ecológicos en el hospedador $A$. muticus, la especie $C$. nitidum mostró los valores más elevados de intensidad, abundancia y dominancia, mientras que $B$. cristovata otorgó los valores más altos de prevalencia.

Neocurtilla claraziana presentó una mayor diversidad de nematodos que $A$. muticus. Blatticola cristovata también evidenció los valores más elevados de prevalencia, además de dominancia y abundancia, mientras que B. bonaerensis mostró la intensidad más elevada. Los valores mínimos de dominancia se dieron en los juveniles de la familia Diplogasteridae, los de intensidad en Binema sp., los de prevalencia en G. skrjabini, Cameronia n. sp, B. klossae y en los juveniles de los diplogastéridos y finalmente los de abundancia en los juveniles de la familia Diplogasteridae.

El valor del índice de Shannon-Weaver permitió concluir que la diversidad específica en $N$. claraziana fue levemente superior a la de A. muticus $(1,77$ y 1,12 respectivamente).

De acuerdo a los resultados obtenidos con el Coeficiente de similaridad de Sørensen se pudo determinar que el grado de semejanza de la nematofauna presente en las dos especies de hospedadores es pequeño. Solo el $16 \%$ del total de las especies se encontraron presentes en ambas especies de insectos.

No fue posible determinar la presencia de especies centrales y secundarias en ninguno de los hospedadores ya que no hubo una especie de nematodo que presentara una prevalencia superior al $23 \%$.

Muller et al. (2001) evidenciaron bajos niveles de parasitismo y mortalidad con nematodos del Orden Oxyurida, parásitos de cucarachas. Los autores correlacionaron la carga parasitaria, mortalidad y morbilidad en diferentes poblaciones de hospedadores, desarrollando un modelo matemático para estimar el efecto del parásito Blatticola blattae Chabaud, 1974 en la dinámica poblacional de Blattella germanica L., 1767 como hospedador. De acuerdo a este modelo, el parásito suprimió a la población de cucarachas adultas en un $11 \%$, un valor que podría considerarse insuficiente para el control biológico. 
En base a resultados previos obtenidos por otros autores relacionados al ciclo de vida y patogenia, además de lo observado en este trabajo en el cual no se evidenció mortalidad asociada al parasitismo luego de la semana en la que se mantuvieron a los hospedadores vivos, los nematodos pertenecientes a las familias Thelastomatidae, Travassosinematidae, Rhabditidae, Diplogasteridae y Chepalobidae hallados en este estudio, no serían a priori eficaces para controlar o reducir su tamaño poblacional. Es posible que los bajos valores observados en los índices parasitarios, junto con la ausencia de una asociación con una bacteria simbionte, sean la causa de no haber provocado mortalidad en las especies hospedadoras. Además, la relación parásitohospedador se basa en la mayoría de los casos en provocar un daño en este último, sin ocasionarle la muerte.

En lo referente a las experiencias realizadas con $H$. bacteriophora, fue observada una susceptibilidad de ninfas de $A$. muticus hacia el nematodo, con una mortalidad del 55,5\% tanto para la suspensión de 10.000 JIs como la aplicación de cadáveres. Los nematodos fueron capaces de multiplicarse y completar el ciclo dentro de esta especie hospedadora, lo que permitiría el establecimiento y posibilidad de reciclarse en el ambiente. Estos resultados son elevados, si se considera la mortalidad alcanzada en estudios anteriores realizados por Georgis y Poinar (1989) de un 8\%. Concentraciones más elevadas deberían evaluarse para intentar determinar una mayor efectividad sin afectar la reproducción y producción de los nematodos dentro de los insectos hospedadores.

La aplicación de JIs de H. bacteriophora y/o cadáveres de T. molitor como se ensayó en este estudio en laboratorio podría brindar dos vías alternativas para controlar las poblaciones de estos insectos plaga que en principio podrían utilizarse sin la necesidad de formulaciones, lo cual facilitaría la aplicación y producción y disminuiría los gastos. La utilización de cadáveres podría ser un método más eficiente para aplicar a campo, y mantener adecuados niveles de humedad y protección contra los rayos UV, lo cual permitiría una mayor longevidad y supervivencia, que a su vez favorecería el establecimiento en el ambiente. 
Los entomonematodos encontrados en este trabajo de tesis fueron hallados naturalmente en su totalidad en el sistema digestivo de grillos y grillotopos. La mayoría pertenecieron al orden Oxyurida.

El hábito solitario de $A$. muticus y $N$. claraziana, sumado a su alta capacidad de dispersión podría justificar las bajas prevalecias obtenidas para los entomonematodos encontrados.

En el caso de las infecciones experimentales con $H$. bacteriophora los nematodos se hallaron parasitando la cavidad general del cuerpo de los insectos.

El registro de nematodos entomopatógenos en Gryllidae y Gryllotalpidae es escaso en el mundo, existiendo solo un registro en la naturaleza, Steinernema scapterisci parasitando a Scapteriscus borelli, aislado por Stock, (1992) en la localidad de Colón, en Argentina.

Con respecto a la especie $A$. muticus no se vió una gran diversidad de entomonematodos en comparación a Gryllodes laplatae, otra especie de grillos plaga de la provincia de Buenos Aires, siendo descriptas en este último seis especies del género Cephalobium, dos especies del orden Oxyurida, Cameronia laplatae y Neyraiella distinctus (Camino y de Villalobos, 2002) y una del orden Mermithida, Hexamermis macrostomata (Camino y Stock, 1994).

Si consideramos a $N$. claraziana se recuperaron siete especies del orden Oxyurida y una del orden Rhabditida. Estableciendo una comparación con otras especies de grillotopos se observa que $N$. claraziana posee una diversidad de entomonematodos mayor a especies como Gryllotalpa gryllotalpa L., 1758, similar a Gryllotalpa hexadactyla Perty, 1832, pero muy inferior a Gryllotalpa africana. A nivel mundial se han hallado dos especies de thelastomátidos y tres de travassosinemátidos en G. hexadactyla, dos especies de thelastomátidos y seis de travassosinemátidos en $G$. gryllotalpa y finalmente siete especies de thelastomátidos, un rhabdítido (Cruznema brevicaudatum) y 27 especies de travassosinemátidos en G. africana (Adamson y van Waerebeke, 1992 a, b; Singh y Malti, 2003; Shah y Rizvi, 2004; Shah, 2007; Shah et al., 2012).

De los resultados obtenidos se puede concluir que la región del Gran La Plata, es una zona con gran diversidad de entomonematodos oxyúridos parásitos de las familias Gryllidae y Gryllotalpidae. Si bien A. muticus presentó mayor número de individuos, su diversidad de nematodos fue menor con respecto a $N$. claraziana. 
Futuros estudios sobre el ciclo de vida, la longevidad, la estacionalidad y la dinámica parásito-hospedador deben aplicarse para determinar si estas poblaciones de nematodos ejercen algún efecto sobre estos insectos plaga.

Debido a la patogenia obtenida por $H$. bacteriophora este nematodo podría constituir un potencial agente de biocontrol nativo, capaz de ocasionar mortalidad en ejemplares de $A$. muticus, pudiendo completar su ciclo de vida en el hospedador, y aplicable bajo dos posibles vías de introducción. Estudios futuros deberán continuarse para determinar los requerimientos a campo de manera de ejercer un control eficiente, determinando el impacto de los entomonematodos sobre la fauna benéfica asociada y la oportunidad de los tratamientos, para lo cual es importante diseñar estrategias de control. 


\section{CONCLUSIONES}

Se analizaron ninfas y adultos de dos especies de ortópteros plaga, una especie perteneciente a la familia Gryllidae y otra a la familia Gryllotalpidae, halladas en estaciones experimentales, plazas, parques y espacios de recreación de la ciudad de La plata y el Gran La Plata. Esta investigación posibilitó concluir en lo referente a lo taxonómico:

Se hallaron 11 especies de nematodos, recolectados de grillos y grillotopos en estadios ninfales y adultos.

- Se observaron dos tipos de asociación nematodo/insecto: parasitismo (Thelastomatidae, Travassosinematidae, Cephalobidae, Diplogasteridae) y patogenia (Heterorhabditidae).

Los entomonematodos fueron hallados naturalmente en el sistema digestivo de grillos y grillotopos (Thelastomatidae, Travassosinematidae, Cephalobidae, Diplogasteridae) y en cavidad general en infecciones experimentales con $H$. bacteriophora (Heterorhabditidae).

El hallazgo de la especie Plectus parietinus en el sistema digestivo del grillo Anurogryllus muticus correspondería a un evento azaroso durante la alimentación del hospedador.

- $\quad$ Se registraron por primera vez para Argentina las especies Cephalobium nitidum, Cephalobellus magalhaesi y Gryllophila skrjabini.

Cruznema tripartitum constituyó el primer registro de esta especie asociado a insectos.

- $\quad$ Se encontró y describió una nueva especie: Cameronia $\mathrm{n}$. sp.

- $\quad$ Se encontró y describió una posible nueva especie: Binema sp. 
En relación al aspecto ecológico se pudo concluir que:

- $\quad$ En A. muticus la especie más numerosa fue C. nitidum y en N. claraziana fue B. cristovata.

Blatticola cristovata presentó los valores más elevados de frecuencia con un $45,6 \%$ en $N$. claraziana, mientras que en $A$. muticus el mayor valor se vió en $C$. nitidum.

- $\quad$ En ambos hospedadores B. cristovata presentó los valores más elevados de prevalencia.

Cephalobium nitidum evidenció los valores más altos de intensidad en $A$. muticus $(59,5)$, mientras que para $N$. claraziana esto se observó con B. bonaerensis $(3,42)$.

- $\quad$ Cephalobium nitidum mostró los valores más altos de abundancia $(0,31)$ en $A$. muticus y B. cristovata los más elevados en $N$. claraziana $(0,70)$.

- Las familias Thelastomatidae, Travassosinematidae, Cephalobidae y Rhabditidae no provocaron mortalidad sobre los insectos hospedadores.

- $\quad$ Heterorhabditis bacteriophora cepa VELI fue patogénico contra el grillo Anurogryllus muticus.

Las infecciones experimentales realizadas con $H$. bacteriophora en $A$. muticus fueron exitosas, determinándose infectividad bajo dos formas de aplicación: por suspensión y cadáveres infectados.

- La mortalidad observada y la capacidad completar su ciclo vital en el hospedador convierten a Heterorhabditis bacteriophora cepa VELI en un potencial agente de biocontrol. 


\section{PERSPECTIVAS FUTURAS}

- Ampliar la diversidad específica hacia otras regiones de la Provincia de Buenos Aires y en provincias vecinas en búsqueda de nematodos patógenos.

- Seguir con los muestreos con el fin de hallar a los machos correspondientes para clarificar las especies no identificadas.

- Evaluar la posibilidad de diseñar primers para la identificación de las especies Binema sp. y Cameronia n. sp.

- Continuar estudios relacionados con las aplicaciones a campo de $H$. bacteriophora en lo referente a dosis, frecuencia y momento de aplicación, biología y ciclo de los hospedadores. 


\section{REFERENCIAS BIBLIOGRÁFICAS}

Achinelly, M. F. (2004). Estudios referentes a la utilización del nemátodo Strelkovimermis spiculatus (Nematoda: Mermithidae) como agente de control biológico de culícidos (Diptera: Culicidae). Tesis doctoral. Facultad de Ciencias Naturales y Museo, UNLP.

Achinelly, M. F.; Camino, N. B. (2007). A new species of Blatticola Schwenk, 1926 (Oxyurida, Thelastomatidae) a parasite of Anurogryllus muticus (De Geer, 1773) (Orthoptera, Gryllidae) from Argentina. Papeis Avulsos de Zoologia 47 (15):181-186.

Achinelly, M. F.; Micieli, V. (2013). Host range of the parasite Strelkovimermis spiculatus (Nematoda: Mermithidae) in Argentina mosquitoes. Journal of Vector Ecology 38 (1):69-73.

Achinelly, M. F., Eliceche, D. and Camino, N. B. (2011). Pathogenicity, biology and production of a new isolate of Heterorhabditis bacteriophora (Poinar, 1976) (Nematoda: Heterorhabditidae) from Argentina. XLIV Annual Meeting Society Invertebrate Pathology . Halifax, Canadá, pp. 61 (Abstract).

Achinelly, M. F.; Camino, N.; Eliceche, D.; Salas, A.; Rusconi, M. (en prensa). Status of entomopathogenic nematodes in integrated pest management strategies in Argentina. CABI.

Adamson, M. L. (1987). Oxyuridan (Nematoda) parasites of Scaphiostreptus seychellarum with comments on the families Pulchrocephalidae Kloss, 1959 and Travassosinematidae Rao, 1958. Canadian Journal of Zoology 65: 2747-2754. 
Adamson, M. L.; van Waerebeke, D. (1992 a). Revision of Thelastomatoidea, Oxyurida of invertebrate hosts I. Thelastomatidae, Protrelloididae and Pseudonymidae. Systematic Parasitology 20: 21-63.

Adamson, M. L.; van Waerebeke, D. (1992 b). Revision of Thelastomatoidea, Oxyurida of invertebrate hosts II. Travassosinematidae. Systematic Parasitology 21: 169-188.

Adamson, M. L.; van Waerebeke, D. (1992 c). Revision of Thelastomatoidea, Oxyurida of invertebrate hosts II. Hystrignathidae. Systematic Parasitology 22: 111130.

Aldrovandi, U. (1623). De Animalibus Insectis. Frankfort: 271.

Andrassy, I. (1983). A taxonomic review of the suborder Rhabditina (Nematoda: Secernentea). Paris, Orstom. 241 pp.

Artigas, P. (1929). Uma nova espécie de nematoideo do gênero Cephalobium Cobb, 1920. Boletim de Biologia, São Paulo 4:81-84.

Baker, G. L. (1986). The ecology of mermithid nematode parasites of grasshoppers and locusts in south-eastern Australia. In: R.A. Samson, F.M. Vlak and D. Peters. Fundamental and applied aspects of invertebrate pathology. Wageningen: Foundation of the Fourth International Colloquium of Invertebrate Pathology, pp. 277-280. 
Basir, M.A. (1956). Oxyuroid parasites of Arthropoda. A monographic study. 1 Thelastomatidae. 2 Oxyuroidae. Zoologica, Stuttgart 38 (108): 79 pp.

Bedding R. A.; Akhurst, R. J. (1975). A simple technique for the detection of insect parasitic rhabditid nematodes in soil. Nematologica 21: 109-110.

Belaich, M. N.; Buldain, B.; Ghiringhelli, D.; Hyman, B.; Micieli, V.; Achinelly, M. F. (2015). Nucleotide sequence differentiation of argentine isolates of the mosquito parasitic nematode Strelkovimermis spiculatus (Nematoda: Mermithidae). Journal of Vector Ecology 40: 415-418.

Betancourt, C.; Scatoni, B. (2010). Guía de insectos y ácaros de importancia agrícola y forestal en el Uruguay. Universidad de la República, Facultad de Agronomía. Ed. Hemisferio Sur. 582 pp.

Bird, A. F.; Bird, J. (1991). The structure of nematodes. UK, Academic Press. 315 pp.

Bovien, P. (1937). Some types of associations between nematodes and insects. Saertryk af Videnskabelige Medd. Fra Dansk. Naturhist. Forenig 101: 1-114.

Brusca, R. C.; Brusca G. J. (2005). Invertebrados. 2da edición. McGraw Hill / Interamericana de España, S. A. 1005 pp.

Bush, A. O.; Fernandez, J. C.; Esch, G. W.; Seed, J. R. (2001). Parasitism. The diversity and ecology of animal parasites. Cambridge University Press. United Kingdom, 566 pp. 
Bush, A. O.; Lafferty, K. D.; Lotz, J. M.; Shostak, A. W. (1997). Parasitology mets ecology on its own terms: Margolis et al. revisited. Journal of Parasitology 83: 575583.

Cabrera, A. L. (1971). Fitogeografía de la República Argentina. Sociedad Argentina de Botánica 14:1-42.

Camino, N.B. (1988). Descripción de Octomyomermis bonaerensis sp. n. (Nematoda: Mermithidae) parásita de larvas de Simulium bonaerense Coscarón y Wygodzinsky (Diptera: Simuliidae). Revista Ibérica de Parasitología 48 (2):183-186.

Camino, N.B. (1989). Primer registro de culícidos (Diptera: Culicidae) parasitados por Hydromermis sp. (Nematoda: Mermithidae). Neotrópica 35 (94): 67-70.

Camino, N. B.; Achinelly, N. B. (2008). Nematodos de insectos (generalidades). Buenos Aires, Dunken. 117 pp.

Camino, N. B.; Achinelly, M. F.; Rusconi, J. M.; Eliceche, D.; Salas, A. (2014). Biodiversity of entomonematodes parasitizing soil pest white grubs (Scarabaeidae) of Buenos Aires, Argentina. Neotropical Helminthology 8 (2): 227-233.

Camino, N.B.; De Villalobos, L.C. (2002). Neyraiella distinctus sp. n. (Oxyurida: Blattophilidae) parásita de ninfas de Gryllodes laplatae Sauss (Orthoptera:Gryllidae) en la Argentina. Memorias do Instituto Oswaldo Cruz 97 (3): 325-327. 
Camino, N. B.; Maiztegui (2002). A New Species of Thelastomathidae (Nematoda) a parasite of Neocurtilla claraziana Saussure (Orthoptera, Gryllotalpidae) in Argentina. Memorias do Instituto Oswaldo Cruz 97 (5): 655-656.

Camino, N.B.; Reboredo, G.R. (1998). Nemátodos parásitos de larvas de Diloboderus abderus (Coleoptera: Scarabaeidae) en la Provincia de Buenos Aires. Monografía 19, CIC: $1-11$.

Camino, N. B.; Reboredo, G. R. (1999). Binema bonaerensis n. sp. (Oxurida: Thelastomatidae) Parasite of Neocurtilla claraziana Saussure (Orthoptera, Gryllotalpidae) in Argentina. Memorias do Instituto Oswaldo Cruz 94 (3): 311-313.

Camino, N.B.; Reboredo, G.R. (2000 a). Cephalobellus lobulata n. sp. (Oxyurida: Thelastomatidae) a parasite of Neocurtilla claraziana Saussure (Orthoptera: Gryllotalpidae) from Argentina. Memorias do Instituto Oswaldo Cruz 95 (1): 49-51.

Camino, N.B.; Reboredo, G.R. (2000 b). Nueva especie de Cephalobium (Rhabditida: Diplogasteridae) parásito de ninfas de Gryllodes laplatae (Orthoptera: Gryllidae) en la Argentina. Iheringia serie Zoológica (89): 183-186.

Camino, N.B.; Reboredo, G.R. (2004). Three new species of Cephalobium (Nematoda, Cephalobiidae) parasites of Gryllodes laplatae (Orthoptera, Gryllidae) from Argentina. Iheringia serie zoológica 94 (1): 19-22. 
Camino, $\mathbf{N}$.B.; Stock, S.P. (1989). Hexamermis hortensis sp. n. (Nematoda: Mermithidae) parásita de larvas de Spodoptera frugiperda (Smith) (Lepidoptera: Noctuidae) en Argentina. Revista Ibérica de Parasitología 49(4):329-333.

Camino, N. B.; Stock, S. P. (1994). Hexamermis macrostoma n.sp. (Nemata: Mermithidae) parasitizing the cricket Gryllodes laplatae (Orthoptera:Gryllidae) in Argentina. Fundamental and Applied Nematology 17(5):397-399.

Chitwood, B. G.; Chitwood, M. B. (1977). Introduction to Nematology. Baltimore, Maryland, University Park Press. 334 pp.

Christie, J. R. (1937). Mermis subnigrescens, a nematode parasite of grasshoppers and other insects. Journal of Agricultural Research 55: 353-364.

Cigliano, M. M.; Pocco, M. E.; Lange, C. E. (2011). Grasshoppers of the Andes: New Melanoplinae and Gomphocerinae taxa (Orthoptera: Acridoidea: Acrididae) from Huascarán National Park and Callejón de Huaylas, Ancash, Perú. Zoosystema 33: 523544.

Cobb, N. A. (1920). One hundred new nemas. Contributions of a Science of Nematology 9: 217-343.

Courtney, W. D.; Polley, D.; Miller, V. L. (1955). TAF, an improved fixative in nematode technique. Plant Disease Reporter 39, 570. 
De la Fuente, J. A. (1994). Zoología de Artrópodos. McGraw-Hill Interamericana. 805 pp.

Del Valle, E.; Lax, P.; Rondán Dueñas, J.; Doucet, M. (2013). Effects of insect cadavers infected by Heterorhabditis bacteriophora and Steinernema diaprepesi on Meloidogyne incognita parasitism in pepper and summer squash plants. Ciencia $e$ Investigación Agraria 40 (1): 109-118.

Desgarennes, D.; Sánchez-Nava, P.; Peña-Santiago, R.; Carrión, G. (2009). Nematofauna asociada a la rizósfera de papas (Solanum tuberosum) cultivadas en la zona productora de la zona del Cofre de Perote, Veracruz, México. Revista Mexicana de Biodiversidad 80 (3): 611-614.

Desgarennes, D.; Carrión, G.; Nuñez-Sanchez, A. E.; Zulueta, R.; ZárateContreras, J. A. (2011). Nematofauna asociada a la rizósfera de Saccharum officinarum en la región Costa-Centro de Veracruz, Mexico. Agrociencia 45 (7): 785795.

Di Battista, M. C.; Fischer, S.; Campos, R. E. (2015). Prevalence of parasitism and adult survival of Aedes albifasciatus (Diptera: Culicidae) parasitized by Strelkovimermis spiculatus (Nematoda: Mermithidae). Journal of Vector Ecology 40: 393-397.

Doucet, M. (1986). Los nematodos insecticidas: una realidad. Nota informativa Nro. 5. Sociedad Argentina de Nematología. 3 pp.

Doucet, M. (1999). Nematodos del suelo citados en asociación con el cultivo de ajo en 
Argentina. Nematology Mediterranean 27: 215-219.

Doucet, M.; Bertolotti, (1995). New records of entomogenous nematodes

(Steinernematidae, Heterorhabditidae) in Córdoba, Argentina. Nematropica 25: 86.

Doucet, M.; Lax, P.; Coronel, N. (2008). The soybean cyst nematode Heterodera glycines Ichinohe, 1952 in Argentina. En: A. Ciancio, K. G. Mukerji (Eds.). Integrated management and biocontrol of vegetable and grain crops nematodes. Springer, Holanda, 127-148.

Farooqui, M.N. (1970). Some known and new genera and species of the family Thelastomatidae Travassos, 1929. Rivista di Parassitologia 31: 195-214.

Fedorko, A.; Stanuszek, S. (1971). Pristionchus uniformis sp. n. (Nematoda, Rhabditida, Diplogasteridae), a facultative parasite of Leptinotarsa decemlineata Say and Melolontha melolonta L. in Poland. Morphology and biology. Acta Parasitologica Polonica 19 (7): 95-112.

Gaugler, R.; Kaya, H. K. (1990). Entomopathogenic Nematodes in Biological Control. Boca Raton, Florida, CRC Press. 365 pp.

Georgis, R.; Poinar, G. O. (1989). Field effectiveness of entomophilic nematodes Neoaplectana and Heterorhabditis. In: Integrated Pest Management for Turfgrass and Ornamentals. Leslie, A. R.; Metcalf, R. L. Eds. U. S. Environmental Protection Agency, Washington, D. C. 213 p. 
Goodey, T; Triffitt, M. J. (1927). On the presence of flagellates in the intestine of the nematode Diplogaster longicaudata. Protozoology (Suppl. to Jour. Helminth.) 3:47-58.

Hayslip, N.C. (1943). Notes on biological studies of mole crickets at Plant City Florida. Florida Entomology 26: 33-46.

Holovachov, O.; Bolstrom, S. (2010). Identification of Plectida (Nematoda). EUMAINE, Gent and Nematology, UC Riverside. 98 pp.

Holovachov, O.; De Ley, P. (2006). Order Plectida. In: Eyualem, A., Traunspurger, W. and Andrassy, I. (eds). Freshwater Nematodes: Taxonomy and Ecology. CAB International, Wallingford, UK, pp 611-647.

Hudson, W. G. (1984). Other behavior, damage and sampling. Pp. 16-21. In T. J.Walker (ed.), Mole crickets in Florida. Agricultural Experimental Station Bulletin. 846. IFAS, University of Florida, Gainesville.

Hunt, D. J. (1981). On Artigasia horridospina n. sp., Longior semialata n. sp., Mentecle magnifica n. sp., Paraxyo ensincriatus n. sp. (Oxyurida: Hystrignathidae) and Pulcrocephala? pulchrocephala Travassos, 1925 (Oxyuridae: Pulchrocephalidae). Systematic Parasitology 3: 33-52.

Hunt, D. J. (1983). Observations of the genus Indiana Chakravarty, 1943 (Oxyurida: Pulchrocephalidae). Systematic Parasitology 3: 33-52. 
Kaya, H.; Stock, S.P. (1997). Techniques in insect nematology. In: L.A. Lacey (Ed.) Techniques in insect pathology. London: Academic Press. 281-324.

Kloss, G. R. (1960). Organizacao filogenética dos nematoides parasitos intestinais dos artropodes (Nota previa). Atlas do Sociedade de Biologia do Rio de Janeiro. 3: 9-12.

Liebermann, J. (1955). Bioecología y systematica del grillo argentino. Natura 1(9): 147-56.

Linster, M. (1671). Phil. Trans. R. S. London 6: 4064.

Maggenti, A. R. (1991). Nemata: Higher Classification. Chapter 5. In: Manual of Agricultural Nematology, W. R. Nickle, Ed. Marcel Dekker, Inc. New York, pp. 147-187.

Manzanilla-Lopez, R. H.; Marbán- Mendoza, N. (2012). Practical Plant Nematology. México, Colegio de Postgraduados. 883 pp.

Marchissio, S. L.; Miralles, D. (1987). Cameronia arecoensis sp. n. (Nematoda: Thelastomatidae) parasite intestinal de Neocurtilla claraziana (Saussure, 1974) (Orthoptera: Gryllotalpidae). Neotrópica 33 (90): 127-132.

Marchissio, S. L.; Miralles, D. (1993). Talpicola klossae sp. n. y nuevo registro de Binema korsakowi (Sergiev, 1923) (Nematoda: Thelastomatidae) parásitos de Neocurtilla claraziana (Orthoptera: Gryllotalpidae). Neotrópica 39 (101-102): 79-82. 
Micieli, M. V.; Risso, P.; Achinelly, M. F.; Villar, M.; Muttis, E. (2012). Population dynamics between the mermithid Strelkovimermis spiculatus (Nematoda: Mermithidae) and the floodwater mosquito Ochlerotatus

albifasciatus (Diptera: Culicidae) over time. Biological Control. 61(1): 55-63.

Morales, G.; Arelis-Pino, Luz. (1987). Parasitología cuantitativa. Caracas, Venezuela, Editotial Acta Científica Venezolana. 132 pp.

Muller-Graf, C. D. M.; Jobet, M; Cloarec, C.; Rivault, C.; van Baalen, M.; Morand, S. (2001). Population dynamics of host-parasite interactions in a cockroachoxyuroid system. Oikos 95: 431-440.

Parveen, R.; Jairajpuri, D. S. (1984). Cameronia klossi n. sp. (Nematoda:

Thelastomatidae) from the mole cricket, Gryllotalpa Africana from Aligarh. Revista Ibérica de Parasitología 44 (2): 153-158.

Parveen, R.; Jairajpuri, D.S. (1985). Binema parva sp. n., a parasitic nematode of the mole cricket Gryllotalpa africana. Revista di Parassitalogia 46: 347-350.

Poinar Jr, G. O. (1975). Entomogenous nematodes: a manual and host list of insectnematode associations. (Ed.) Brill, E. J. Leiden, The Netherlands. 317 pp.

Poinar Jr, G. O. (1976). Description and biology of a new insect parasitic rhabditoid, Heterorhabditis bacteriophora N. Gen., N. Sp. (Rhabditida: Heterorhabditidae N. Fam.). Nematologica 21: 463-470. 
Poinar Jr, G. O. (1977). CIH key to the groups and genera of nematode parasites of invertebrates. Commonwealth Agricultural Bureaux. Farnham Royal, Buckinghamshire, U.K. 43 pp.

Poinar Jr, G. O. (1979). Nematodes for biological control of insects. CRC Press. Boca Raton, Florida. 277 pp.

Poinar Jr, G. O. (1983). Nematodes parasites of invertebrates. In: The Natural History of Nematodes. Prentice-Hall, Inc., Englewood Cliffs, New Jersey.

Poinar Jr, G. O. (1990). Biology and taxonomy of Steinernematidae and Heterorhabditidae. pp. 23-61 in Gaugler, R., and H. K. Kaya (Eds.), Entomopathogenic Nematodes in Biological Control. CRC Press. Boca Ratón, Florida. 365 pp.

Poinar Jr, G. O.; Camino, N. B. (1986). Strelkovimermis spiculatus n. sp. (Mermithidae: Nematoda) parasitizing Aedes albifasciatus Mac. (Culicidae: Diptera) in Argentina. Journal of Nematology 18(3):317-319.

Rao, P. N. (1958). Studies on the nematode parasites of insects and other arthropods. Arquivos do Museu Nacional, Rio de Janeiro 46: 33-84.

Reboredo, G.R.; Camino, N.B. (1998). Two new species of nematodes (Rhabditida: Diplogasteridae y Rhabditidae) parasites of Gryllodes laplatae (Orthoptera: Gryllidae) in Argentina. Memorias do Instituto Oswaldo Cruz 93 (6):763-766. 
Reboredo, G.R.; Camino, N.B. (2001). Una nueva especie del género Cameronia Basir (Oxyurida: Thelastomatidae) parásita de Gryllodes laplatae Sauss (Orthoptera:Gryllidae) en Argentina. Boletín Chileno de Parasitología 56: 42-44.

Regen, J. (1922). Eine Mermithidae aus der Leibeshohle von Liogryllus campestris L. Zoologischer Anzeiger 55: 124-129.

Rizvi, A. N.; Jairajpuri, D. S. (2002). Studies on a new and some known species of insect oxyurid nematodes. Revista Ibérica de Parasitología 62: 1-7.

Rizvi, A. N.; Jairajpuri, D. S.; Shah, M. M. (2002). Gryllophila nihali n. sp., Protrellatus indicus n. sp. (Oxyurida: Thelastomatoidea). International Journal of Nematology 12 (1): 29-34.

Rupert, E. E.; Fox, R. S.; Barnes, R. D. (2004). Invertebarate Zoology, a Functionary Evolutionary Approach. Seventh Edition. Brooks Cole Thompson, Belmont, California. $963 \mathrm{pp}$.

Rusconi, J. M.; Camino, N. B.; Achinelly, M. F. (en prensa). Nematodes (Mermithidae) parasitizing grasshoppers (Orthoptera: Acrididae) in the Pampean region, Argentina. Brazilian Journal of Biology.

Salas, A.; Eliceche, D.; Belaich, M.; Achinelly; M. F. (2013). Biología, patogenicidad y multiplicación de un aislamiento nativo del nematodo entomopatógeno Heterorhabditis bacteriophora proveniente de huertas de cultivo orgánico en Argentina. XLV Annual Meeting of Organization of Nematologists of Tropical America. 
Sergiev, P. G. (1923). Two new nematodes from the intestine of Gryllotalpa vulgaris. Trudy Gosudarstvennogo Instituta Eksperimental noi Veterinarii 1: 183-190.

Shah, M. M. (2007). Two new species of Cameronia Basir, 1948 (Oxyurida, Thelastomatoidea, Thelastomatidae) from Manipur, North-East India. Acta Parasitológica 52 (3): 225-232.

Shah, M. M.; Mohilal, N.; Pramodini; Bina, L. (2012). Parasitic Nematodes of some Insects from Manipur, India. Ed. Dr. Mohammad Manjur Shah. 206 pp.

Shah, M. M.; Rizvi, A. N. (2004). Some studies on three known species of the genus Binema Travassos, 1925 (Travassosinematidae: Thelastomatidae) from Manipur, NorthEast India. Parassitologia 46: 317-326.

Singh H. S.; Malti. (2003). On a known and some unknown species of nematode parasites of Gryllotalpa africana. Journal of Experimental Zoology 6(2): 329-350.

Singh, H. S.; Singh, P. K. (1990). A new species of the genus Mirzaiella (Basir). Indian Journal of Parasitology 14: 201-202.

Singh, P. K.; Rastogi, P.; Singh, H. S. (2014). Description of a new species of Cephalobellus Cobb 1920 (Oxyurida: Thelastomatidae) from the host Blatta orientalis L. (Orthoptera: Blattidae). International Journal of Current Microbiology and Applied Science 3 (4): 1032-1042. 
Skrjabin, K. I.; Schikhovaloba, N. P.; Lagodovskaya, E. A. (1966). Oxyurids of Invertebrates. Nauka. Moscow. 538 pp.

Sokal, R. R.; Rohlf, F. J. (1980). Introducción a la bioestadística. Barcelona. Editorial Reverté, S. A. 365 pp.

Stenersen, J. (2004). Chemical pesticedes: mode of action and toxicology. Boca Raton, Florida. CRC Press. 295 pp.

Stock, S. P. (1992). Presence of Steinernema scapterisci Nguyen et Smart parasitizing the mole cricket Scapteriscus borelli in Argentina. Nematología Mediterranea 20: 163165.

Stock, S. P.; Camino, N. B. (1996). Nematodos Entomopatógenos. En: Microorganismos patógenos empleados en el control microbiano de insectos plaga. Ed. R. Lecuona. Talleres Gráficos Mariano Mas, Buenos Aires. Pp 105-118.

Tewarson, N.C.; Gupta, V. (1978). Nematode parasites of invertebrates. Indian Journal of Zootomy 17: 21-24.

Thorne, G. (1961). Principles of nematology. New York, NY, USA, Mc Graw- Hill Book Company, Inc. 553 pp.

Travassos, L. (1925). Contribucao ao conhocimento dos Nematodeos dos Arthropodes. Sciencia Medica, Rio de Janeiro 3: 416-422. 
Vega, F. E.; Kaya, H. K. (2012). Insect Pathology. London, UK, Elsevier. 490 pp.

Weaver, J.E.; Sommers, R.A. (1969). Life history of the short-tailed cricket, Anurogryllus muticus, in Central Louisiana. Annals of the Entomological Society of America 62: 337-342.

West, M.J.; Alexander, R.D. (1963). Sub-social behavior in a burrowing cricket Anurogryllus muticus (de Geer) Orthoptera: Gryllidae. The ohio Journal of Sicence 63:19-24.

Wise de Valdez, M. R. (2006). Predator avoidance behavior of Aedes aegypti mosquito larvae infected with mermithid nematodes (Nematoda: Mermithidae). Journal of Vector Ecology 32 (1): 150-153. 


\section{Páginas web}

Bream's Landscaping (2016). http://www.breamslandscapinginc.com/common-floridapests.html

University of Florida, Entomology and Nematology Department (2016). http://entomology.ifas.ufl.edu.

Orthoptera Species File.

(2016).

http://orthoptera.speciesfile.org/HomePage/Orthoptera/HomePage.aspx 
ANEXO 


\begin{tabular}{|c|c|c|c|}
\hline Machos & Cruznema tripartitum $(\mathrm{n}=5)$ & Cephalobium nitidum $(\mathrm{n}=84)$ & Blatticola cristovata $(\mathrm{n}=5)$ \\
\hline Longitud total & $932 \pm 83,2(816-1008)$ & $2192 \pm 49,9(2136-2232)$ & $1824 \pm 191,5(1656-2040)$ \\
\hline Ancho a nivel de las papilas cefálicas & $10,5 \pm(9-18)$ & 9 & $12,6 \pm 4(9-18)$ \\
\hline Distancia anterior al anillo nervioso & & $137,5 \pm 8,02(173-189)$ & $105,7 \pm 22,6(81-117)$ \\
\hline Ancho a nivel del anillo nervioso & & $69 \pm 10,3(63-81)$ & $49,5 \pm 9(36-54)$ \\
\hline Longitud del esófago & $175 \pm 4,6(171-179)$ & $243 \pm 9(234-252)$ & $250,2 \pm 21,5(225-279)$ \\
\hline Distancia anterior al bulbo & $129,5 \pm 4,04(126-133)$ & $198,6 \pm 8,02(191-207)$ & $174,2 \pm 27,8(134-207)$ \\
\hline Distancia anterior al poro excretor & & $279 \pm 9(270-288)$ & \\
\hline Ancho medio & $108 \pm 10,3(63-90)$ & $102 \pm 13,7(90-117)$ & $99 \pm 19,7(81-135)$ \\
\hline Ancho a nivel del ano & 36 & $62 \pm 9,7(36-81)$ & $48,6 \pm 10,2(36-63)$ \\
\hline Longitud de la espícula & $39 \pm 4,6(36-45)$ & $49 \pm 10,2(27-63)$ & 36 \\
\hline Ancho de la espícula & 9 & 9 & 9 \\
\hline Longitud de la cola & $40,5 \pm 7,5(36-54)$ & $174,7 \pm 35,2(126-252)$ & $72 \pm 15,05(54-99)$ \\
\hline
\end{tabular}

Tabla 1. Caracteres morfométricos de los nematodos machos hallados en este estudio 


\begin{tabular}{|c|c|c|c|c|c|}
\hline Hembra & Cruznema tripartitum $(\mathrm{n}=5)$ & Cephalobium nitidum $(\mathrm{n}=184)$ & Cephalobellus magalhaesi $(\mathrm{n}=130)$ & Binema bonaerensis $(\mathrm{n}=72)$ & Binema klosse $(\mathrm{n}=3)$ \\
\hline Longitud total & $1392 \pm 145,3(1200-1536)$ & $2844 \pm 412,2(2496-3432)$ & $5862 \pm 413,08(5520-6456)$ & $1671 \pm 107,6(1575-1773)$ & $3504 \pm 475,1(3168-3840)$ \\
\hline Ancho a nivel de las papilas cefálicas & $16,5 \pm 3,5(9-18)$ & $13,5 \pm 5,1(9-18)$ & $22,5 \pm 5,19(18-27)$ & $22,5 \pm 5,1(18-27)$ & $31,5 \pm 6,3(27-36)$ \\
\hline Distancia anterior al anillo nervioso & & $290,2 \pm 21,2(261-306)$ & $261 \pm 12,7(252-270)$ & $85,5 \pm 5,1(81-90)$ & $108 \pm 12,7(99-117)$ \\
\hline Ancho a nivel del anillo nervioso & & $81 \pm 12,7(63-90)$ & $126 \pm 12,7(108-135)$ & $110,2 \pm 4,5(103-135)$ & $72 \pm 12,7(63-81)$ \\
\hline Longitud del esófago & $195,5 \pm 17,1(171-225)$ & $391,5 \pm 33,2(342-414)$ & $569,2 \pm 11,3(558-585)$ & $346,5 \pm 15,5(333-360)$ & $352 \pm 11,3(344-360)$ \\
\hline Distancia anterior al bulbo & $145,7 \pm 19,2(108-180)$ & $240,7 \pm 17,03(216-25)$ & $469,3 \pm 11,3(458-485)$ & $244,2 \pm 13,5(144-360)$ & $198 \pm 25,4(180-216)$ \\
\hline Distancia anterior al poro excretor & & & $774 \pm 7(767-781)$ & $427,5 \pm 44,5(396-495)$ & $508,5 \pm 57,2(468-549)$ \\
\hline Ancho medio & $108 \pm 10,3(99-117)$ & $126 \pm 14,6(108-144)$ & $292,5 \pm 21,4(270-315)$ & $235,3 \pm 49,3(233-260)$ & $315 \pm 63,6(270-360)$ \\
\hline Ancho a nivel de la vulva & $76,5 \pm 9(72-90)$ & $121,4 \pm 22,04(99-144)$ & $272,2 \pm 4,5(270-279)$ & $218,2 \pm 13,5(207-234)$ & $288 \pm 76,3(234-342)$ \\
\hline Longitud de la vulva & 9 & $22,5 \pm 5,1(18-27)$ & $29,2 \pm 4,5(27-36)$ & $20,2 \pm 4,5(18-27)$ & 18 \\
\hline Ancho de la vulva & 18 & $13,5 \pm 5,1(9-18)$ & $11,2 \pm 4,5(9-18)$ & $13,5 \pm 5,1(9-18)$ & 36 \\
\hline V & $83,03 \% \pm 3,1(80 \%-86,8 \%)$ & $46,6 \% \pm 0,02(44 \%-57 \%)$ & $50,8 \% \pm 3,4(46,5 \%-55 \%)$ & $54,6 \% \pm 0,03(51,7 \%-60 \%)$ & $52,3 \% \pm 1,15(51 \%-53 \%)$ \\
\hline Ancho posterior & $99 \pm 10,3(90-108)$ & $78,7 \pm 17,2(72-90)$ & $195,7 \pm 13,5(189-216)$ & $132,7 \pm 18,5(108-153)$ & $180 \pm 63,6(135-225)$ \\
\hline Longitud de la cola & $135 \pm 20,7(117-153)$ & $276,7 \pm 11,3(261-288)$ & $270 \pm 5,7(263-277)$ & $265,5 \pm 37,1(225-315)$ & $108 \pm 12,7(99-117)$ \\
\hline Longitud de los huevos & $32,4 \pm 19,9(18-45)$ & $75 \pm 6,3(72-81)$ & $57 \pm 6,3(54-63)$ & $60,75 \pm 4,5(54-63)$ & $58,5 \pm 6,3(54-63)$ \\
\hline Ancho de los huevos & $27 \pm 12,7(18-36)$ & $33 \pm 6,3(27-36)$ & $42 \pm 6,3(36-45)$ & $33,75 \pm 4,5(27-36)$ & $31,5 \pm 6,3(27-36)$ \\
\hline
\end{tabular}

Tabla 2. Caracteres morfométricos de los nematodos hembras hallados en este estudio (en parte) 


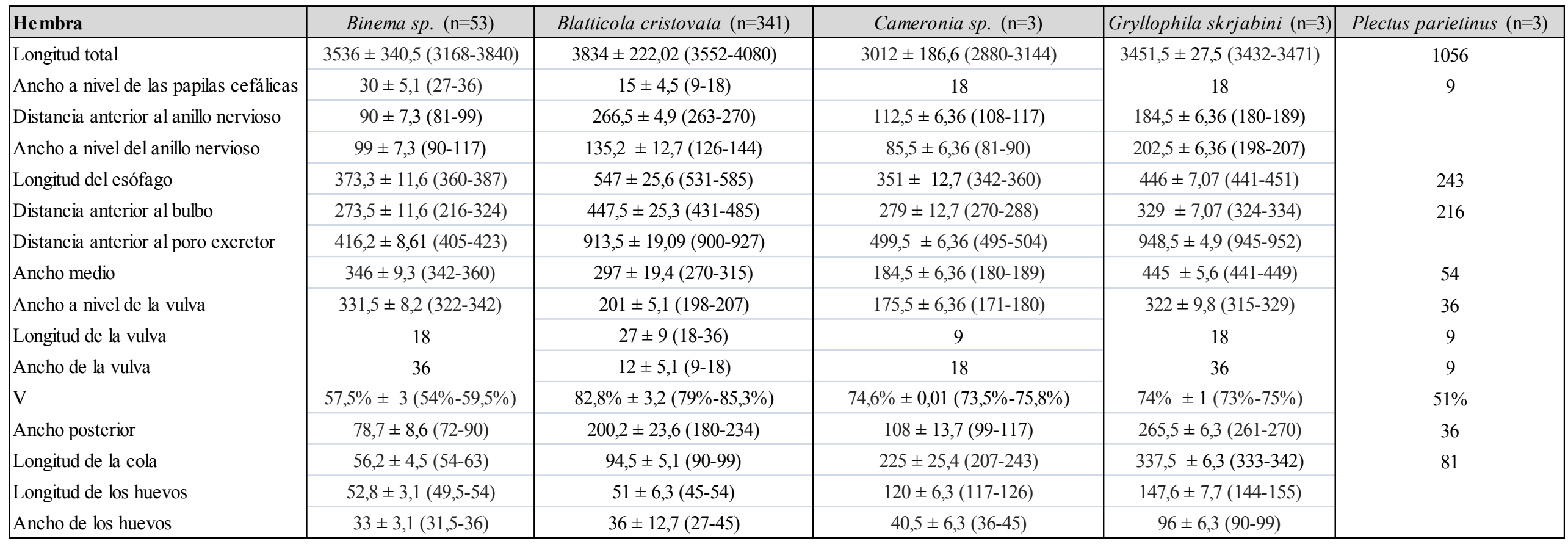

Tabla 3. Caracteres morfométricos de los nematodos hembras hallados en este estudio (en parte) 
José Matías Rusconi

2017

\begin{tabular}{|c|c|c|}
\hline Especie & País & Autor \\
\hline Cameronia biovata & India & Basir, 1948 \\
\hline C. aspiculata & India & Farooqui, 1970 \\
\hline C. nisari & India & Parveen \& Jairajpuri, 1985 \\
\hline C. psilocephala & India & Rao, 1958 \\
\hline C. travassosi & India & Farooqui, 1968 \\
\hline C. manipurensis & India & Shah, 2007 \\
\hline C. triovata & India & Shah, 2007 \\
\hline
\end{tabular}

Tabla 4. Especies del género Cameronia 


\begin{tabular}{|c|c|c|}
\hline Especie & País & Autor \\
\hline Blatticola blattae & Estados Unidos, India, Africa del norte & (Graeffe, 1860) Chitwood, 1932 \\
\hline B. barryi & Nueva Zelanda & Zervos, 1987 \\
\hline B. blatti & India & (Farooqui, 1966), n. comb. \\
\hline B. blattelicola & India & (Basir, 1940), n. comb. \\
\hline B. caucasica & Ex U.S.S.R. (Cáucaso) & (Skrjabin, 1927), n. comb. \\
\hline B. guptai & India & Duggal \& Aulakh, 1988), n. comb. \\
\hline B. heterogamiae & Africa del Norte & (Galeb, 1878) Chitwood, 1932 \\
\hline B. monandros & Nueva Zelanda & Zervos, 1983 \\
\hline B. ophistoplatia & Pakistán & Ahmed \& Jabin, 1966 \\
\hline B. supellaimae & India & Rao \& Rao, 1965 \\
\hline B. tuapakae & Nueva Zelanda & Dale, 1966 \\
\hline
\end{tabular}

Tabla 5. Especies del género Blatticola 


\begin{tabular}{lll}
\hline Especies & País & Autor \\
\hline Binema korsakowi & Ex U.S.S.R. (Crimea), India, Madagascar y Brasil & (Sergiev, 1923), Basir, 1956 \\
B. mirzaia & India & (Basir, 1940) Basir, 1956 \\
B. ornata & Brasil, Bolivia, India y Madagascar & Travassos, 1925 \\
B. pseudornatum & Alemania & Leibersperger, 1960 \\
\hline
\end{tabular}

Tabla 6. Especies del género Binema 


\begin{tabular}{|c|c|c|}
\hline Especies & País & Autor \\
\hline Cephalobellus papilliger & Australia & Cobb, 1920 \\
\hline C. annulobellus & India & Jairajpuri \& Parveen, 1984 \\
\hline C. brevicaudatus & Estados Unidos & (Leidy, 1851) Christie, 1933 \\
\hline C. costelytra & Nueva Zelanda & Dale, 1964 \\
\hline C. cuspidatum & Alemania & (Rudolphi, 1814) Leibersperger, 1960 \\
\hline C. cylindricum & Estados Unidos & Christie, 1931 \\
\hline C. galliardi & Francia & (Dollfus, 1952) Basir, 1956 \\
\hline C. glomeridis & Alemania & (Linstow, 1885) Jarry, 1964 \\
\hline C. granatensis & España, Austria, Suecia, Suiza, Alemania y Francia & (Serrano Sanchez, 1955) Jarry, 1964 \\
\hline C. hexodontos & Madagascar & Van Waerebeke, 1970 \\
\hline C. indiana & India & (Basir, 1940) Basir, 1956 \\
\hline C. jewari & India & $(\mathrm{Lal}, 1968)$ n. comb. \\
\hline C. lucani & Alemania & (Leibersperger, 1960) n. rank. \\
\hline C. magalhaesi & Brasil & Schwenk, 1926 \\
\hline C. melolonthae & Alemania & Leibersperger, 1960 \\
\hline C. osmodermae & Alemania & Leibersperger, 1960 \\
\hline C. ovumglutinosus & Madagascar & Van Waerebeke, 1978 \\
\hline C. potosiae & Alemania & Leibersperger, 1960 \\
\hline C. skaifei & Sudáfrica & Osche, 1960 \\
\hline C. spicatus & India & Jairajpuri \& Parveen, 1984 \\
\hline C. tipulae & Alemania, Francia y Suiza & (Leibersperger, 1960) n. rank. \\
\hline
\end{tabular}


José Matías Rusconi 2017

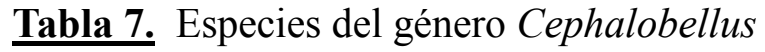

